\title{
Grundlagen der systemischen Therapie
}

\author{
10.1 Neue Konzepte der systemischen Therapie - 123 \\ 10.2 Hinweise zur Prophylaxe und Therapie von Komplikationen der Chemotherapie - 127 \\ 10.3 Prophylaxe und Therapie von Komplikationen der Immuntherapie - 152
}

\subsection{Neue Konzepte der systemischen Therapie}

\section{Schuler}

\subsubsection{Einleitung}

Die Einführung sog. »zielgerichteter Medikamente« hat einen Paradigmenwechsel in der Systemtherapie maligner Erkrankungen ausgelöst. Voraussetzung hierfür waren die in den letzten 25 Jahren gesammelten Erkenntnisse der molekularbiologischen, molekulargenetischen und immunologischen Grundlagenforschung, die ein besseres Verständnis der pathogenetischen Prozesse im Rahmen der malignen Transformation und Tumorprogression sowie die Identifikation strategischer Zielstrukturen (»Targets«) ermöglichen. Auf diese Weise wurde ein neuer Ansatz der Entwicklung antineoplastischer Therapeutika angestoßen, der auf die Wirkung an spezifischen Molekülaktivitäten und nicht primär auf zelluläre Endpunkte (Wachstumshemmung, Zelltod) ausgerichtet ist.

Obwohl hiermit teilweise hochspezifische Substanzen identifiziert werden konnten, ist weiterhin deren konventionelle toxikologische und pharmakologische präklinische und klinische Entwicklung erforderlich. Dabei zeigt sich häufig in der klinischen Prüfung, dass bei sehr hoher Selektivität allenfalls eine Untergruppe ansonsten histologisch uniformer Tumoren auf das jeweilige Therapeutikum anspricht. Insofern kann am Ende klassischer klinischer Prüfungen zielgerichteter Therapeutika deren scheinbare Unwirksamkeit stehen, da die Studienkollektive oft das der Substanz entsprechende Tumorprofil nicht oder nur in geringer Zahl repräsentieren. Somit kommt in Ergänzung zu Histomorphologie und Immunhistochemie der weiteren molekularen und genetischen Charakterisierung von Tumorbiopsien eine entscheidende Bedeutung zu. Bislang bei soliden Tumoren klinisch wirksame und zugelassene, zielgerichtete Tumortherapeutika weisen entweder einen breiten Wirkansatz auf oder sie sind nur bei molekularpathologisch definierten Subgruppen von Tumoren effektiv. Im Folgenden werden die wesentlichen Prinzipien der zielgerichteten Tumortherapie zusammengefasst und mit Beispielen aus der Onkologie urologischer Tumoren belegt.

\subsubsection{Hemmung von Rezeptortyrosinkinasen}

Das klassische Resultat der Aktivierung zellulärer Onkogene ist die Deregulation der intrazellulären Übertragung von Signalen, die durch Wachstums- und Überlebensfaktoren induziert werden. Dies kann auf der Ebene der membrangebundenen Wachstumsfaktorrezeptoren erfol- 


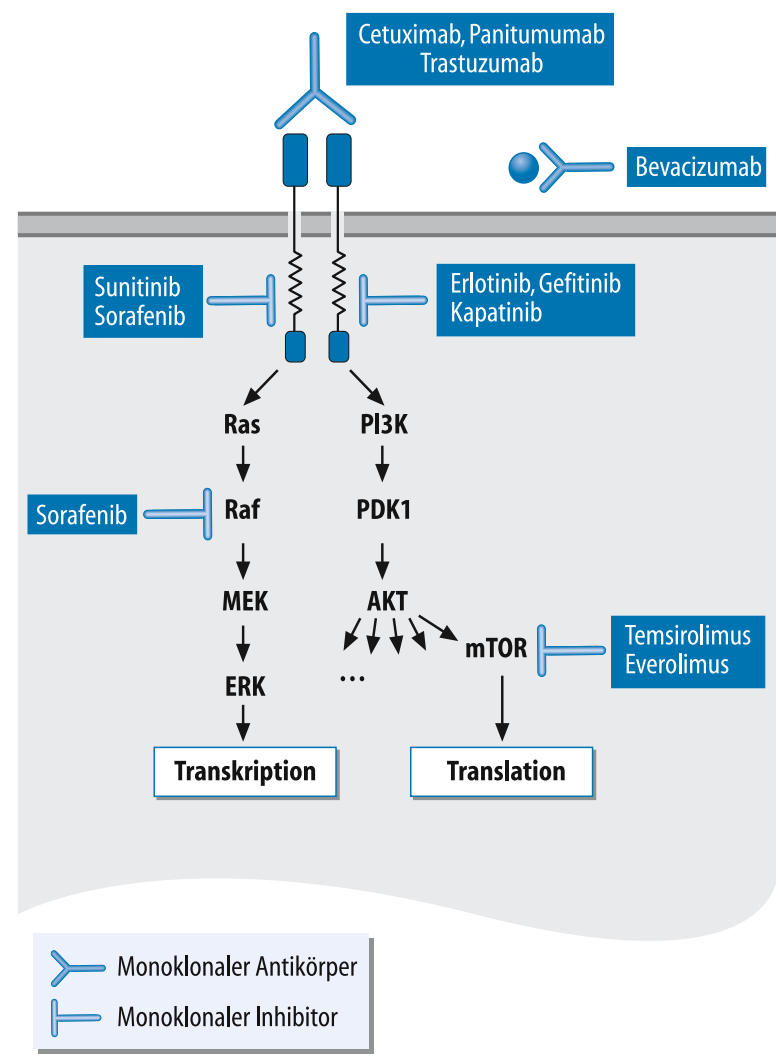

- Abb. 10.1. Schema der Angriffspunkte monoklonaler Antikörper und niedermolekularer Inhibitoren in den durch Rezeptortyrosinkinasen aktivierten Signalübertragungswegen

gen, die beispielsweise aufgrund von Genamplifikationen überexprimiert sind (z. B. Her2/Neu) oder durch spezifische Mutationen eine endogene Aktivierung aufweisen (z.B. Mutationen des epidermalen Wachstumsfaktorrezeptors EGFR). Folge ist eine Signalübermittlung auch bei physiologischerweise subeffektiven Konzentrationen oder gar in Abwesenheit des jeweiligen Wachstumsfaktors. Nach heutigem Verständnis werden durch deregulierte Wachstumsfaktorrezeptoren zwei wesentliche Signalübertragungswege (• Abb. 10.1) aktiviert: der sog. Mitogen-aktivierte Proteinkinase(MAPK)-Weg und der Proteinkinase-B(AKT)-Signalweg. Der MAPK-Weg vermittelt vor allem Proliferations- und Wachstumssignale, während der AKT-Weg vornehmlich das Zellüberleben und den Zellstoffwechsel, aber auch Proliferation und Motilität beeinflusst. Ferner können deregulierte Wachstumsfaktorrezeptoren auch auf Transkriptionsfaktoren, wie die Signal-Transducer-and-Activator (STAT)-Familie oder die NF-kB-Familie sowie weitere Signalübertragungswege einwirken.
Der klassische pharmakologische Ansatz zur Hemmung deregulierter Wachstumsfaktorrezeptoren ist der Einsatz kleiner, zellpermeabler Moleküle, die die intrazelluläre Enzymaktivität der Rezeptoren (in der Regel Tyrosinkinasen) inhibieren. Dabei unterscheidet man Substanzen, die im katalytischen Zentrum der Tyrosinkinase kompetitiv, aber reversibel binden, von solchen Substanzen, die die Kinase durch irreversible Bindung blockieren. Zur ersten Gruppe gehören beispielsweise die EGFR-Inhibitoren Erlotinib und Gefitinib sowie der duale EGFR/Her2/Neu-Inhibitor Lapatinib. Erlotinib ist zur Therapie von Patienten mit Pankreaskarzinomen sowie mit rezidivierten nicht-kleinzelligen Lungenkarzinomen (NSCLC) zugelassen, wobei beim NSCLC vor allem eine Subgruppe von Patienten mit aktivierenden Mutationen des EGFR zu profitieren scheint. Sowohl Erlotinib als auch Gefitinib, das vor allem im ostasiatischen Raum ebenfalls erfolgreich bei Patienten mit NSCLC eingesetzt wird, wurden im Rahmen von Phase-II-Studien bei Patienten mit Urothel- und Nierenzellkarzinomen geprüft. Die klinische Aktivität bei unselektierten Patienten war moderat, so dass der Einsatz außerhalb klinischer Studien derzeit nicht empfohlen werden kann. In klinischer Entwicklung befinden sich derzeit eine Reihe irreversibler Inhibitoren des EGFR und von $\mathrm{Her} / \mathrm{Neu}$, die in vitro eine deutlich höhere Potenz aufweisen. Es bleibt abzuwarten, ob sich dies in eine breitere klinische Effektivität umsetzt.

Eine weitere therapeutische Strategie bei deregulierten Wachstumsfaktorrezeptoren ist der Einsatz monoklonaler Antikörper, die den jeweiligen Rezeptor extrazellulär binden und so mit dessen Signalübertragung interferieren. Beispiele hierfür sind Trastuzumab (anti-Her2/Neu), Cetuximab und Panitumumab (antiEGFR), die bereits zur Behandlung von Patientinnen mit Mammakarzinom bzw. Patienten mit kolorektalen Karzinomen oder Kopf-Hals-Tumoren zugelassen sind. Für Trastuzumab liegen positive Daten aus Phase-IIStudien bei Patienten mit Her2/Neu-überexprimierenden Urothelkarzinomen vor. Ebenso scheinen einzelne Patienten mit Urothel- oder Nierenzellkarzinomen von Cetuximab zu profitieren. Retrospektive Untersuchungen bei Patienten mit kolorektalen Karzinomen, die mit Cetuximab oder Panitumumab behandelt wurden, wiesen nach, dass nur Patienten mit Tumoren ohne Mutation des Onkogens K-ras von der Antikörpertherapie profitieren. Insofern bleibt $\mathrm{zu}$ prüfen, ob eine entsprechende Subgruppe von Patienten mit Urothelkarzinomen ebenfalls besser auf anti-EGFR-Kombinationstherapien anspricht. Der Einsatz dieser Antikörper außerhalb klinischer Prüfungen ist derzeit jedoch nicht gerechtfertigt. 


\section{- Zusammenfassende Bewertung Der klinische Einsatz von gegen Rezeptortyrosinkina- sen gerichteteten Inhibitoren oder monoklonalen An- tikörpern ist für Patienten mit urogenitalen Tumoren nicht etabliert. Bei der Beurteilung von Antikörperthe- rapien gegen Wachstumsfaktorrezeptoren ist zu be- rücksichtigen, dass zumindest ein Teil deren Wirkung durch immunologische Mechanismen, insbesondere die Antikörper-vermittelte zelluläre Zytotoxizität (ADCC), zurückgeführt werden kann. Im Gegensatz hierzu weisen kleine zellpermeable Moleküle wie Er- lotinib, Gefitinib und Lapatinib diesen zweiten mögli- chen Effektormechanismus nicht auf, was helfen kann, die teilweise diskrepanten Studienergebnisse dieser beiden Modalitäten zu erklären.}

\subsubsection{Hemmung intrazellulärer Signalübertragungsmoleküle}

Deregulationen der den Rezeptortyrosinkinasen nachgeschalteteten Schritte der intrazellulären Signalübertragung sind häufige Ereignisse in malignen Tumoren. Dies kann durch aktivierende Mutationen von Signalmolekülen oder durch inaktivierende Mutationen bzw. Verlust negativer Regulatoren, wie Tumorsuppressorgenen, erfolgen. Beispiele aktivierender Mutationen im MAPK-Weg betreffen die GTPase Ras (eine der häufigsten Mutationen, die etwa bei einem Drittel aller malignen Tumoren nachweisbar ist) oder die MAPK B-Raf. Ein typischer negativer Regulator des MAPK-Weges, der in Tumoren inaktiviert sein kann, ist der Tumorsuppressor NF1. Konsequenz ist die endogene Überaktivierung folgender Schritte des Signalweges, wie sie u. a. durch die Kinasen MEK und ERK vermittelt werden. Aberrationen im AKT-Signalweg finden sich u. a. durch aktivierende Mutationen der Phosphoinositid-3-Kinase (PI3K) und AKT. Weitaus häufiger ist allerdings der Verlust des negativen Regulators der PI3K, des Tumorsuppressors "Phosphatase and Tensin Homolog Deleted from Chromosome 10« (PTEN). Dies führt zu einer Überaktivierung der PI3K mit konsekutiver Stimulation der AKT, die eine Vielzahl weiterer Signal- und Regulatormoleküle reguliert.

Ein prominentes Zielmolekül von AKT ist die Kinase "mammalian Target of Rapamycin" (mTOR), die durch die natürlichen Substanz Rapamycin und dessen Derivate im Komplex mit dem endogenen Bindungspartner $» 12 \mathrm{kD}$ FK506-binding protein « (FKB12) spezifisch gehemmt wird. Weitere pathophysiologisch relevante Wege der Deregulation von mTOR, die Inak- tivierung der Tumorsuppressorgenprodukte von TSC1 (Harmatin), TSC2 (Tuberin) und LKB1, finden sich bei der tuberösen Sklerose, der Lymphangioleiomyomatose sowie dem Peutz-Jeghers-Syndrom. Die Kinase mTOR ist zwar nur eines der vielen biologisch bedeutsamen Zielmoleküle von $\mathrm{AKT}$, jedoch reguliert sie bedeutende zelluläre Funktionen wie die für die Proteinsynthese essenzielle Translation.

Beispielhaft findet sich unter den urologischen Tumoren beim Nierenzellkarzinom gehäuft eine Überaktivierung des MAPK-Weges, während der Verlust des Tumorsuppressors PTEN mit konsekutiver AKT-Überaktivierung beim Prostatakarzinom quantitativ hoch relevant ist. Dem folgend wird der Inhibitor Sorafenib, der unter anderem als Hemmstoff der Raf-Kinasen entwickelt wurde, erfolgreich beim metastasierten Nierenzellkarzinom eingesetzt. Auch Inhibitoren von mTOR, wie Temsirolimus und Everolimus, zeigten sich beim metastasierten Nierenzellkarzinom effektiv, wobei in keiner der Zulassungsstudien der Nachweis einer Überaktivierung der MAPK- oder AKT-Wege für den Studieneinschluss erforderlich war. Es bleibt spekulativ, ob dies zu den relativ geringen Remissionsraten und moderaten klinischen Effekten, die in diesen Studien beobachtet wurden, beigetragen hat. Wichtig ist, dass beide Substanzklassen eine signifikante Verbesserung des progressionsfreien Überlebens und Gesamtüberlebens (Temsirolimus) dieser bislang medikamentös nicht in relevantem Umfang kontrollierbaren Erkrankung erzielen. Weitere pharmakologische Modulatoren der MAPK- (u. a. MEK-Inhibitoren) und AKT- (PI3K-Inhibitoren, AKT-Inhibitoren) Wege sowie anderer Signalkaskaden (z. B. Proteinkinase-C-Inhibitoren) sind bereits in klinischer Entwicklung und werden hoffentlich die aktuell verfügbaren mTORInhibitoren und Multikinaseinhibitoren klinisch sinnvoll ergänzen können.

\subsubsection{Hemmung angiogenetischer Signale}

Neben der Modulation von Signalwegen in der Tumorzelle wurde in den letzten Jahren die Bedeutung der Tumorstroma für die Progression maligner Erkrankungen in den Vordergrund gerückt. Hierzu zählen unter anderem mesenchymale Zellen, Immunzellen und das den Tumor versorgende Gefäßsystem. Der von Judah Folkman aufgestellten Hypothese folgend, dass eine Zerstörung der Tumorgefäße einen therapeutischen Einfluss auf die Erkrankung haben kann, wurden eine Reihe sog. "anti-angiogenetischer " Substanzen klinisch entwickelt. Am weitesten fortgeschritten sind hierbei der monoklo- 
nale Antikörper Bevacizumab, der gegen den vaskulären endothelialen Wachstumsfaktor (VEGF) gerichtet ist und diesen neutralisiert, sowie die Multikinaseinhibitoren Sunitinib und Sorafenib, die mehrere Rezeptortyrosinkinasen (Sunitinib: VEGF-Rezeptor, PDGF-Rezeptor, c-Kit, Flt-3; Sorafenib: VEGF-Rezeptor, PDGF-Rezeptor) und intrazellulare Kinasen (Sorafenib: Raf-Kinasen) hemmen.

Alle drei Substanzen sind in der Behandlung des fortgeschrittenen Nierenzellkarzinoms effektiv und zugelassen. Dies kann dadurch erklärt werden, dass auch beim sporadischen klarzelligen Nierenzellkarzinom häufig eine Inaktivierung des von-Hippel-Lindau Tumorsuppressors vorliegt, welcher ein negativer Regulator des Transkriptionsfaktors Hypoxie-induzierter Faktor-1 $\alpha$ (HIF-1 $\alpha$ ) ist. HIF-1a Induziert wiederum pro-angiogenetische Faktoren wie VEGF, so dass diesen Faktoren in der Pathogenese des klarzelligen Nierenzellkarzinoms eine besondere Bedeutung zuzukommen scheint. Unklar ist, ob die Wirkung von Bevacizumab in der Tat auf der Hemmung der Tumorangiogenese beruht oder vielmehr den Aufbau der Tumorgefäße moduliert. Auffällig ist, dass Bevacizumab beim Nierenzellkarzinom in Kombination mit der Immunzytokin Interferon- $\alpha$, aber auch alleine objektive Remissionen erzielen kann, während es in anderen Tumorerkrankungen, wie dem kolorektalen Karzinom oder bei Lungenkarzinomen nur in Kombination mit zytotoxischer Chemotherapie effektiv ist. Ebenso ist klinisch schwer zu differenzieren, ob die Multikinaseinhibitoren Sunitinib und noch mehr Sorafenib präferentiell indirekt über die Hemmung der Tumorangiogenese, oder auch durch direkte Wirkung in der Tumorzelle effektiv sind.

Entsprechend der klinischen Effektivität dieses Behandlungsansatzes befindet sich aktuell eine Vielzahl weiterer Substanzen in klinischer Entwicklung. Dies umfasst rekombinante Rezeptorfusionsproteine, die ähnlich wie Bevacizumab zu einem Entzug sezernierter angiogenetischer Wachstumsfaktoren führen, sowie mehrere niedermolekulare Hemmstoffe von Rezeptortyrosinkinasen mit Aktivität gegen angiogenetische Rezeptoren.

\subsubsection{Modulation von Apoptosesignalwegen}

Ein breiter, aber zielgerichteter therapeutischer Ansatz besteht in der pharmakologischen Modulation von Signalwegen, die für den programmierten Zelltod (Apoptose) von Tumorzellen, aber auch Stromazellen, entscheidend sind. Apoptose kann alleine durch die Aktivierung von Onkogenen, aber auch durch Zytostatika, Strahlen, Entzug von Wachstums- und Überlebensfaktoren so- wie weitere Streßreize ausgelöst werden. Entsprechend kommt es im Rahmen der malignen Transformation und Tumorprogression gesetzmäßig zur Hemmung der Apoptose, was sich nachteilig auf die Effektivität zytotoxischer Therapeutika auswirken kann.

Essenzielle Effektoren der Apoptose sind spezifische Enzyme, die sog. Caspasen. Diese werden über zwei Signalwege aktiviert ( Abb. 10.2): Der extrinsische Signalweg beginnt mit der Bindung von sog. »Todesliganden« wie TRAIL oder FasL an spezifischer "Todesrezeptoren" der Tumornekrosefaktor (TNF)-Familie. Die RezeptorLiganden-Interaktion fördert die Bildung eines Komplexes, welcher die Aktivierung von Caspasen nach sich zieht. Der intrinsische Signalweg wird durch Stressreize, aber auch zytotoxische Therapeutika induziert. Insbesondere DNS-Strangbrüche aktivieren den Tumorsuppressor p53, der über das sog. BH3-Protein PUMA die pro- und anti-apoptotischen Mitglieder der BCL-2-Proteinfamilie moduliert. Zusätzlich gibt es p53-unabhängige Wege der intrinsischen Apoptoseaktivierung, die über weitere der mittlerweile 14 Mitglieder umfassenden Gruppe der BH3-Proteine vermittelt werden. Gemeinsam führt eine Aktivierung von BH3-Proteinen zu einem funktionellen Übergewicht pro-apoptotischer BCL-2-Proteine, wie

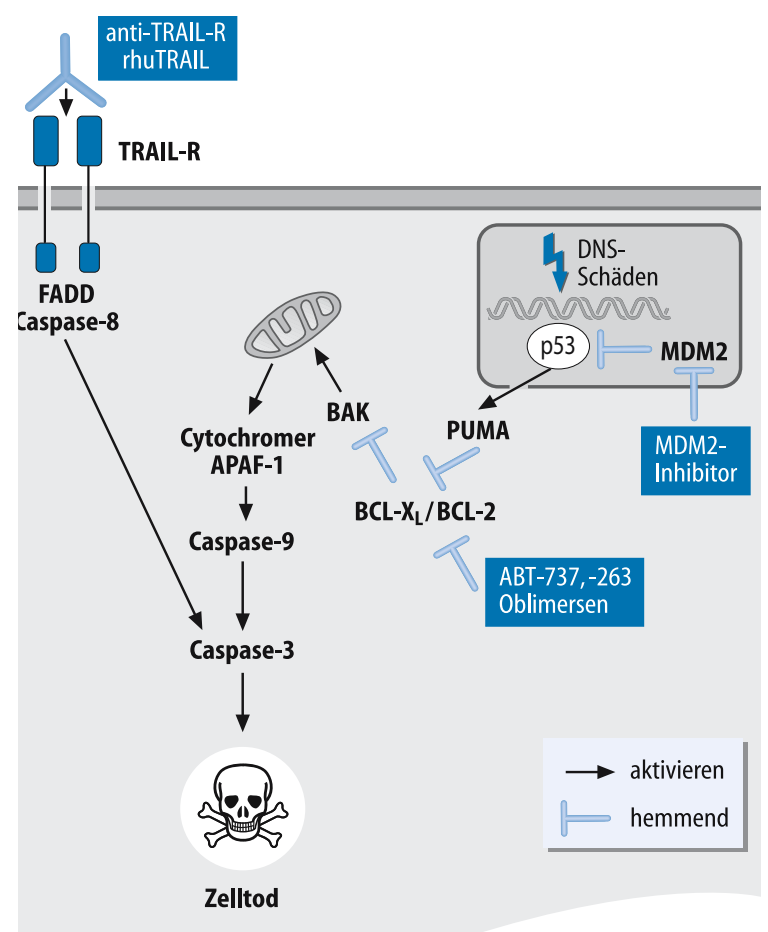

- Abb. 10.2. Signalwege des programmierten Zelltodes und therapeutische Ansatzpunkte ( $\rightarrow$ aktivieren; $\Vdash$ hemmen) 
BAK und BAX, was eine Permeabilisierung der äußeren Mitochondrienmembran nach sich zieht. Hierdurch werden Cytochrom c und weitere apoptogene Proteine aus den Mitochondrien freigesetzt und die Ausbildung des sog. Apoptosomkomplexes induziert, der wiederum Caspasen aktiviert.

Mögliche therapeutische Angriffspunkte in diesen Signalwegen ist einerseits die Verwendung agonistischer Antikörper gegen »Todesrezeptoren« oder rekombinanter, aktivierter »Todesliganden«. Beide Prinzipien sind für das TRAIL-Liganden-Rezeptorsystem in klinischer Erprobung. Eine intrazelluläre pharmakologische Modulation der Signalwege kann auf der Ebene des Tumorsuppressors p53 erfolgen; hier sind beispielsweise mehrere pharmakologische Regulatoren des physiologischen Inhibitors von p53, der Ubiquitinligase MDM2, in klinischer Entwicklung.

Ein weiteres attraktives Target sind die anti-apoptotischen BCL-2-Proteine. Oblimersen, ein Antisenseoligonukleotid gegen BCL-2, wurde bereits im Rahmen von Phase-III-Studien bei Patienten mit chronischer lymphatischer Leukämie und malignen Melanomen erprobt. Mehrere Antagonisten von BCL-2 und BCL-XL, wie z. B. ABT-737 und ABT-263, wurden präklinisch entwickelt. $\mathrm{Zu}$ ABT-263 liegen auch erste Ergebnisse aus Phase-IStudien vor. Weitere Zielmoleküle, die an der Regulation der Apoptose beteiligt sind, umfassen Mitglieder der "Inhibitor of Apoptosis" (IAP)-Familie, wie XIAP, cIAP1 und cIAP2. Für diese Proteine wurden verschiedene niedermolekulare Inhibitoren identifiziert, die in die klinische Entwicklung drängen.

\section{Zusammenfassende Bewertung \\ Zielgerichtete Hemmstoffe der Angiogenese und des AKT-Signalweges sind wesentlicher Bestandteil des Behandlungsalgorithmus von Patienten mit fortge- schrittenem Nierenzellkarzinom. Dem gegenüber befindet sich die therapeutische Modulation der apo- ptotischen Signaltransduktion noch in einem frühen Entwicklungsstadium. Aufgrund des potenziell breiten, entitätsübergreifenden Wirkungsansatzes sind hiermit jedoch große Hoffnungen verbunden.}

\subsection{Hinweise zur Prophylaxe und Therapie von Komplikationen der Chemotherapie}

T. Jäger, S. Krege, H. Rübben

Die Toxizität ist neben dem Ansprechen des Tumors und dem Überleben des Patienten das wichtigste Kriterium zur Beurteilung einer Therapie. Daher bedarf es einer exakten Dokumentation von Nebenwirkungen der jeweiligen Therapie. Therapiebedingte Nebenwirkungen und Folgezustände können nur dann als solche erkannt werden, wenn die Ausgangssituation bekannt ist, d.h. dass alle relevanten Parameter bereits vor Beginn der Therapie überprüft und dokumentiert werden.

Die Vermeidung von Nebenwirkungen erfordert genaue Kenntnis des jeweiligen Nebenwirkungsspektrums eines Chemotherapeutikums, der Wechselwirkungen mit anderen Medikamenten sowie der notwendigen Dosismodifikationen bei Einschränkung der verschiedenen Organsysteme, z. B. der Knochenmarkreserve. Bereits bei der Indikationsstellung zur Chemotherapie müssen der Allgemeinzustand und das Alter des Patienten sowie Vorbehandlungen berücksichtigt werden. Für einige Indikationsgebiete innerhalb der urologischen Onkologie wird die klassische Chemotherapie zugunsten targetspezifischer Therapeutika in Zukunft in den Hintergrund treten. Für das fortgeschrittene Nierenzellkarzinom ist dieser Paradigmenwechsel von kombinierten Immun-Chemotherapien hin $\mathrm{zu}$ modernen targetspezifischen Substanzen mit teilweise grundsätzlich anderen Nebenwirkungsprofilen bereits vollzogen ( Kap. 21.6.3).

\subsubsection{Kriterien zur Beurteilung von Nebenwirkungen}

Die grundsätzliche Graduierung der Nebenwirkungen erfolgt nach WHO-Kriterien (• Tab. 10.1).

Prinzipiell müssen akute und chronische Nebenwirkungen voneinander unterschieden werden. Als akute Nebenwirkungen und Therapiefolgen sind Ereignisse zu verstehen, die innerhalb von 90 Tagen nach Beendigung der onkologischen Therapie auftreten können. Von chronischen Nebenwirkungen spricht man bei Ereignissen ab dem 91. Tag nach Beendigung der Therapie (Perez u. Brady 1993).

Die meisten Klassifikationen erfassen akute Nebenwirkungen. Eine detaillierte Erfassung objektiv messbarer Parameter ist mit der NCI-Klassifikation möglich (- Tab. 10.2). Es wird zunehmend versucht, subjektive Parameter wie Allgemeinbefinden und Schmerzempfinden z.B. durch visuelle Analogskalen zu objektivieren, die individuelle Beurteilung fällt aber nach wie vor schwer, da der Begriff der Lebensqualität heterogenen Einflüssen unterliegt.

Unverzichtbar wird die Beurteilung der Lebensqualität dort, wo die Chemotherapie überwiegend unter der Zielsetzung der Lebensqualitätsverbesserung eingesetzt 


\begin{tabular}{|l|l}
\hline $\begin{array}{l}\text { - Tab. 10.1. Graduierung der Nebenwirkungen nach WHO } \\
\text { (Toxizitätsgrade) }\end{array}$ \\
\hline Toxizitätsgrad & Defintion \\
\hline Grad 0 & Keine Nebenwirkungen \\
\hline Grad 1 & $\begin{array}{l}\text { Geringe Nebenwirkungen ohne Einfluss } \\
\text { auf Dosis und Dauer der Chemotherapie } \\
\text { und ohne Einfluss auf den Allgemeinzu- } \\
\text { stand }\end{array}$ \\
\hline Grad 2 & $\begin{array}{l}\text { Mäßige Nebenwirkungen mit Verschlech- } \\
\text { terung des Allgemeinbefindens und/oder } \\
\text { notwendiger Reduktion der Chemothera- } \\
\text { peutika }\end{array}$ \\
\hline Grad 3 & $\begin{array}{l}\text { Ausgeprägte Nebenwirkungen, die einen } \\
\text { Abbruch oder eine Unterbrechung der } \\
\text { Chemotherapie erforderlich machen }\end{array}$ \\
\hline Grad 4 & $\begin{array}{l}\text { Schwere Nebenwirkungen, die eine statio- } \\
\text { näre Aufnahme bedingen }\end{array}$ \\
\hline Grad 5 & \begin{tabular}{l} 
Tod durch Chemotherapie \\
\hline
\end{tabular}
\end{tabular}

wird. Dies trifft z. B. für die Therapie des hormonrefraktären Prostatakarzinoms zu. Von der Arbeitsgemeinschaft Urologische Onkologie (AUO) wurden inzwischen Lebensqualitätsbögen für die verschiedenen Tumorentitäten erstellt ( $\triangleright$ Kap. 3).

\subsubsection{Kontraindikationen und Toxizität}

Die häufigsten Faktoren, die bei einer Chemotherapie zu einer Dosisreduktion, einer Verlängerung des Zeitintervalls bis zur Verabreichung oder dem Unterlassen der Verabreichung der jeweiligen Chemotherapie führen, sind im Folgenden aufgeführt, sie sind als (relative) Kontraindikationen zu betrachten:

- reduzierter Allgemeinzustand (WHO-Score >2),

- Knochenmarkinsuffizienz,

- Niereninsuffizienz,

- Leberinsuffizienz,

- Herzinsuffizienz,

- Lungenfunktionsstörung,

- vorausgegangene Chemotherapie,

- vorausgegangene Strahlentherapie.

Hinzu können Störungen weiterer Organsysteme kommen, wie z.B. Hörschäden, die eine Modifikation einer platinhaltigen Therapie erfordern. - Tab. 10.3 gibt einen

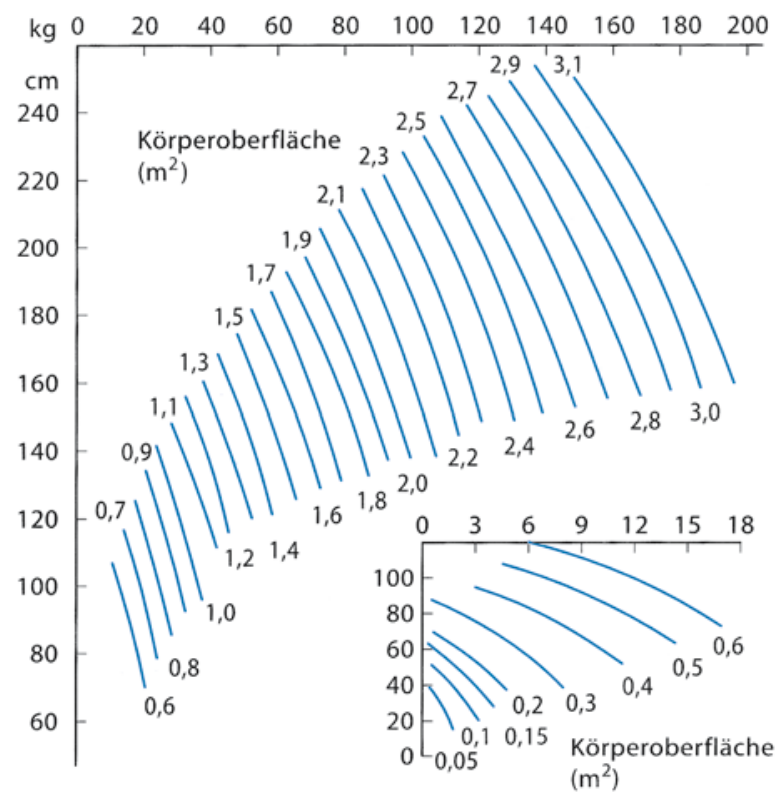

- Abb. 10.3. Nomogramm zur Bestimmung der Dosierung eines Zytostatikums

Überblick über die jeweiligen Toxizitäten, Wechselwirkungen und relativen Kontraindikationen der in der Uroonkologie gebräuchlichen Chemotherapeutika.

Das Ausmaß der Organfunktion bestimmt in der Regel die Dosierung des Zytostatikums. Die normale Dosierung erfolgt anhand von Nomogrammen (• Abb. 10.3), wobei im Erwachsenenalter aufgrund der Pharmakokinetik der Medikamente eine Dosierung nach Körperoberfläche berechnet wird.

\section{Myelotoxizität}

Myelotoxisch wirksame Substanzen führen zu einer verminderten Zellbildung im Knochenmark mit Proliferationsstörung hämatopoetischer Zellen. Die Panzytopenie ist definiert als Anämie, Leukozytopenie und Thrombozytopenie.

Die Dosierung myelotoxischer Zytostatika erfolgt in Abhängigkeit von der im peripheren Blut gemessenen Leukozyten-, Granulozyten- und Thrombozytenzahl. Darüber hinaus müssen bei geplanter Chemotherapie Grad und Dauer der chemotherapiebedingten Myelosuppression bestimmt werden. Der Eintritt der Myelosuppression nach Gabe von Zytostatika ist substanzspezifisch unterschiedlich. In - Tab. 10.4 werden Eintritt und Dauer der Knochenmarkinsuffizienz in Abhängigkeit vom verwandten Zytostatikum dargestellt. 
- Tab. 10.2. NCl-Toxizitätskriterien (höchste Toxizität während des Zyklus bewerten und markieren. (Nach NCI 1993)

\begin{tabular}{|c|c|c|c|c|c|}
\hline & 0 & 1 & 2 & 3 & 4 \\
\hline \multicolumn{6}{|c|}{ Blutparameter/Blutbild } \\
\hline $\begin{array}{l}\text { Hämoglobin } \\
\text { (g/100 ml) }\end{array}$ & Normal & 10,0-normal & $8,0-10,0$ & $6,5-7,9$ & $<6,5$ \\
\hline $\begin{array}{l}\text { Leukozyten } \\
\left(\times 10^{9} / \mathrm{I}\right)\end{array}$ & $\geq 24,0$ & $3,0-3,9$ & $2,0-2,9$ & $1,0-1,9$ & $<1,0$ \\
\hline $\begin{array}{l}\text { Granulozyten } \\
\left(\times 10^{9} / \mathrm{I}\right)\end{array}$ & $\geq 22,0$ & $1,5-1,9$ & $1,0-1,4$ & $0,5-0,9$ & $<0,5$ \\
\hline $\begin{array}{l}\text { Thrombozyten } \\
\left(\times 10^{9} / \mathrm{I}\right)\end{array}$ & Normal & 75,0-normal & $50,0-74,9$ & $25,0-49,9$ & $<25,0$ \\
\hline Lymphozyten & $\leq 2,0$ & $1,5-1,9$ & $1,0-1,4$ & $0,5-0,9$ & $<0,5$ \\
\hline Andere Blutwerte & Keine & Geringe & Mäßige & Schwere & Lebensbedrohliche \\
\hline \multicolumn{6}{|l|}{ Blutungen } \\
\hline (Klinische) & Keine & $\begin{array}{l}\text { Geringe, keine } \\
\text { Transfusion }\end{array}$ & $\begin{array}{l}\text { Erheblicher Blut- } \\
\text { verlust, 1-2 Trans- } \\
\text { fusionen }\end{array}$ & $\begin{array}{l}\text { Erheblicher Blut- } \\
\text { verlust, 3-4 Trans- } \\
\text { fusionen }\end{array}$ & $\begin{array}{l}\text { Massiver Blut- } \\
\text { verlust, }>4 \text { Trans- } \\
\text { fusionen }\end{array}$ \\
\hline \multicolumn{6}{|l|}{ Infektion } \\
\hline & Keine & $\begin{array}{l}\text { Geringe, nicht } \\
\text { behandlungs- } \\
\text { bedürftig }\end{array}$ & $\begin{array}{l}\text { Mäßiggradige p.o. } \\
\text { Antibiose }\end{array}$ & $\begin{array}{l}\text { Schwere, i.v. anti- } \\
\text { biotische antimyko- } \\
\text { tische oder statio- } \\
\text { näre Behandlung }\end{array}$ & Lebensbedrohliche \\
\hline \multicolumn{6}{|l|}{ Magen-Darm-Trakt } \\
\hline Übelkeit & Nicht vorhanden & $\begin{array}{l}\text { Nahrungsaufnahme } \\
\text { möglich }\end{array}$ & $\begin{array}{l}\text { Reduzierte Nah- } \\
\text { rungsaufnahme, Es- } \\
\text { sen jedoch möglich }\end{array}$ & $\begin{array}{l}\text { Keine Nahrungsauf- } \\
\text { nahme möglich, be- } \\
\text { handlungsbedürftig }\end{array}$ & - \\
\hline Erbrechen & Nicht vorhanden & 1-mal/Tag & 2- bis 5-mal/Tag & 6-10-mal/Tag & $\begin{array}{l}>10-\mathrm{mal} / \mathrm{Tag} \text { oder } \\
\text { parenterale Substi- } \\
\text { tution }\end{array}$ \\
\hline Diarrhö & Nicht vorhanden & $\begin{array}{l}\text { Vermehrt } \\
\text { (2-3 Stühle/Tag) }\end{array}$ & $\begin{array}{l}\text { Vermehrt (4-6 Stüh- } \\
\text { le/Tag) oder nächt- } \\
\text { liche Stühle oder } \\
\text { mäßige Krämpfe }\end{array}$ & $\begin{array}{l}\text { Vermehrt (7-9 } \\
\text { Stühle/Tag) oder } \\
\text { Inkontinenz oder } \\
\text { schwere Krämpfe }\end{array}$ & $\begin{array}{l}\geq 10 \text { Stühle/Tag } \\
\text { oder blutige Diar- } \\
\text { rhöen oder parente- } \\
\text { rale Substitution }\end{array}$ \\
\hline Stomatitis & Keine Veränderung & $\begin{array}{l}\text { Schmerzlose Ulzera, } \\
\text { Erytheme oder mil- } \\
\text { des Wundsein }\end{array}$ & $\begin{array}{l}\text { Schmerzhafte Ery- } \\
\text { theme, Ödeme oder } \\
\text { Ulzera, feste Speise } \\
\text { möglich }\end{array}$ & $\begin{array}{l}\text { Schmerzhafte Ery- } \\
\text { theme, Ödeme oder } \\
\text { Ulzera, Flüssignah- } \\
\text { rung erforderlich }\end{array}$ & $\begin{array}{l}\text { Enterale oder } \\
\text { parenterale Ernäh- } \\
\text { rung erforderlich }\end{array}$ \\
\hline $\begin{array}{l}\text { Ösophagitis/ } \\
\text { Dysphagie }\end{array}$ & Nicht vorhanden & $\begin{array}{l}\text { Schmerzlose Ulzera, } \\
\text { Erytheme, geringes } \\
\text { Wundsein }\end{array}$ & $\begin{array}{l}\text { Schmerzhafte Ery- } \\
\text { theme, Ödeme oder } \\
\text { Ulzera oder mäßige } \\
\text { Dysphagie; in der } \\
\text { Lage, ohne Analge- } \\
\text { tika zu essen }\end{array}$ & $\begin{array}{l}\text { Keine feste Nah- } \\
\text { rungsaufnahme } \\
\text { möglich oder benö- } \\
\text { tigt Analgetika, um } \\
\text { essen zu können }\end{array}$ & $\begin{array}{l}\text { Enterale oder } \\
\text { parenterale Ernäh- } \\
\text { rung oder komplet- } \\
\text { ter Verschluss oder } \\
\text { Perforation }\end{array}$ \\
\hline Anorexie & Nicht vorhanden & Gering & Mäßig & Schwer & Lebensbedrohlich \\
\hline Gastritis/Ulkus & Nicht vorhanden & Antazida & $\begin{array}{l}\text { Erfordert forcierte } \\
\text { Therapie oder kon- } \\
\text { servative Therapie }\end{array}$ & $\begin{array}{l}\text { Therapieresistent, } \\
\text { erfordert operatives } \\
\text { Vorgehen }\end{array}$ & $\begin{array}{l}\text { Perforation oder } \\
\text { Blutung }\end{array}$ \\
\hline
\end{tabular}


- Tab. 10.2. Fortsetzung

\begin{tabular}{|c|c|c|c|c|c|}
\hline & 0 & 1 & 2 & 3 & 4 \\
\hline $\begin{array}{l}\text { Dünndarm- } \\
\text { obstruktion }\end{array}$ & Nicht vorhanden & - & $\begin{array}{l}\text { Intermittierend, } \\
\text { keine Intervention }\end{array}$ & $\begin{array}{l}\text { Intervention } \\
\text { erforderlich }\end{array}$ & $\begin{array}{l}\text { Operation } \\
\text { erforderlich }\end{array}$ \\
\hline Intestinale Fistel & Nicht vorhanden & - & - & Vorhanden & - \\
\hline $\begin{array}{l}\text { Andere } \\
\text { gastrointestinale } \\
\text { Erkrankungen }\end{array}$ & Keine & Geringe & Mäßige & Schwere & Lebensbedrohliche \\
\hline $\begin{array}{l}\text { Andere Schleim- } \\
\text { hauterkrankungen }\end{array}$ & Keine & $\begin{array}{l}\text { Erythem oder } \\
\text { geringer Schmerz, } \\
\text { nicht behandlungs- } \\
\text { bedürftig }\end{array}$ & $\begin{array}{l}\text { Fleckige und se- } \\
\text { rosanguinöse Ab- } \\
\text { sonderungen oder } \\
\text { Schmerzen oder } \\
\text { Narkotikabedarf }\end{array}$ & $\begin{array}{l}\text { Konfluent fibrinöse } \\
\text { Mukositis oder } \\
\text { Ulzeration oder } \\
\text { Narkotika zur } \\
\text { Schmerzbehand- } \\
\text { lung }\end{array}$ & Nekrose \\
\hline \multicolumn{6}{|l|}{ Leber } \\
\hline Bilirubin & Normal & - & $<1,5 \times N$ & $1,5-3,0 \times \mathrm{N}$ & $>3,0 \times \mathrm{N}$ \\
\hline $\begin{array}{l}\text { Transaminasen } \\
\text { (SGOT/SGPT) }\end{array}$ & Normal & $\leq 2,5 \times \mathrm{N}$ & $2,6-5,0 \times \mathrm{N}$ & $5,1-20,0 \times \mathrm{N}$ & $>20 \times N$ \\
\hline $\begin{array}{l}\text { Alkalische } \\
\text { Phosphatase }\end{array}$ & Normal & $\leq 2,5 \times \mathrm{N}$ & $2,6-5,0 \times \mathrm{N}$ & $5,1-20,0 \times \mathrm{N}$ & $>20,0 \times N$ \\
\hline Klinisches Bild & Keine Änderung & - & - & Präkoma & Hepatisches Koma \\
\hline $\begin{array}{l}\text { Andere Leber- } \\
\text { erkrankungen }\end{array}$ & - & Geringe & Mäßiggradige & Schwere & Lebensbedrohliche \\
\hline \multicolumn{6}{|l|}{ Harntrakt } \\
\hline $\begin{array}{l}\text { Kreatinin } \\
\text { (Serum) }\end{array}$ & Normal & $<1,5 \times \mathrm{N}$ & $1,5-3,0 \times \mathrm{N}$ & $3,1-6,0 \times \mathrm{N}$ & $>6,0 \times \mathrm{N}$ \\
\hline Proteinurie & Keine & $\begin{array}{l}-1+\text { oder } \\
-<0,3 \mathrm{~g} \% \text { oder } \\
-<3 \mathrm{~g} / \mathrm{l}\end{array}$ & $\begin{array}{l}\text { - 2-3+ oder } \\
\text { - 0,3-1,0 g\% oder } \\
\text { - } 3-10 \mathrm{~g} / \mathrm{l}\end{array}$ & $\begin{array}{l}-4+\text { oder } \\
->1,0 \mathrm{~g} \% \text { oder } \\
->10 \mathrm{~g} / \mathrm{l}\end{array}$ & $\begin{array}{l}\text { Nephrotisches } \\
\text { Syndrom }\end{array}$ \\
\hline Hämaturie & Keine & $\begin{array}{l}\text { Nur mikroskopisch } \\
\text { sichtbar }\end{array}$ & $\begin{array}{l}\text { Beträchtlich, keine } \\
\text { Gerinnsel }\end{array}$ & $\begin{array}{l}\text { Beträchtlich + } \\
\text { Gerinnsel }\end{array}$ & $\begin{array}{l}\text { Beträchtlich, Trans- } \\
\text { fusion erforderlich }\end{array}$ \\
\hline \multicolumn{6}{|l|}{ Harnstoff } \\
\hline (mg\%) & Normal $<20$ & $21-30$ & $31-50$ & $>50$ & - \\
\hline$(\mathrm{mmol} / \mathrm{l})$ & Normal $<7,5$ & $7,6-10,9$ & $11-18$ & $>18$ & \\
\hline $\begin{array}{l}\text { Hämorrhagische } \\
\text { Zystitis }\end{array}$ & Keine & $\begin{array}{l}\text { Blut mikroskopisch } \\
\text { sichtbar }\end{array}$ & $\begin{array}{l}\text { Blut makroskopisch } \\
\text { sichtbar }\end{array}$ & $\begin{array}{l}\text { Blasenspülung } \\
\text { erforderlich }\end{array}$ & $\begin{array}{l}\text { Zystektomie } \\
\text { oder Transfusion } \\
\text { erforderlich }\end{array}$ \\
\hline Nierenversagen & - & - & - & - & Dialyse erforderlich \\
\hline Inkontinenz & Keine & $\begin{array}{l}\text { Beim Husten, } \\
\text { Niesen etc. }\end{array}$ & $\begin{array}{l}\text { Spontan, Kontrolle } \\
\text { möglich }\end{array}$ & Unkontrolliert & - \\
\hline Dysurie & Keine & Geringer Schmerz & $\begin{array}{l}\text { Schmerzen oder } \\
\text { Brennen beim } \\
\text { Wasserlassen, } \\
\text { konrollierbardurch } \\
\text { Pyridium }\end{array}$ & $\begin{array}{l}\text { Nicht kontrollierbar } \\
\text { durch Pyridium }\end{array}$ & - \\
\hline
\end{tabular}


- Tab. 10.2. Fortsetzung

\begin{tabular}{|c|c|c|c|c|c|}
\hline & 0 & 1 & 2 & 3 & 4 \\
\hline Harnverhaltung & Keine & $\begin{array}{l}\text { Restharn }>100 \mathrm{ml} \\
\text { oder Katheter gele- } \\
\text { gentlich notwendig } \\
\text { oder Schwierigkei- } \\
\text { ten beim Wasser- } \\
\text { lassen }\end{array}$ & $\begin{array}{l}\text { Katheterisierung } \\
\text { zur Entleerung } \\
\text { erforderlich }\end{array}$ & $\begin{array}{l}\text { Chirurgischer } \\
\text { Eingriff (TUR oder } \\
\text { Dilatation) erfor- } \\
\text { derlich }\end{array}$ & - \\
\hline $\begin{array}{l}\text { Vermehrter } \\
\text { Harndrang }\end{array}$ & Keiner & $\begin{array}{l}\text { Vermehrter oder } \\
\text { nächtlicher Harn- } \\
\text { drang bis zu 2-fach } \\
\text { des Normalen }\end{array}$ & $\begin{array}{l}\text { Vermehrt }>2 \text {-fach } \\
\text { des Normalen, } \\
\text { jedoch weniger als } \\
\text { stündlich }\end{array}$ & $\begin{array}{l}\text { Starker Harndrang, } \\
\text { stündlich oder } \\
\text { mehr oder Kathe- } \\
\text { terisierung erfor- } \\
\text { derlich }\end{array}$ & - \\
\hline Blasenkrämpfe & Keine & - & Vorhanden & - & - \\
\hline Ureterobstruktion & Keine & $\begin{array}{l}\text { Unilateral, kein } \\
\text { Eingriff erforderlich }\end{array}$ & $\begin{array}{l}\text { Bilateral, kein } \\
\text { Eingriff erforderlich }\end{array}$ & $\begin{array}{l}\text { Inkomplett } \\
\text { bilateral, jedoch } \\
\text { Stentimplantation, } \\
\text { Nephrostomie oder } \\
\text { Operation erfor- } \\
\text { derlich }\end{array}$ & $\begin{array}{l}\text { Komplette bilatera- } \\
\text { le Obstruktion }\end{array}$ \\
\hline Fistel & Keine & - & - & Vorhanden & - \\
\hline $\begin{array}{l}\text { Niere/Blase } \\
\text { sonstiges }\end{array}$ & - & Gering & Mäßggradig & Schwer & Lebensbedrohlich \\
\hline \multicolumn{6}{|l|}{ Alopezie } \\
\hline & Kein Haarverlust & $\begin{array}{l}\text { Geringer Haar- } \\
\text { verlust }\end{array}$ & $\begin{array}{l}\text { Ausgeprägter oder } \\
\text { totaler Haarverlust }\end{array}$ & - & - \\
\hline \multicolumn{6}{|l|}{ Lunge } \\
\hline Dyspnoe & Keine (Änderung) & $\begin{array}{l}\text { Asymptomatisch, } \\
\text { mit Veränderungen } \\
\text { im Lungenfunk- } \\
\text { tionstest }\end{array}$ & $\begin{array}{l}\text { Dyspnoe unter star- } \\
\text { ker Belastung }\end{array}$ & $\begin{array}{l}\text { Dyspnoe unter nor- } \\
\text { maler Belastung }\end{array}$ & Ruhedyspnoe \\
\hline $\mathrm{pO}_{2} / \mathrm{pCO}_{2}$ & $\begin{array}{l}\text { Keine Veränderung } \\
\text { oder } \mathrm{pO}_{2}>85 \text { und } \\
\mathrm{pCO}_{2} \leq 40\end{array}$ & $\begin{array}{l}\mathrm{pO}_{2} 71-85, \mathrm{pCO}_{2} \\
41-50\end{array}$ & $\begin{array}{l}\mathrm{pO}_{2} 61-70, \mathrm{pCO}_{2} \\
51-60\end{array}$ & $\begin{array}{l}\mathrm{pO}_{2} 51-60 \\
\mathrm{pCO}_{2} 61-70\end{array}$ & $\begin{array}{l}\mathrm{pO}_{2} \leq 50 \text { oder } \\
\mathrm{pCO}_{2} \geq 70\end{array}$ \\
\hline Lungenfunktion & $\begin{array}{l}>90 \% \text { gegenüber } \\
\text { des Ausgangswer- } \\
\text { tes vor Behandlung }\end{array}$ & $\begin{array}{l}77-90 \% \text { gegenüber } \\
\text { vor Behandlung }\end{array}$ & $\begin{array}{l}51-75 \% \text { gegenüber } \\
\text { vor Behandlung }\end{array}$ & $\begin{array}{l}26-50 \% \text { gegenüber } \\
\text { vor Behandlung }\end{array}$ & $\begin{array}{l}\leq 25 \% \text { gegenüber } \\
\text { vor Behandlung }\end{array}$ \\
\hline Lungenfibrose & Keine & $\begin{array}{l}\text { Röntgenologische } \\
\text { Veränderungen } \\
\text { beschwerdefrei }\end{array}$ & - & $\begin{array}{l}\text { Veränderungen mit } \\
\text { Symptomen }\end{array}$ & - \\
\hline Lungenödem & Keine & - & - & $\begin{array}{l}\text { Röntgenologische } \\
\text { Veränderungen und } \\
\text { Gabe von Diuretika } \\
\text { erforderlich }\end{array}$ & $\begin{array}{l}\text { Intubation } \\
\text { erforderlich }\end{array}$ \\
\hline $\begin{array}{l}\text { Pneumonie } \\
\text { (nicht infektiöse) }\end{array}$ & Keine & $\begin{array}{l}\text { Röntgenologische } \\
\text { Veränderungen }\end{array}$ & Steroide erforderlich & $\begin{array}{l}\text { Sauerstoff } \\
\text { erforderlich }\end{array}$ & $\begin{array}{l}\text { Assistierte Beat- } \\
\text { mung erforderlich }\end{array}$ \\
\hline Pleuraler Erguss & Kein & Vorhanden & - & - & - \\
\hline
\end{tabular}




\begin{tabular}{|c|c|c|c|c|c|}
\hline & 0 & 1 & 2 & 3 & 4 \\
\hline Husten & Kein & $\begin{array}{l}\text { Gering, Linderung } \\
\text { durch nicht rezept- } \\
\text { pflichtige Medika- } \\
\text { mente }\end{array}$ & $\begin{array}{l}\text { Erfordert rezept- } \\
\text { pflichtige Antitus- } \\
\text { siva }\end{array}$ & $\begin{array}{l}\text { Unkontrollierter } \\
\text { Husten }\end{array}$ & - \\
\hline Lunge sonstiges & - & Gering & Mäßiggradig & Schwer & Lebensbedrohlich \\
\hline \multicolumn{6}{|c|}{ Kardiovaskuläre Ereignisse } \\
\hline Arrhythmien & Keine & $\begin{array}{l}\text { Asymptomatisch, } \\
\text { flüchtig, nicht } \\
\text { therapiebedürftig }\end{array}$ & $\begin{array}{l}\text { Wiederkehrend } \\
\text { oder persistierend, } \\
\text { nicht therapie- } \\
\text { bedürftig }\end{array}$ & Therapiebedürftig & $\begin{array}{l}\text { Monitoring erfor- } \\
\text { derlich oder ventr. } \\
\text { Tachykardie oder } \\
\text { Fibrillation }\end{array}$ \\
\hline Funktion & Unauffälig & $\begin{array}{l}\text { Asymptomatisch, } \\
\text { Abfall der } \\
\text { linksventrikulären } \\
\text { Ejektionsfraktion } \\
\text { um }<20 \% \text { des Ur- } \\
\text { sprungsvolumens }\end{array}$ & $\begin{array}{l}\text { Asymptomatisch, } \\
\text { Abfall der linksven- } \\
\text { trikulären Ejekti- } \\
\text { onsfraktion } \geq 20 \% \\
\text { des Ursprungs- } \\
\text { volumens }\end{array}$ & $\begin{array}{l}\text { Geringe kongestive } \\
\text { Herzinsuffizienz, auf } \\
\text { Therapie anspre- } \\
\text { chend }\end{array}$ & $\begin{array}{l}\text { Erhebliche } \\
\text { kongestive Herz- } \\
\text { insuffizienz, } \\
\text { therapierefraktär }\end{array}$ \\
\hline Ischämie & Keine & $\begin{array}{l}\text { Unspezifische } \\
\text { T-Wellen-Abflachung }\end{array}$ & $\begin{array}{l}\text { Asymptomatische } \\
\text { ST- und T-Wellen- } \\
\text { Veränderung } \rightarrow \\
\text { Ischämie }\end{array}$ & $\begin{array}{l}\text { Angina oder } \\
\text { Infarktereignis }\end{array}$ & Akuter Infarkt \\
\hline Perikard & Unauffällig & $\begin{array}{l}\text { Asymptomatischer } \\
\text { Erguss, keine Inter- } \\
\text { vention erforderlich }\end{array}$ & $\begin{array}{l}\text { Perikarditis (Reiben, } \\
\text { Brustschmerzen, } \\
\text { EKG-, Veränderun- } \\
\text { gen) }\end{array}$ & $\begin{array}{l}\text { Symptomatischer } \\
\text { Erguss: Drainage } \\
\text { erforderlich }\end{array}$ & $\begin{array}{l}\text { Tamponade: } \\
\text { Drainage dringend } \\
\text { erforderlich }\end{array}$ \\
\hline Sonstiges & - & Gering & Mäßiggradig & Schwer & Lebensbedrohlich \\
\hline Hypertonie & Keine Änderung & $\begin{array}{l}\text { Asymptomatisch, } \\
\text { vorübergehen- } \\
\text { der Anstieg } \\
\text { um }>20 \mathrm{mmHg} \\
\text { (D) oder } \\
>150 / 100 \mathrm{mmHg} \\
\text { bei vorherigen } \\
\text { Normalwerten, } \\
\text { nicht therapie- } \\
\text { bedürftig }\end{array}$ & $\begin{array}{l}\text { Wiederkehrender } \\
\text { oder persistie- } \\
\text { render Anstieg } \\
\text { um }>20 \mathrm{mmHg} \\
\text { (D) oder } \\
>150 / 100 \mathrm{mmHg} \\
\text { bei vorherigen } \\
\text { Normalwerten, } \\
\text { nicht therapie- } \\
\text { bedürftig }\end{array}$ & $\begin{array}{l}\text { Therapie erforder- } \\
\text { lich }\end{array}$ & Hypertensive Krise \\
\hline Hypotonie & Keine (Änderungen) & $\begin{array}{l}\text { Nicht therapie- } \\
\text { bedürftig (inkl. } \\
\text { vorübergehende } \\
\text { Therapie der ortho- } \\
\text { statischen Hypo- } \\
\text { tension) }\end{array}$ & $\begin{array}{l}\text { Erfordert Flüssig- } \\
\text { keitsersatz oder } \\
\text { andere Therapie, } \\
\text { jedoch keine statio- } \\
\text { näre Behandlung }\end{array}$ & $\begin{array}{l}\text { Erfordert statio- } \\
\text { näre Behandlung: } \\
\text { Normalisierung } \\
\text { innerhalb } 48 \text { h nach } \\
\text { Abbruch der Medi- } \\
\text { kation }\end{array}$ & $\begin{array}{l}\text { Erfordert stationäre } \\
\text { Behandlung von } \\
\text { mehr als } 48 \mathrm{~h} \text { nach } \\
\text { Abbruch der Medi- } \\
\text { kation }\end{array}$ \\
\hline $\begin{array}{l}\text { Phlebitis/Throm- } \\
\text { bose/Embolie }\end{array}$ & - & - & $\begin{array}{l}\text { Oberflächliche } \\
\text { Phlebitis (nicht } \\
\text { lokal) }\end{array}$ & $\begin{array}{l}\text { Tiefe Venen- } \\
\text { thrombose }\end{array}$ & $\begin{array}{l}\text { (Zerebrale/hepati- } \\
\text { sche/pulmonale/ } \\
\text { andere Infarzie- } \\
\text { rung) oder Lungen- } \\
\text { embolie }\end{array}$ \\
\hline Ödeme & Keine & $\begin{array}{l}\text { 1+ oder nur abend- } \\
\text { liches Auftreten }\end{array}$ & $\begin{array}{l}\text { 2+ oder Auftreten } \\
\text { während des } \\
\text { gesamten Tages }\end{array}$ & $3+$ & $\begin{array}{l}\text { 4+ generalisierte } \\
\text { Anasarka }\end{array}$ \\
\hline
\end{tabular}


- Tab. 10.2. Fortsetzung

\begin{tabular}{|c|c|c|c|c|c|}
\hline & 0 & 1 & 2 & 3 & 4 \\
\hline \multicolumn{6}{|l|}{ Neurologie } \\
\hline Sensorium & Keine (Änderungen) & $\begin{array}{l}\text { Milde Parästhesien, } \\
\text { Verlust der tiefen } \\
\text { Sehnenreflexe }\end{array}$ & $\begin{array}{l}\text { Geringer oder } \\
\text { mäßiger objektiver } \\
\text { Verlust, mäßiggra- } \\
\text { dige Parästhesien }\end{array}$ & $\begin{array}{l}\text { Schwerer objektiver } \\
\text { sensibler Verlust } \\
\text { oder Parästhesien } \\
\text { mit Funktionsein- } \\
\text { bußen }\end{array}$ & - \\
\hline Motorik & Keine (Änderungen) & $\begin{array}{l}\text { Subjektive Schwä- } \\
\text { che: klinisch ohne } \\
\text { Befund }\end{array}$ & $\begin{array}{l}\text { Objektive Schwäche } \\
\text { ohne signifikante } \\
\text { Funktionseinbußen }\end{array}$ & $\begin{array}{l}\text { Objektive Schwäche, } \\
\text { Funktionseinbußen }\end{array}$ & Paralyse \\
\hline Bewusstsein & Klar & $\begin{array}{l}\text { Leichte Somnolenz } \\
\text { oder Agitiertheit }\end{array}$ & $\begin{array}{l}\text { Mäßiggradige } \\
\text { Somnolenz oder } \\
\text { Agitiertheit }\end{array}$ & $\begin{array}{l}\text { Starke Somnolenz, } \\
\text { Agitiertheit, Dys- } \\
\text { orientierung oder } \\
\text { Halluzinationen }\end{array}$ & $\begin{array}{l}\text { Koma, Anfälle, } \\
\text { toxische Psychose }\end{array}$ \\
\hline Koordination & Normal & $\begin{array}{l}\text { Leichte } \\
\text { Dyskoordination, } \\
\text { Dysdiadochokinese }\end{array}$ & $\begin{array}{l}\text { Intentionstremor, Dy- } \\
\text { semtrie, undeutliche } \\
\text { Sprache, Nystagmus }\end{array}$ & $\begin{array}{l}\text { Lokomotorische } \\
\text { Ataxie }\end{array}$ & Zerebelläre Nekrose \\
\hline Gemütslage & Keine (Änderungen) & $\begin{array}{l}\text { Leichte Ängstlich- } \\
\text { keit oder Depression }\end{array}$ & $\begin{array}{l}\text { Mäßiggradige } \\
\text { Angstzustände } \\
\text { oder Depression }\end{array}$ & $\begin{array}{l}\text { Schwere Angst- } \\
\text { zustände oder } \\
\text { Depressionen }\end{array}$ & $\begin{array}{l}\text { Selbstmord- } \\
\text { absichten }\end{array}$ \\
\hline Kopfschmerzen & Keine & Leichte & $\begin{array}{l}\text { Mäßige bis starke, } \\
\text { jedoch vorüberge- } \\
\text { hend }\end{array}$ & $\begin{array}{l}\text { Anhaltende und } \\
\text { starke }\end{array}$ & - \\
\hline $\begin{array}{l}\text { Neurologische } \\
\text { Obstipation }\end{array}$ & Keine (Änderung) & Leichte & Mäßiggradige & Starke & Ileus $>96 \mathrm{~h}$ \\
\hline Gehör & Keine Änderung & $\begin{array}{l}\text { Nur audiometrisch } \\
\text { messbarer asymp- } \\
\text { tomatischer Hör- } \\
\text { verlust }\end{array}$ & Tinnitus & $\begin{array}{l}\text { Funktionsbedingter } \\
\text { Hörverlust, Korrek- } \\
\text { tur mir Hörhilfe }\end{array}$ & $\begin{array}{l}\text { Nichtkorrigierbare } \\
\text { Ertaubung }\end{array}$ \\
\hline Sehvermögen & Keine Änderung & - & - & $\begin{array}{l}\text { Symptomatischer } \\
\text { subtotaler Seh- } \\
\text { verlust }\end{array}$ & Erblindung \\
\hline Schmerzen & Keine & \multirow{2}{*}{$\begin{array}{l}\text { Geringe Verände- } \\
\text { rungen, keine nega- } \\
\text { tive Konsequenzen } \\
\text { für sich oder für die } \\
\text { Familie }\end{array}$} & \multirow{2}{*}{$\begin{array}{l}\text { Mäßiggradige } \\
\text { negativer Einfluss } \\
\text { auf sich selbst oder } \\
\text { auf die Familie }\end{array}$} & \multirow{2}{*}{$\begin{array}{l}\text { Schwere, gefährdet } \\
\text { sich oder andere }\end{array}$} & \multirow{2}{*}{$\begin{array}{l}\text { Unerträgliches } \\
\text { psychotisches } \\
\text { Verhalten }\end{array}$} \\
\hline $\begin{array}{l}\text { Verhaltens- } \\
\text { änderungen }\end{array}$ & Keine & & & & \\
\hline $\begin{array}{l}\text { Schwindel/ } \\
\text { Vertigo }\end{array}$ & $\begin{array}{l}\text { Kein Einfluss auf } \\
\text { den Alltag }\end{array}$ & - & Arbeitsunfähig & - & - \\
\hline Geschmack & Normal & $\begin{array}{l}\text { Leicht veränderter } \\
\text { Geschmack, metalli- } \\
\text { scher Geschmack }\end{array}$ & $\begin{array}{l}\text { Deutlich veränder- } \\
\text { ter Geschmack }\end{array}$ & - & - \\
\hline Schlafstörungen & Keine & $\begin{array}{l}\text { Gelegentliche Schlaf- } \\
\text { störungen, Einnah- } \\
\text { me von Tabletten }\end{array}$ & - & $\begin{array}{l}\text { Schlafstörungen } \\
\text { trotz Medikation }\end{array}$ & - \\
\hline $\begin{array}{l}\text { Neurologie } \\
\text { Sonstiges }\end{array}$ & - & Gering & Mäßiggradig & Schwer & Lebensbedrohlich \\
\hline
\end{tabular}


- Tab. 10.2. Fortsetzung

\begin{tabular}{|c|c|c|c|c|c|}
\hline & 0 & 1 & 2 & 3 & 4 \\
\hline \multicolumn{6}{|l|}{ Dermatologie } \\
\hline Haut & $\begin{array}{l}\text { Keine } \\
\text { Veränderungen }\end{array}$ & $\begin{array}{l}\text { Gestreute makulare } \\
\text { oder papulöse } \\
\text { Eruption oder } \\
\text { asymptomatisches } \\
\text { Erythem }\end{array}$ & $\begin{array}{l}\text { Gestreute makuläre } \\
\text { oder papulöse Erup- } \\
\text { tion oder Pruritus } \\
\text { oder andere assozi- } \\
\text { ierende Symptome }\end{array}$ & $\begin{array}{l}\text { Generalisierte ma- } \\
\text { kulöse Symptoma- } \\
\text { tik, papulös oder } \\
\text { vesikuläre Eruption }\end{array}$ & $\begin{array}{l}\text { Exfoliative Derma- } \\
\text { titis oder ulzerie- } \\
\text { rende Dermatitis }\end{array}$ \\
\hline Lokal & Keine & Schmerz & $\begin{array}{l}\text { Schmerz und } \\
\text { Schwellung mit } \\
\text { Inflammation oder } \\
\text { Phlebitis }\end{array}$ & Ulzeration & $\begin{array}{l}\text { Plastische Chirurgie } \\
\text { erforderlich }\end{array}$ \\
\hline Allergie & Keine & $\begin{array}{l}\text { Vorübergehendes } \\
\text { Arzneimittelfieber, } \\
<38^{\circ} \mathrm{C}\end{array}$ & $\begin{array}{l}\text { Urtikaria, Arznei- } \\
\text { mittelfieber, } \geq 38^{\circ} \mathrm{C} \\
\text { leichter Bronchos- } \\
\text { pasmus }\end{array}$ & $\begin{array}{l}\text { Serrumkrankheit, } \\
\text { Bronchospasmus, } \\
\text { parenterale Medi- } \\
\text { kation }\end{array}$ & Anaphylaxie \\
\hline \multicolumn{6}{|c|}{ Grippeähnliche Symptome } \\
\hline $\begin{array}{l}\text { Fieber } \\
\text { (nicht infek- } \\
\text { tionsbedingt) }\end{array}$ & Kein & $37,1-38,0^{\circ} \mathrm{C}$ & $38,1-40,0^{\circ} \mathrm{C}$ & $>40^{\circ} \mathrm{C}<24 \mathrm{~h}$ & $\begin{array}{l}>40^{\circ} \mathrm{C}<24 \mathrm{~h} \text { oder } \\
\text { Fieber verbunden } \\
\text { mit Hypotension }\end{array}$ \\
\hline Schüttelfrost & Kein & $\begin{array}{l}\text { Geringer oder } \\
\text { kurzer }\end{array}$ & $\begin{array}{l}\text { Ausgeprägter und } \\
\text { lang anhaltender }\end{array}$ & - & - \\
\hline $\begin{array}{l}\text { Myalgie/ } \\
\text { Arthralgie }\end{array}$ & Keine & Geringe & $\begin{array}{l}\text { Bewegungsein- } \\
\text { schränkung }\end{array}$ & Arbeitsunfähig & - \\
\hline Schweiß & Normal & $\begin{array}{l}\text { Gering und } \\
\text { gelegentlich }\end{array}$ & $\begin{array}{l}\text { Häufig und nass- } \\
\text { geschwitzt, Nacht- } \\
\text { schweiß }\end{array}$ & & \\
\hline Unwohlsein & Kein & $\begin{array}{l}\text { Gering, keine Beein- } \\
\text { trächtigung der } \\
\text { täglichen Aktivi- } \\
\text { täten }\end{array}$ & $\begin{array}{l}\text { Beeinträchtigt den } \\
\text { normalen Tages- } \\
\text { rhythmus oder } \\
\text { Bettruhe }<50 \% \text { der } \\
\text { täglichen Aktivität }\end{array}$ & $\begin{array}{l}>50 \% \text { des Tages der } \\
\text { normalen Wachzeit } \\
\text { im Bett oder Stuhl }\end{array}$ & $\begin{array}{l}\text { Bettlägerig oder } \\
\text { nicht in der Lage, } \\
\text { für sich selbst zu } \\
\text { sorgen }\end{array}$ \\
\hline $\begin{array}{l}\text { Andere grippeähn- } \\
\text { liche Symptome }\end{array}$ & & Geringe & Mäßiggradige & Schwere & Lebensbedrohliche \\
\hline $\begin{array}{l}\text { Gewichts- } \\
\text { zunahme }\end{array}$ & $<5,0 \%$ & $5,0-9,9 \%$ & $10,0-19,9 \%$ & $\geq 20,0 \%$ & - \\
\hline $\begin{array}{l}\text { Gewichts- } \\
\text { abnahme }\end{array}$ & $<5,0 \%$ & $5,0-9,9 \%$ & $10,0-19,9 \%$ & $\geq 20,0 \%$ & \\
\hline \multicolumn{6}{|l|}{ Stoffwechsel } \\
\hline Hyperglykämie & $\begin{array}{l}-<116 \mathrm{mg} / \mathrm{dl} \\
-<6,2 \mathrm{mmol} / \mathrm{l}\end{array}$ & $\begin{array}{l}-116-160 \\
-6,2-8,9\end{array}$ & $\begin{array}{l}-161-250 \\
-9,0-13,9\end{array}$ & $\begin{array}{l}-251-500 \\
-14,0-27,8\end{array}$ & $\begin{aligned}- & >500 \text { oder } \\
& \text { Ketoazidose } \\
- & >27,8 \text { oder } \\
& \text { Ketoazidosis }\end{aligned}$ \\
\hline Hypoglykämie & $\begin{array}{l}->64 \mathrm{mg} / \mathrm{dl} \\
->3,6 \mathrm{mmol} / \mathrm{l}\end{array}$ & $\begin{array}{l}-55-64 \\
-3,1-3,6\end{array}$ & $\begin{array}{l}-40-54 \\
-2,2-3,0\end{array}$ & $\begin{array}{l}-30-39 \\
-1,7-2,1\end{array}$ & $\begin{array}{l}-<30 \\
-<1,7\end{array}$ \\
\hline Amylase & Normal & $<1,5 \times \mathrm{N}$ & $1,5-2,0 \times \mathrm{N}$ & $>2,1-5,0 \times \mathrm{N}$ & $>5,1 \times N$ \\
\hline Hyperkalzämie & $\begin{array}{l}-<10,6 \mathrm{mg} / \mathrm{dl} \\
-<2,65 \mathrm{mmol} / \mathrm{l}\end{array}$ & $\begin{array}{l}-10,6-11,5 \\
-2,65-2,87\end{array}$ & $\begin{array}{l}-11,6-12,5 \\
-2,88-3,12\end{array}$ & $\begin{array}{l}-12,5-13,5 \\
-3,13-3,37\end{array}$ & $\begin{array}{l}-\geq 13,5 \\
-\geq 3,37\end{array}$ \\
\hline
\end{tabular}


- Tab. 10.2. Fortsetzung

\begin{tabular}{|c|c|c|c|c|c|}
\hline & 0 & 1 & 2 & 3 & 4 \\
\hline Hypokalzämie & $\begin{array}{l}->8,4 \mathrm{mg} / \mathrm{dl} \\
->2,1 \mathrm{mmol} / \mathrm{l}\end{array}$ & $\begin{array}{l}-8,4-7,8 \\
-2,1-1,95\end{array}$ & $\begin{array}{l}-7,7-7,0 \\
-1,94-1,75\end{array}$ & $\begin{array}{l}-6,9-6,1 \\
-1,74-1,51\end{array}$ & $\begin{array}{l}-\leq 6,0 \\
-\leq 1,50\end{array}$ \\
\hline Hypomagnesämie & $->1,4 \mathrm{mmol} / \mathrm{l}$ & $-1,4-1,2$ & $-1,1-0,9$ & $-0,8-0,6$ & $-\leq 0,5$ \\
\hline Hyponatriämie & - Normal oder >135 & $-131-135$ & $-126-130$ & $-121-125$ & $-\geq 120$ \\
\hline Hypokaliämie & - Normal & $-3,1-3,5$ & $-2,6-3,0$ & $-2,1-2,5$ & $-\geq 2,0$ \\
\hline Andere & - & Gering & Mäßiggradig & Schwer & Lebensbedrohlich \\
\hline \multicolumn{6}{|l|}{ Blutgerinnung } \\
\hline Fibrinogen & Normal & $0,99-0,75 \times N$ & $0,74-0,50 \times \mathrm{N}$ & $0,49-0,25 \times \mathrm{N}$ & $\leq 0,24 \times N$ \\
\hline Prothrombinzeit & Normal & $1,01-1,25 \times N$ & $1,26-1,50 \times \mathrm{N}$ & $1,51-2,00 \times \mathrm{N}$ & $>2,00 \times \mathrm{N}$ \\
\hline $\begin{array}{l}\text { Partielle Throm- } \\
\text { boblastinzeit }\end{array}$ & Normal & $1,01-1,66 \times \mathrm{N}$ & $1,67-2,33 \times N$ & $2,34-3,00 \times \mathrm{N}$ & $>3,00 \times \mathrm{N}$ \\
\hline $\begin{array}{l}\text { Andere Blutgerin- } \\
\text { nungswerte }\end{array}$ & - & Gering & Mäßiggradig & Schwer & Lebensbedrohlich \\
\hline $\begin{array}{l}\text { Subaquale } \\
\text { Blutungszeit }\end{array}$ & Normal & Verlängert $>3 \mathrm{~min}$ & & & \\
\hline \multicolumn{6}{|l|}{ Endokrin } \\
\hline Libido & Normal & $\begin{array}{l}\text { Herabgesetzte } \\
\text { Funktion }\end{array}$ & - & $\begin{array}{l}\text { Nicht mehr } \\
\text { vorhanden }\end{array}$ & \\
\hline Potenz & Normal & $\begin{array}{l}\text { Herabgesetzte } \\
\text { Funktion }\end{array}$ & - & $\begin{array}{l}\text { Nicht mehr } \\
\text { vorhanden }\end{array}$ & \\
\hline Sterilität & - & - & Ja & - & \\
\hline Amenorrhö & Nein & Ja & - & - & \\
\hline Gynäkomastie & Keine & Geringe & $\begin{array}{l}\text { Verstärkte und } \\
\text { schmerzhafte }\end{array}$ & - & - \\
\hline Hitzewallungen & Keine & $\begin{array}{l}\text { Mild oder }<1 \text { pro } \\
\text { Tag }\end{array}$ & $\begin{array}{l}\text { Mehr und } \geq 1 \text { pro } \\
\text { Tag }\end{array}$ & $\begin{array}{l}\text { Häufig, beeinträch- } \\
\text { tigt das normale } \\
\text { Leben }\end{array}$ & - \\
\hline $\begin{array}{l}\text { Cushing- } \\
\text { Syndrom }\end{array}$ & Normal & Gering & Verstärkt & - & - \\
\hline Andere & - & Gering & Mäßiggradig & Schwer & Lebensbedrohlich \\
\hline \multicolumn{6}{|l|}{ Auge } \\
\hline $\begin{array}{l}\text { Konjunktivitis/ } \\
\text { Keratitis }\end{array}$ & Keine & $\begin{array}{l}\text { Erythem oder Che- } \\
\text { mosis, keine Steroi- } \\
\text { de oder Antibiotika } \\
\text { erforderlich }\end{array}$ & $\begin{array}{l}\text { Steroide oder Anti- } \\
\text { biotika erforderlich }\end{array}$ & $\begin{array}{l}\text { Cornealulzeration } \\
\text { oder Sichttrübung }\end{array}$ & - \\
\hline Trockenes Auge & Nein & - & $\begin{array}{l}\text { Erfordert artifizielle } \\
\text { Tränenflüssigkeit }\end{array}$ & - & $\begin{array}{l}\text { Enukleation } \\
\text { erforderlich }\end{array}$ \\
\hline Glaukom & Keine (Änderung) & - & - & Ja & - \\
\hline Andere & - & Gering & Mäßiggradig & Schwer & Lebensbedrohlich \\
\hline
\end{tabular}




\begin{tabular}{|c|c|c|c|c|c|c|}
\hline & 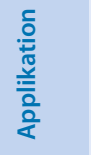 & 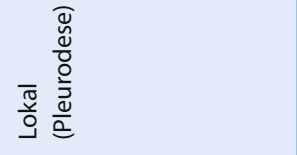 & 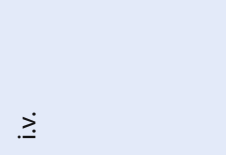 & $\stackrel{\geq}{\geqq}$ & 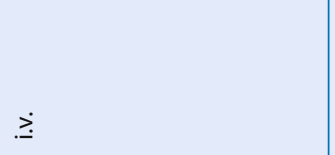 & 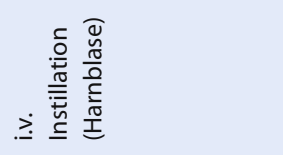 \\
\hline 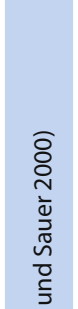 & 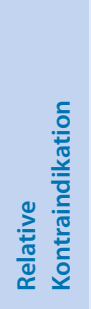 & 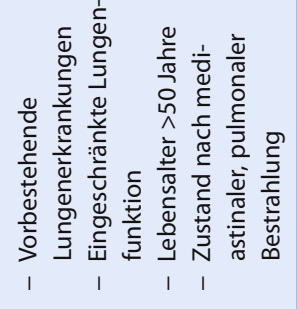 & 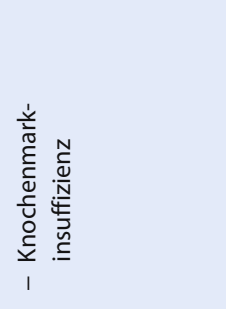 & 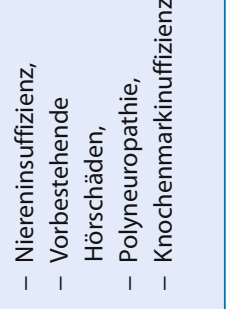 & 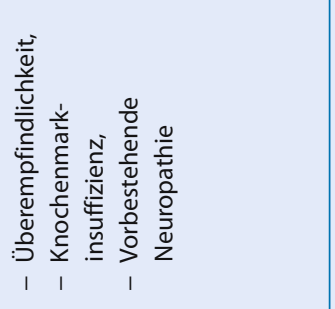 & 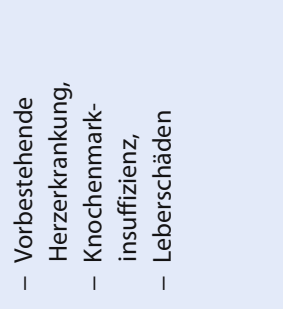 \\
\hline 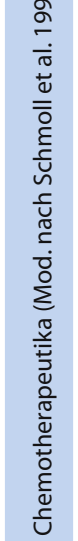 & 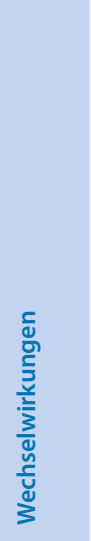 & 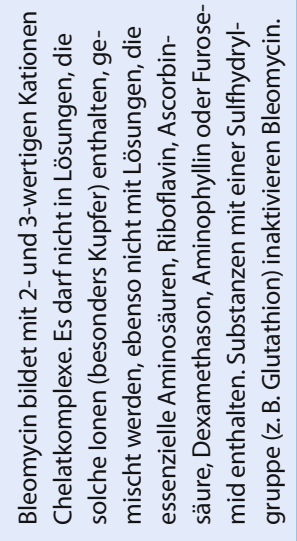 & 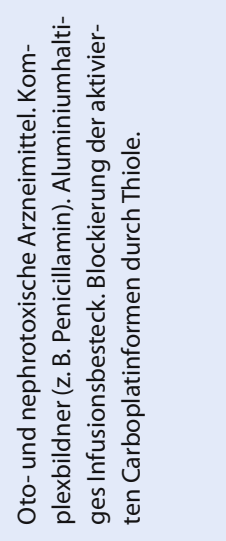 & 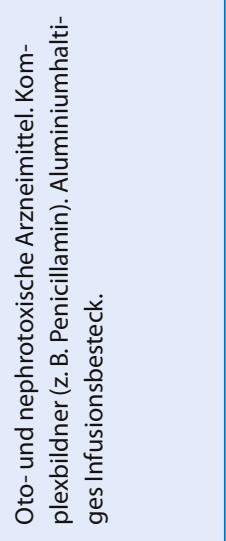 & 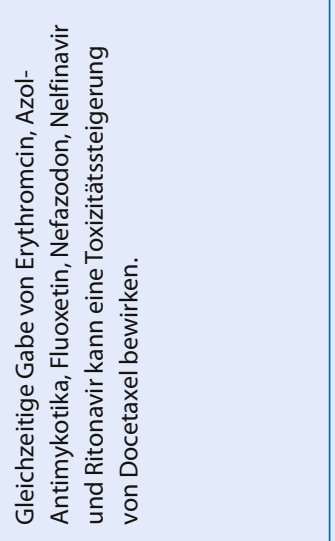 & 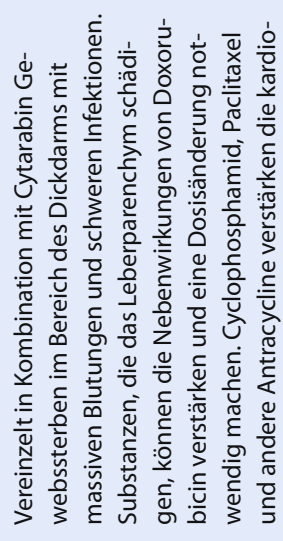 \\
\hline 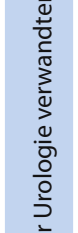 & 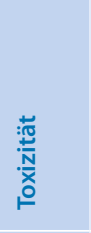 & 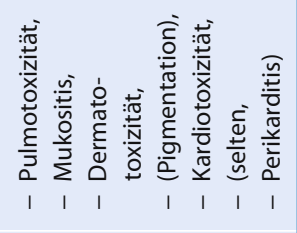 & 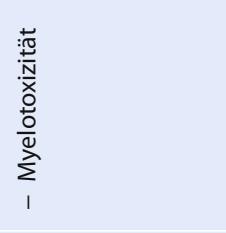 & 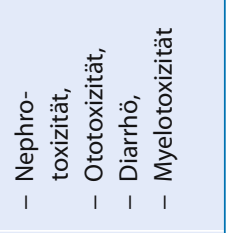 & 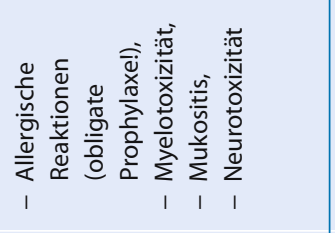 & 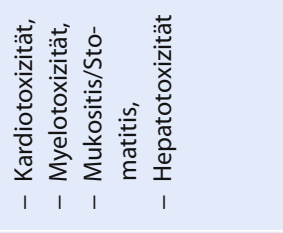 \\
\hline 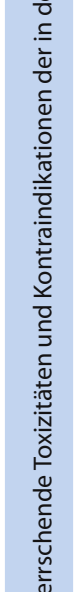 & 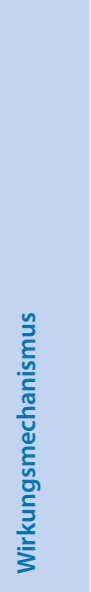 & 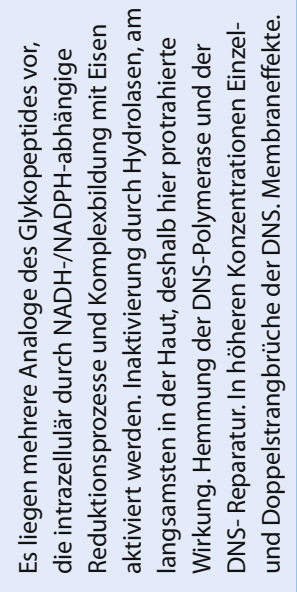 & 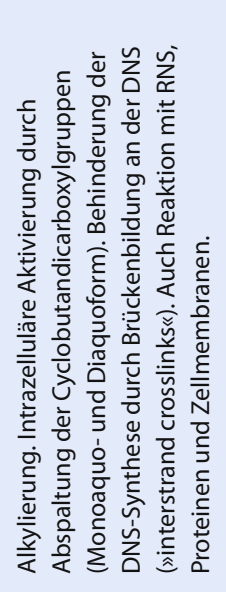 & 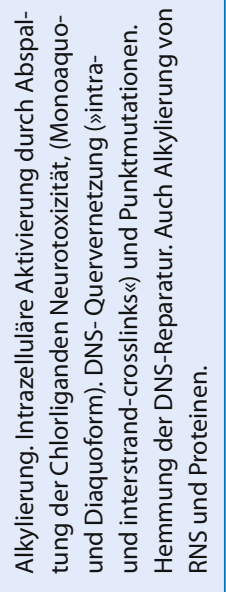 & 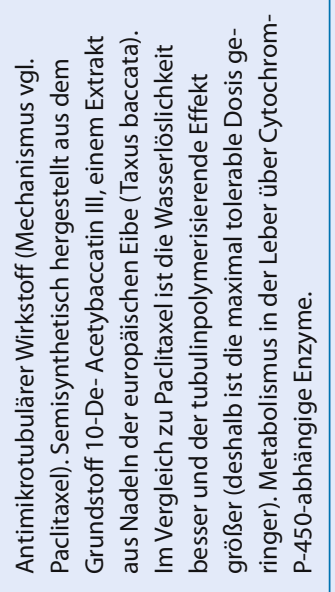 & 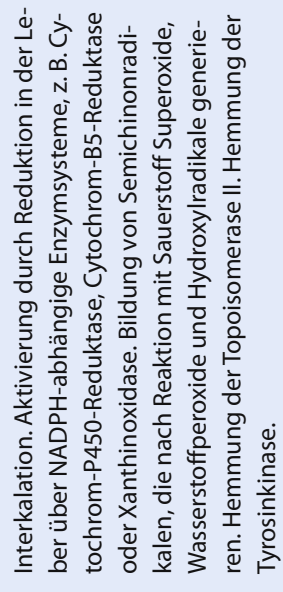 \\
\hline $\begin{array}{l}\stackrel{0}{0} \\
\dot{m} \\
\stackrel{0}{0} \\
0 \\
\stackrel{0}{\sigma} \\
\stackrel{0}{0}\end{array}$ & 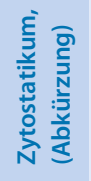 & 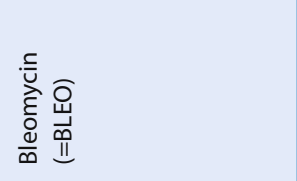 & 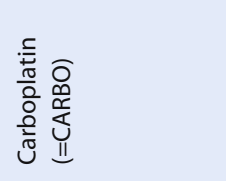 & 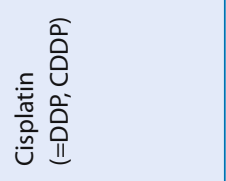 & 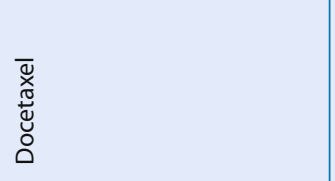 & 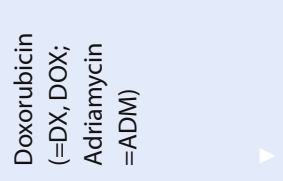 \\
\hline
\end{tabular}




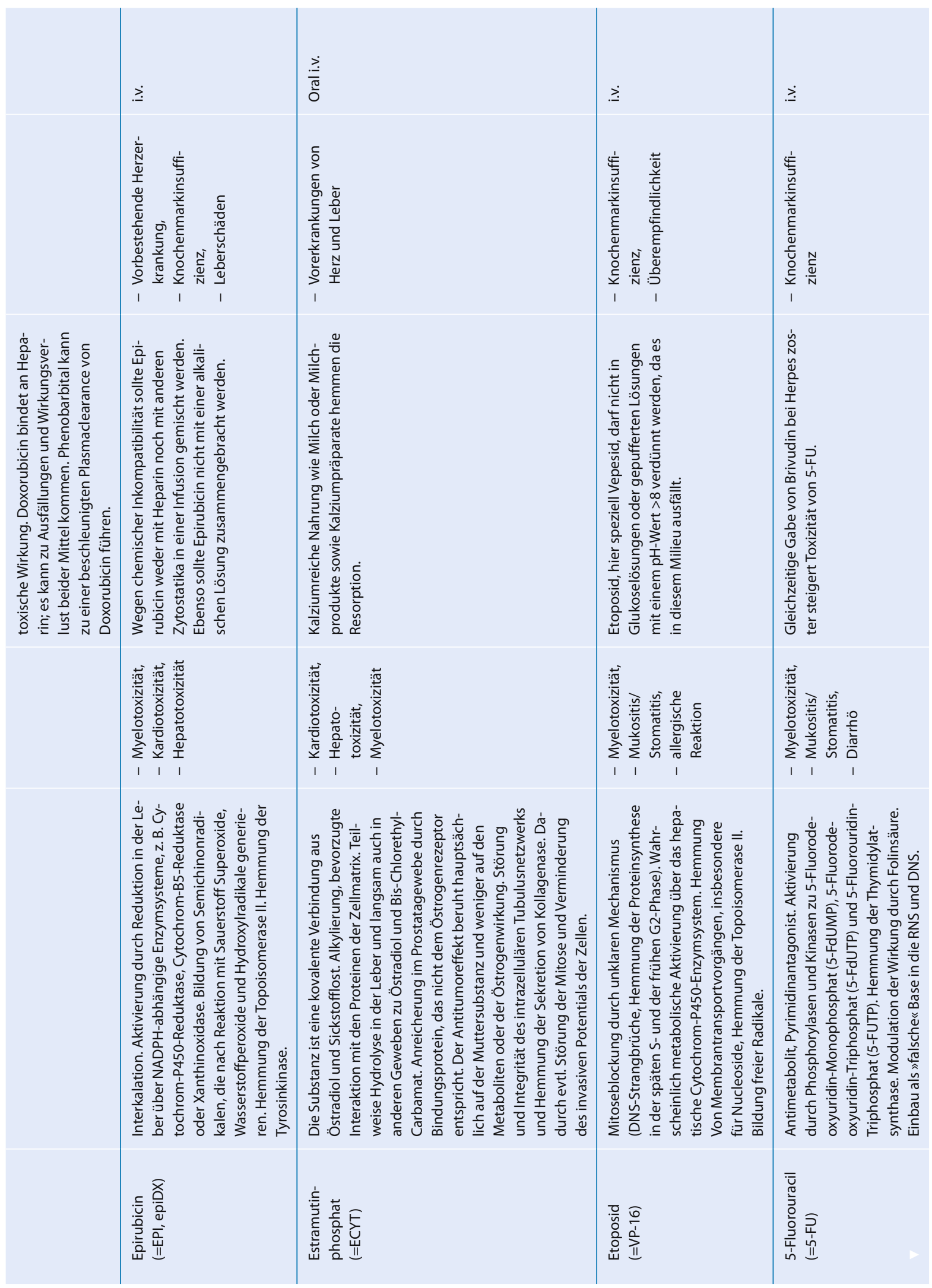




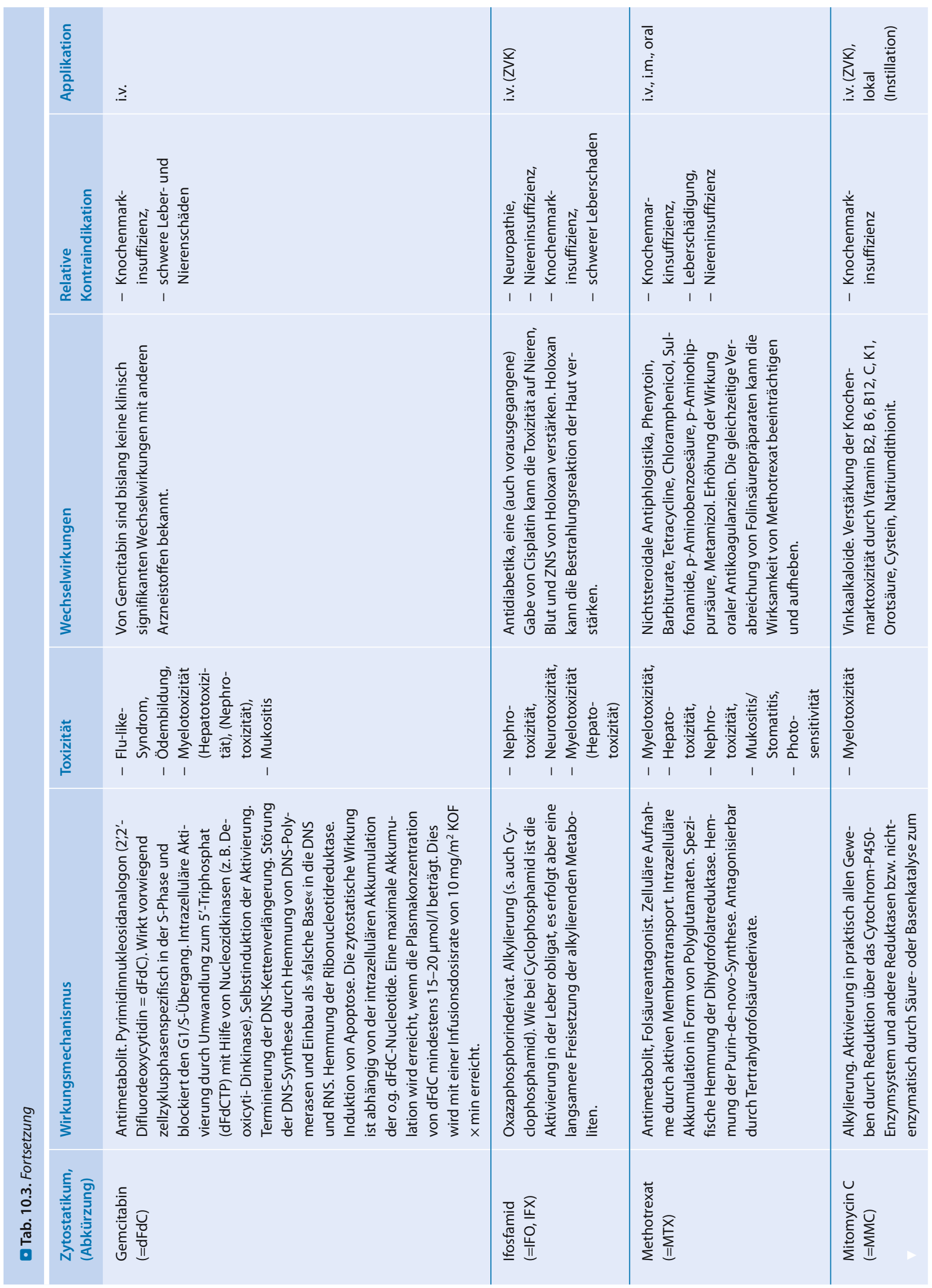




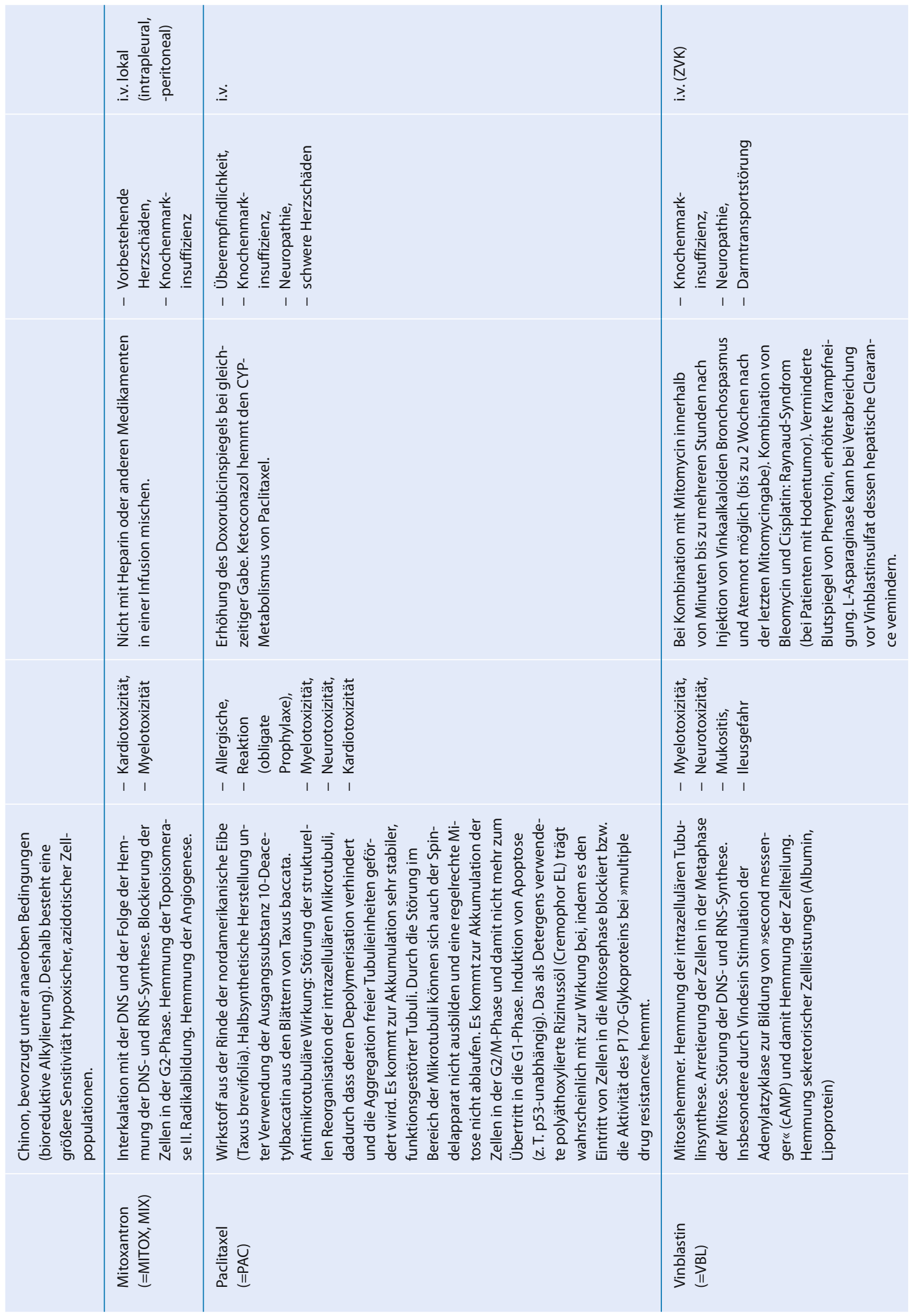


Die Dosis des Chemotherapeutikums wird den hämatologischen Parametern angepasst (• Tab. 10.5).

Durch die Untersuchungen von Pizzo (1984) konnte gezeigt werden, dass der Grad der Granulozytopenie mit Auftreten schwerer infektiöser Komplikationen korreliert. Eine Granulozytopenie von weniger als 1000 pro $\mathrm{mm}^{3}$ verursacht bei $12 \%$ der Patienten eine fieberhafte Infektion. Ein Granulozytenabfall auf Werte von weniger als 100 Granulozyten pro $\mathrm{mm}^{3}$ führt sogar bei $30 \%$ der Patienten zu einem fieberhaften Infekt. Mit zunehmender

\begin{tabular}{|l|l|l|}
\hline \multicolumn{2}{|l}{$\begin{array}{l}\text { O Tab. 10.4. Zeitliche Differenzen im Auftreten des Nadirs in } \\
\text { Abhängigkeit vom verwandten Zytostatikum }\end{array}$} \\
\hline Substanz & $\begin{array}{l}\text { Tag der maximalen Myelosuppression } \\
\text { (»Nadiru) }\end{array}$ \\
\hline Vinblastin & $4-10$ \\
\hline Doxorubicin & $6-13$ \\
\hline Epirubicin & $6-13$ \\
\hline Mitoxantron & $6-13$ \\
\hline Methotrexat & $7-14$ \\
\hline Ifosfamid & $7-14$ \\
\hline Gemcitabin & $7-14$ \\
\hline 5-Fluorouracil & $9-14$ \\
\hline Docetaxel & $10-12$ \\
\hline Paclitaxel & $10-12$ \\
\hline Cisplatin & $12-14$ \\
\hline Carboplatin & $12-14$ \\
\hline Etoposid & 16 \\
\hline
\end{tabular}

Dauer der Granulozytopenie steigt zudem die Inzidenz der Sepsis bis auf $100 \%$ an.

Aufgrund der nur kurzen Halbwertszeit der Granulozyten $(6 \mathrm{~h})$ sind Granulozytentransfusionen nur von begrenztem klinischem Nutzen.

Die Myelotoxizität stellte lange Zeit bei vielen Therapien die limitierende Nebenwirkung dar. Mit der Möglichkeit, hämatopoetische Wachstumsfaktoren, die die Bildung der verschiedenen Blutzellen und ihre Ausreifung regulieren, gentechnologisch, d.h. rekombinant, herzustellen, konnte die Myelotoxizität als limitierender Faktor überwunden werden (Bronchud et al. 1988; Gabrilove et al. 1988). Bokemeyer (2002) zeigte einen Überlebensvorteil von Patienten unter Chemotherapie, bei denen der Hämoglobinwert unter Chemotherapie auf über 10,5g/ $\mathrm{dl}$ eingestellt wurde, so dass der Therapieerfolg hierdurch auch diesbezüglich positiv zu beeinflussen ist.

$\mathrm{Zu}$ den humanen koloniestimulierenden Faktoren der Hämatopoese gehören (Platzer 1990): GM-CSF, GCSF, M-CSF, SCF, IL-3, IL-6, IL-11, Erythropoetin und Thrombopoetin.

Von klinischer Bedeutung sind heute:

- G-CSF (z. B. Filgastim, Lenogastrim),

- GM-CSF (z. B. Molgramostim),

- Erythropoetin.

Golde (1990) konnte unterschiedliche In-vivo-Effekte der hämatopoetischen Wachstumsfaktoren auf die entsprechenden Zielzellen nachweisen (•Tab. 10.6). Kuderer et al. zeigten in einer Metaanalyse von 14 randomisierten Studien mit Kontroll-/Placebo-Arm und prophylaktischer G-CSF-Gabe bei Standardchemotherapie $(n=3091)$ einen signifikanten Rückgang febriler Neutropenien. Die Häufigkeit infektionsassoziierter Mortalität war unter

- Tab. 10.5. Myelotoxisch wirksame Substanzen - Richtlinien zur Dosisreduktion

\begin{tabular}{|c|c|c|c|c|}
\hline Leukozyten/nl & $>3000$ & $2500-3000$ & $2000-2500$ & $<2000$ \\
\hline Thrombozyten/nl & $>150000$ & 100000-150000 & 75000-100000 & $<75000$ \\
\hline $\begin{array}{l}\text { - Cisplatin } \\
\text { - Carboplatin } \\
\text { - Docetaxel } \\
\text { - Doxorubicin } \\
\text { - Etoposid } \\
\text { - Epirubicin } \\
\text { - 5-Fluorouracil } \\
\text { - Gemcitabin } \\
\text { - Ifosfamid } \\
\text { - Methotrexat } \\
\text { - Mitomycin C } \\
\text { - Mitoxantron } \\
\text { - Paclitaxel } \\
\text { - Vinblastin }\end{array}$ & $100 \%$ der Solldosis & $75 \%$ der Solldosis & $50 \%$ der Solldosis & $\begin{array}{l}\text { Verschiebung bis zur } \\
\text { Überwindung des } \\
\text { Nadir }\end{array}$ \\
\hline
\end{tabular}


G-CSF-Gabe ebenfalls signifikant reduziert. Die relative Dosisintensität war unter prophylaktischer G-CSF-Gabe signifikant höher als in der Kontrollgruppe (Kuderer et al. 2005). Inzidenz und Ausprägungsgrad der Mukositis konnte bei G-CSF-behandelten Patienten ebenfalls signifikant verringert werden (Gabrilove et al. 1988). Darüber hinaus konnte auch im Rahmen dieser Studie die Chemotherapie zeitgerecht bei allen Patienten verabreicht und die Gesamtzahl der Tage mit Neutropenie und behandlungsbedürftigem Fieber signifikant verkürzt werden.

Von den genannten Interleukinen zeigt das IL-11 nach myelotoxischer Therapie einen positiven Effekt auf die Thrombozytenregeneration (Du u. Williams 1994). Aufgrund der hohen Nebenwirkungsrate konnte aber in Deutschland und Europa keine Zulassung erfolgen.

Verbindliche Dosierungs- und Applikationsrichtlinien liegen bislang für die in $\bullet$ Tab. 10.7 genannten Substanzen vor.

Durch die Gabe von Depotpräparaten kann eine Verlängerung der Applikationsintervalle erzielt werden. Für Darbepoetin konnte ein Vorteil der Applikation im 3-wöchentlichen Intervall als Fixdosis $(500 \mu \mathrm{g})$ gegenüber der

- Tab. 10.6. Wachstumsfaktoren (+ stimuliert, ? mögliche Wirkung, - keine Wirkung)

\begin{tabular}{l|l|l|l|l}
\hline Ziel & EPO & G-CSF & GM-CSF & $\begin{array}{l}\text { Thrombo- } \\
\text { poetin }\end{array}$ \\
\hline Erythropoese & + & - & - & \\
\hline Neutropoese & - & + & + & \\
\hline Eosinopoese & - & - & + & \\
\hline Monopoese & - & - & + & \\
\hline Lymphopoese & - & - & - & \\
\hline Thrombopoese & + & - & $?$ & + \\
\hline
\end{tabular}

- Tab. 10.7. Dosierungshinweise hämatologischer Wachstumsfaktoren

\begin{tabular}{|l|l|l|}
\hline $\begin{array}{l}\text { Wachstums- } \\
\text { faktor }\end{array}$ & Dosierung & Applikation \\
\hline G-CSF & $\begin{array}{l}5 \mu \mathrm{g} / \mathrm{kg} \mathrm{KG} \mathrm{s.c.} \\
\text { oder i.v. }\end{array}$ & $\begin{array}{l}\text { Täglich, bis zur Über- } \\
\text { windung der Nadirs }\end{array}$ \\
\hline GM-CSF & $\begin{array}{l}5 \mu \mathrm{g} / \mathrm{kg} \text {, maximal } \\
10 \mu \mathrm{g} / \mathrm{kg} \mathrm{KG} \mathrm{s.c.}\end{array}$ & $\begin{array}{l}\text { Täglich, bis zur Über- } \\
\text { windung der Nadirs }\end{array}$ \\
\hline Erythropoetin & $\begin{array}{l}150 \mathrm{IE} / \mathrm{kg} \mathrm{KG} \mathrm{s.C.,} \\
\text { Dosiseskalation bis } \\
\text { 300 IE/kg KG s.c bei } \\
\text { ausbleibendem Re- } \\
\text { tikulozytenanstieg } \\
\text { nach 2-4 Wochen }\end{array}$ & 3-mal pro Woche \\
\hline
\end{tabular}

gewichtsadaptierten wöchentlichen Gabe $(2,25 \mu \mathrm{g} / \mathrm{kg} \mathrm{KG})$ nachgewiesen werden (Canon JL et al. 2005; Rizzo et al. 2002).

\section{Nephrotoxizität}

Verschiedene Zytostatika können zu einer Nierenschädigung führen. Dabei werden akute Schäden wie z. B. nach Cisplatin und Methotrexat von verzögert eintretenden Schäden abgegrenzt. Akute Nierenschäden lassen sich zudem durch protektive Maßnahmen wie z. B. eine forcierte Diurese durch osmotische Diuretika bei Cisplatingabe vermeiden.

Bei der Dosisberechnung von Chemotherapeutika mit renaler Ausscheidung oder renaler Toxizität muss die Nierenfunktion berücksichtigt werden (Carmichael 1992). Bei Nierenfunktionseinschränkungen sind Dosisreduktionen erforderlich. Die Dosismodifikation richtet sich nach der glomerulären Filtrationsrate, die abhängig vom Alter, Geschlecht und Körpergewicht des Patienten ist.

Die glomeruläre Filtrationsrate (GFR) errechnet sich wie folgt:

GFR $(\mathrm{ml} / \mathrm{min})=140$-Alter $($ Jahre $) \times$ Körpergewicht $(\mathrm{KG}) / 72 \times$ Serumkreatinin.

Bei weiblichen Personen wird dieser Wert mit dem Faktor 0,8 multipliziert.

Liegt die glomeruläre Filtrationsrate unter $60 \%$, so sind Dosismodifikationen erforderlich (• Tab. 10.8).

- Tab. 10.8. Dosierungsrichtlinie für Zytostatika bei Einschränkung der glomerulären Filtrationsrate (GFR) auf 10-60\% der Sollgröße

\begin{tabular}{l|l}
\hline Substanz & $\begin{array}{l}\text { Dosierung in \% der errechneten } \\
\text { Gesamtdosis }\end{array}$ \\
\hline Bleomycin & 75 \\
\hline Cisplatin & 50 \\
\hline Carboplatin & 75 \\
\hline Docetaxel & 100 \\
\hline Doxorubicin & 100 \\
\hline Epirubicin & 100 \\
\hline Etoposid & 75 \\
\hline 5-Fluorouracil & 100 \\
\hline Ifosfamid & 50 \\
\hline Mitomycin C & 75 \\
\hline Methotrexat & 50 \\
\hline Paclitaxel & 100 \\
\hline Vinblastin & 75 \\
\hline
\end{tabular}


Liegt die glomeruläre Filtrationsrate unter 10\%, so ist eine Dosisanpassung auf 25-50\% der errechneten Gesamtdosis vorzunehmen. Kontraindiziert sind dann Cisplatin, Streptozotocin und hochdosiertes Methotrexat.

Das alleinige Serumkreatinin ist zur Beurteilung der Nierenfunktion nicht ausreichend, da erst bei einer Funktionseinschränkung von mehr als 50\% ein Anstieg des Serumkreatinins zu verzeichnen ist (»kreatininblinder Bereich«). Unter Zugrundelegung der glomerulären Filtrationsrate (Normalwert: $93-156 \mathrm{ml} / \mathrm{min}$ ) erfolgt die Dosierung renal ausgeschiedener oder potenziell nephrotoxisch wirksamer Chemotherapeutika bei einer glomerulären Filtrationsrate von mehr als 60\% der Sollgröße in unveränderter, d. h. nicht reduzierter Form.

Voraussetzung zur Durchführung einer zytostatischen Therapie mit renal ausgeschiedenen oder potenziell nephrotoxischen Substanzen ist der Ausschluss einer Harnwegsobstruktion. Abflusshindernisse müssen vor Einleitung einer Therapie beseitigt werden. Patienten mit Harnableitung unter Verwendung von Darmabschnitten (Neoblase, Pouches) können unter der Therapie über einen eingelegten Dauerkatheter abgeleitet werden, um eine erneute Resorption der nephrotoxisch und myelotoxisch wirksamen Substanzen aus dem Urin zu vermeiden (Fossa et al. 1990; Krege et al. 2003).

Als protektive Maßnahme ist, wie bereits erwähnt, eine verstärkte Flüssigkeitszufuhr vor Einleitung der Therapie erforderlich.

Abzugrenzen von einer Nierenschädigung durch das toxische Potenzial verschiedener Chemotherapeutika ist das akute Nierenversagen, das durch Tumorzerfall unter erfolgreicher Zytostatikatherapie auftreten kann (»rapid tumor lysis syndrome«).

\section{Hepatotoxizität}

Für Chemotherapeutika, die in der Leber metabolisiert werden, wird bei eingeschränkter Leberfunktion (basierend auf der Bestimmung von Bilirubin und SGOT) eine Dosisreduktion empfohlen (•Tab. 10.9). Verbindliche Richtlinien liegen nicht vor.
Die Beurteilung der Leberfunktion erfolgt anhand des Serumbilirubins, der Serumtransaminasen SGOT/SGPT, der $\gamma$-GT und der alkalischen Phosphatase. Bei erhöhten Transaminasen müssen differenzialdiagnostische Erkrankungen wie Herzinfarkt, Muskelerkrankungen, hämolytische Anämien und diabetische Stoffwechselstörungen ausgeschlossen werden. Bei Erhöhung der alkalischen Serumphosphatase wird das Enzym LAP (Leucinaminopeptidase) bestimmt, das die Unterscheidung zwischen osteogener und biliärer Phosphaterhöhung ermöglicht.

\subsubsection{Kardiotoxizität}

Eine kardiovaskuläre Toxizität tritt in erster Linie bei Anwendung des Anthrazyklins Doxorubicin auf. Neuere Derivate wie Epirubicin und Mitoxantron können zwar ebenfalls eine Kardiomyopathie verursachen, besitzen jedoch eine größere therapeutische Breite.

Bezüglich der durch Anthrazykline verursachten Kardiotoxizität unterscheidet man eine dosisunabhängige Frühform, die mit supraventrikulären Herzrhythmusstörungen, ST-Streckenveränderungen und sehr selten mit letalen ventrikulären Herzrhythmusstörungen einhergeht (Bristow et al. 1978). Subakut kann es in seltenen Fällen nach 3-4 Wochen zu dem prognostisch ungünstigen Perikarditis-Myokarditis-Syndrom kommen.

Abzugrenzen von diesen frühen Veränderungen ist die dosisabhängige Spätform, bei der morphologische Veränderungen im Myokard nachzuweisen sind (Billingham et al. 1978). Diese treten ab einer kumulativen Dosis von $450 \mathrm{mg} / \mathrm{m}^{2} \mathrm{KOF}$ auf. Auch steigt dann das Risiko einer Kardiomyopathie überproportional an. Zusätzliche Risikofaktoren können dies beschleunigen.

Das Ausmaß der Herzinsuffizienz und der Belastungsdyspnoe wird nach den Kriterien der New York Heart Association (NYHA) beurteilt (•Tab. 10.10).

Die kumulative Gesamtdosis darf für bestimmte Zytostatika nicht überschritten werden. Sie beträgt für Doxorubicin $450 \mathrm{mg} / \mathrm{m}^{2} \mathrm{KOF}$, für Epirubicin $900 \mathrm{mg} / \mathrm{m}^{2} \mathrm{KOF}$ und für Mitoxantron $180 \mathrm{mg} / \mathrm{m}^{2} \mathrm{KOF}$.

\begin{tabular}{|c|c|c|c|}
\hline \multicolumn{2}{|l|}{ Leberfunktion } & \multicolumn{2}{|l|}{ Substanzen } \\
\hline Bilirubin ( $\times$ oberer Normwert) & SGOT (IE) & Bilirubin ( $\times$ oberer Normwert) & SGOT (IE) \\
\hline $1-1,5$ & $<60$ & $1-1,5$ & $<60$ \\
\hline $1,5-2,5$ & $60-180$ & $1,5-2,5$ & $60-180$ \\
\hline $2,5-5$ & $>180$ & $2,5-5$ & $>180$ \\
\hline
\end{tabular}


Neben den Anthrazyklinen können auch andere Chemotherapeutika kardiale Nebenwirkungen hervorrufen. So kann es unter Cisplatin, Etoposid und 5-Fluorouracil zu Ischämien des Herzmuskels kommen; bei 5-Fluorouracil, Paclitaxel und Docetaxel wird das Auftreten von Arrhythmien beschrieben (La Bianca et al. 1982). Nach hochdosierter Gabe von Ifosfamid kann es ebenfalls zum Auftreten einer Herzinsuffizienz kommen.

In der Diagnostik haben EKG, Thoraxröntgenaufnahmen und Laborwerte keinerlei prädiktiven Wert im Hinblick auf die Erfassung einer Kardiotoxizität. Sie dienen lediglich der Erfassung von Begleitrisikofaktoren. In der Verlaufskontrolle bewährt hat sich dagegen die Bestimmung der Ejektionsfraktion und der Ventrikelmotilität mittels Herzinnenraumszintigraphie oder Echokardiographie. Bei einer Auswurffraktion unter 45\% in Ruhe oder bei Verminderung um mehr als 10\% von Zyklus zu Zyklus sollte auf die Fortsetzung der Therapie verzichtet werden.

\section{Pneumotoxizität}

Die Beurteilung der therapiebedingten Lungenerkrankungen ist schwierig. Differenzialdiagnostisch müssen oppor-

- Tab. 10.10. Kriterien der New York Heart Association (NYHA)

\begin{tabular}{c|l}
\hline Klasse & Definition \\
\hline I & Uneingeschränkte Belastbarkeit \\
\hline II & $\begin{array}{l}\text { Gewisse Einschränkung bei starker körperlicher } \\
\text { Arbeit, aber der Patient kann ohne Atemnot ein } \\
\text { Stockwerk Treppen steigen (oder 3 Häuserblocks } \\
\text { weit gehen) }\end{array}$ \\
\hline III & $\begin{array}{l}\text { Gewisse Einschränkung bei alltäglichen Verrichtun- } \\
\text { gen; Ersteigen eines Stockwerks (oder 3 Häuser- } \\
\text { blocks weit gehen) nur unter Schwierigkeiten }\end{array}$ \\
\hline IV & Atemnot schon in Ruhe
\end{tabular}

tunistische Infekte, eine Lungenembolie (Hyperkoagulabilität bei Neoplasien) und das Auftreten tumorunabhängiger Lungenerkrankungen berücksichtigt werden. Bestimmte Risikokonstellationen begünstigen jedoch bei Anwendung bestimmter Chemotherapeutika das Auftreten von therapieassoziierten Lungenveränderungen (•Tab. 10.11).

Die häufigsten Lungenveränderungen sind eine chronische Pneumonitis und Fibrose, eine Hypersensitivitätspneumonitis (exogen allergische Alveolitis) und das nichtkardiale Lungenödem. Eine chronische Pneumonitis wird bei einer Vielzahl von Zytostatika beobachtet. Die Symptomatik besteht in einer Belastungsdyspnoe, trockenem Husten und grippalen Allgemeinbeschwerden. Im Thoraxröntgenbild stellen sich diffuse retikuläre, teilweise auch alveoläre Infiltrate dar. An eine Hypersensitivitätspneumonitis muss bei akut auftretender Dyspnoe möglicherweise mit trockenem Husten, Fieber oder Myalgien gedacht werden. Im Thoraxröntgenbild stellen sich hierbei bihiläre, diffuse Infiltrate und evtl. begleitende Pleuraergüsse dar. Die Symptomatik tritt meistens unmittelbar oder wenige Tage nach der Verabreichung der Medikamente auf, häufig nach Beendigung einer Steroidgabe.

Typischerweise finden sich im Differenzialblutbild vermehrt Eosinophile. Eine Hypersensitivitätspneumonitis wird in erster Linie durch Bleomycin und Methotrexat verursacht (Kreisman u. Wolkove 1992; Basser u. Green 1994). Ein Lungenödem kann im Zusammenhang mit der Verabreichung von Methotrexat beobachtet werden. Selten ist ein ARDS-ähnliches Krankheitsbild, das im Zusammenhang mit einer Bleomycintherapie vorkommen kann (Rosenow et al. 1992). Die Manifestation erfolgt in der Regel 6-12 Monate nach der Beendigung der Chemotherapie.

Wichtigste diagnostische Maßnahmen im Zusammenhang mit der Pneumotoxizität stellen neben der klinischen Untersuchung die Lungenfunktionsprüfung, die Röntgenthoraxaufnahme und ggf. das CT der Thoraxorgane dar.

\begin{tabular}{|c|c|}
\hline Klinische Konstellation & Antineoplastische Substanz \\
\hline Kumulative Dosis überschritten & Bleomycin, Busulfan, Carmustin (BCNU) \\
\hline Fortgeschrittenes Lebensalter & Bleomycin \\
\hline Beatmung $/ \mathrm{O}_{2}$-Gabe & Bleomycin, Cyclophosphamid, Mitomycin \\
\hline Bestrahlungstherapie & Bleomycin, Busulfan, Mitomycin \\
\hline Polychemotherapie & Carmustin, Mitomycin, Cyclophosphamid, Bleomycin, Methotrexat \\
\hline
\end{tabular}




\section{Neurotoxizität}

Die Neurotoxizität stellt wie die Myelotoxizität einen therapielimitierenden Faktor vieler Chemotherapeutika dar (Kaplan u. Wiernik 1982). Leider gibt es hier im Gegensatz zur Prävention der Myelotoxizität noch keine geeigneten Gegenmaßnahmen. Somit ist die Neurotoxizität häufig lebensqualitätsbestimmend.

Verschiedene neurologische Syndrome können durch Chemotherapeutika verursacht werden: eine akute oder chronische Enzephalopathie kann auftreten nach Cisplatin (selten), 5-Fluorouracil, Ifosfamid, Methotrexat (hauptsächlich bei hochdosierter Gabe, intrathekaler Gabe oder in Kombination mit Radiotherapie) und Vincristin. Zerebelläre Dysfunktionen werden im Zusammenhang mit 5-Fluorouracil genannt. Eine Dysfunktion der Hirnnerven kann durch Cisplatin und Vinkaalkaloide hervorgerufen werden. Beim Cisplatin ist hier besonders die Schädigung der Hörnerven zu nennen. Eine geringere Ototoxizität weist das Carboplatin auf. Entzündungen der Hirnnerven und des Rückenmarks können nach hochdosierter Methotrexatgabe auftreten bzw. wenn dieses in Kombination mit einer Radiotherapie verabreicht wird.

Die häufigsten peripheren Neuropathien kommen vor bei Cisplatin, Etoposid, Methotrexat, Paclitaxel und den Vinkaalkaloiden (Vincristin > Vinblastin; Obstipation: Vinblastin > Vincristin). Diese können nach Beendigung der Therapie noch zunehmen. Die Rückbildung erfolgt sehr langsam, Restschäden können bleiben. Die Neurotoxizität der Vinkaalkaloide tritt schon ab einer sehr geringen Dosis (ab $6 \mathrm{mg}$ ) auf. Sie umfasst neben der peripheren Neuropathie auch autonome Veränderungen (Obstipation, Impotenz, Hypotension).

Auch die Hirnnerven können in Mitleidenschaft gezogen werden (Rekurrens- und Fazialisparese, Optikusatrophie, Ptosis). Die Rückbildung erfolgt in Abhängigkeit von der kumulativen Dosis, teilweise sehr verzögert. Nach Verabreichung von Paclitaxel werden periphere und autonome Neuropathien beschrieben. Im Vordergrund stehen sensorische Störungen. Auch hier ist die Toxizität kumulativ.

Bei Verwendung potenziell neurotoxischer Substanzen muss daher vor Einleitung der Therapie eine neurologische Untersuchung mit Beurteilung der Sensibilität durchgeführt werden. Ebenso sollten die Funktionen der Hirnnerven (Audiogramm vor Cisplatingabe obligat) erfasst werden.

\section{Dermatotoxizität}

Haut- und Schleimhautreaktionen treten bei den meisten Chemotherapeutika auf (Bronner u. Hood 1983).
Man unterscheidet allergische Reaktionen (Cisplatin, Doxorubicin, Etoposid, 5-Fluorouracil, Methotrexat, Mitomycin C, Paclitaxel), toxische Erytheme (Bleomycin, Etoposid, Methotrexat), Hyperpigmentationen (Bleomycin, an den Schleimhäuten: Cisplatin, Doxorubicin, Etoposid), Photosensitivität (Bleomycin, 5-Fluorouracil, Methotrexat und Vinblastin) sowie Nagelveränderungen (Bleomycin, Doxorubicin, 5-Fluorouracil und Methotrexat).

Das Ausmaß einer Mukositis wird durch die Leukozytendepression bestimmt, andererseits finden sich ausgeprägte Ulzera im Bereich der Schleimhäute auch ohne begleitende Granulozytopenie. Als Prophylaxe wird neben einer Hautpflege die Vermeidung von Schleimhautverletzungen (Vermeidung von Tabak, Alkohol, sehr heißen/kalten Speisen oder Getränken) sowie eine intensive Mundpflege (4-mal täglich $30 \mathrm{~min}$ ) durchgeführt. Die Mundpflege beinhaltet 4-mal täglich durchgeführte Spülungen mit antiseptischen Lösungen (z. B. Hexoral) sowie die Entfernung vorhandener Speisereste und intensive Pflege der Zähne mit einer weichen Bürste.

Zahlreiche Zytostatika (Cisplatin, Carboplatin, Doxorubicin, Methotrexat, Vinblastin, Etoposid, Bleomycin, Ifosfamid, Cyclophosphamid, 5-Fluorouracil, Mitomycin) führen nach systemischer Anwendung zu reversibler Alopezie. Eisgekühlte Kopfhauben können als Alopezieprophylaxe eingesetzt werden, verhindern den Haarausfall jedoch nicht vollständig.

\section{Emesis}

Übelkeit und Erbrechen unter der Chemotherapie schränken die Lebensqualität der Patienten erheblich ein und können eine stationäre Aufnahme bedingen. Die verschiedenen Chemotherapeutika weisen eine unterschiedliche emetogene Potenz auf (•Tab.10.12). Einzelheiten zur Therapie der chemotherapieinduzierten Emesis sind in - Kap. 11 "Supportive Maßnahmen" aufgeführt.

Ziel der antiemetischen Therapie (•Tab. 10.13) ist es, sowohl das akute Erbrechen als auch das verspätet einsetzende Erbrechen und das vor einem neuen Behandlungszyklus entstehende sog. antizipatorische Erbrechen zu verhindern.

Die Verwendung der Antiemetika wird bei cisplatininduziertem Erbrechen unterschiedlich beurteilt. Fink et al. (1987) wiesen eine erhöhte Wirksamkeit von Ondansetron im Vergleich zu Metoclopramid bei akutem cisplatininduziertem Erbrechen nach. 73\% der mit Ondansetron therapierten Patienten wiesen eine vollständige Kontrolle der Emesis auf im Gegensatz zu 41\% der mit 
Metoclopramid behandelten Patienten. Einen positiven Effekt hat außerdem Kortison.

Eine neue Generation der antiemetisch wirksamen Substanzen bildet die Gruppe der Neurokin-1-RezeptorAntagonisten (NK1-Antagonisten). Diese verhindern die Bindung von Mediatoren wie beispielsweise Substanz P an den NK1-Rezeptor, der sowohl in der akuten wie auch in der verzögerten Phase der Emesis eine wichtige Rolle spielt. Während für die $5-\mathrm{HT}_{3}$-Rezeptorantagonisten eine im Therapieverlauf nachlassende Wirkung beschrieben wird, bleibt die der NK1-Antagonisten auch nach mehreren Zyklen erhalten und kann so eine Protektion gegen Nausea und Emesis über mehrere Therapiezyklen gewährleisten (de Wit et al. 2003; Hesketh et al. 2003). In klinischen Studien konnte gezeigt werden, dass die orale Gabe von Aprepitant in einem Kombinationsregime mit einem Serotoninrezeptorantagonisten plus Dexamethason akutes und verzögertes Erbrechen bei hoch emetogenen, auf Cisplatin basierenden Chemotherapien verhindern kann (Aapro et al. 2005)

Tab. 10.12. Chemotherapieinduziertes Erbrechen in Abhängigkeit vom verwendeten Zytostatikum (Toxizitätsgrade)

\begin{tabular}{|l|l|l|}
\hline Grad 1 & Grad 2 & Grad 3 \\
\hline $\begin{array}{l}\text { Bleomycin } \\
\text { Docetaxel }\end{array}$ & $\begin{array}{l}\text { Carboplatin } \\
\text { Dethotrexat }\end{array}$ & $\begin{array}{l}\text { Coxorubicin } \\
\text { Eirubicin }\end{array}$ \\
\hline Vinblastin & Estramustinphosphat \\
& Etoposid & \\
& 5-Fluorouracil & \\
Ifosfamid & \\
& Mitomycin & \\
& Mitoxantron & \\
& Paclitaxel & \\
& & \\
\end{tabular}

\begin{tabular}{|c|c|c|}
\hline \multicolumn{3}{|c|}{$\begin{array}{l}- \text { Tab. 10.13. Substanzen in der Behandlung der Zytostatika } \\
\text { induzierten Nausea und Emesis }\end{array}$} \\
\hline Substanz & Handelsname & Dosierung/Applikation \\
\hline Metoclopramid & Paspertin/MCP & 10-30 mg/Tag i.v. \\
\hline Dimenhydrinat & Vomex & $10-30 \mathrm{mg} /$ Tag i.v. \\
\hline Triflupromazin & Psyquil & $10-30 \mathrm{mg} /$ Tag i.v. \\
\hline Ondansetron* & Zofran & 8-32 mg/Tag i.v. \\
\hline Aprepitant & Emend & $\begin{array}{l}125 \mathrm{mg} / \mathrm{Tag} 1 \text { p.o., } \\
80 \mathrm{mg} / \mathrm{Tag} 2 \text { und } 3 \text { p.o. }\end{array}$ \\
\hline Dexamethason & & 8-12 mg/Tag p.o. \\
\hline
\end{tabular}

* Vergleichbar zu Ondansetron sind die Substanzen Dolasetron, Granisetron, Tropisetron.

\subsubsection{Beeinträchtigung der Fertilität und Induktion von Zweittumoren}

- Tab.10.14 gibt eine Übersicht über die zytostatikabedingte Keimzellschädigung.

In der Urologie spielt die gonadale Toxizität in erster Linie bei den Hodentumorpatienten eine Rolle, da die anderen urologischen Tumoren eher im höheren Lebensalter auftreten. Erschwerend kommt hinzu, dass Hodentumorpatienten bereits $\mathrm{zu} 50-70 \%$ prätherapeutisch eine verminderte Fertilität aufweisen (Fossa et al. 1985). Nach Verabreichung einer Kombinationschemotherapie mit PVB oder PEB kommt es bei $70-90 \%$ der Patienten zu einer Azoospermie (Drasga et al. 1983). Nach 1-3 Jahren weisen jedoch $50-60 \%$ der Patienten wieder eine Spermatogenese auf (Fossa et al. 1985). Von Bedeutung ist in diesem Zusammenhang auch die Anzahl und Art der verabreichten Chemotherapiekurse. So ist nach 2 Kursen einer PEB-Polychemotherapie keine längerdauernde Beeinträchtigung der Fertilität zu befürchten (Pont u. Albrecht 1997).

- Tab. 10.14. Zytostatika, die mit unterschiedlicher Fertilitätseinschränkung assoziiert sind

\begin{tabular}{|c|c|c|}
\hline & Spermatotoxisch & $\begin{array}{l}\text { Ovarielle } \\
\text { Dysfunktion }\end{array}$ \\
\hline \multirow[t]{6}{*}{ Gesichert } & Chlorambucil & Chlorambucil \\
\hline & Cyclophosphamid & Cyclophosphamid \\
\hline & Nitrosoharnstoff & Busulfan \\
\hline & Busulfan & CCNU \\
\hline & Procarbazin & \\
\hline & CCNU & \\
\hline \multirow{3}{*}{$\begin{array}{l}\text { Wahrschein- } \\
\text { lich }\end{array}$} & Doxorubicin & Doxorubicin \\
\hline & Vinblastin & Vinblastin \\
\hline & Cytarabin & Procarbazin \\
\hline \multirow{4}{*}{$\begin{array}{l}\text { Unwahr- } \\
\text { scheinlich }\end{array}$} & Methotrexat & Methotrexat \\
\hline & 5-Fluorouracil & 5-Fluorouracil \\
\hline & 6-Mercaptopurin & 6-Mercaptopurin \\
\hline & Vincristin & Actinomycin D \\
\hline \multirow[t]{3}{*}{ Nicht bekannt } & Bleomycin & Etoposid \\
\hline & Etoposid & Nitrosoharnstoff \\
\hline & Cisplatin & \\
\hline
\end{tabular}


Eine kumulative Cisplatindosis über $600 \mathrm{mg} / \mathrm{m}^{2} \mathrm{KOF}$ führt dagegen zu einer bleibenden Infertilität (Petersen et al. 1994).

Zytostatika sind prinzipiell mutagene Substanzen. So behindern Vinkaalkaloide die Ausbildung des für die Zellteilung benötigten Spindelapparates, Alkylanzien inhibieren die Reduplikation der DNA. Im Tierexperiment konnten mutagene Schädigungen an Keimzellen im Sinne von chromosomalen Translokationen induziert werden, die theoretisch vererbbar sind. Für den Menschen ließ sich diesbezüglich anhand bisher vorliegender Ergebnisse kein erhöhtes Missbildungsrisiko für die Nachkommen chemotherapierter Patienten im Vergleich zur Normalbevölkerung zeigen. Ebenso gibt es bisher keinen Anhalt für ein erhöhtes Tumorrisiko der Nachkommen ehemaliger Tumorpatienten (Thurber 1989).

Andererseits besteht die Möglichkeit beim behandelten Patienten selbst, einen Zweittumor zu entwickeln. Größere Serien liegen im Zusammenhang mit dem Morbus Hodgkin vor, bei dem das Risiko einer therapieassoziierten sekundären akuten myeloischen Leukämie besteht. Allgemein wird die AML als häufigste Zweitneoplasie nach Chemotherapie betrachtet. Bei Hodentumorpatienten, die im Rahmen der Polychemotherapie Etoposid in einer Gesamtdosis $>2 \mathrm{~g}$ erhielten, liegt das Risiko einer sekundären AML 3- bis 8-fach höher gegenüber der Normalbevölkerung (Nichols et al. 1993; Bokemeyer et al. 1994). Solide Zweitneoplasien stehen vorwiegend mit einer vorangegangenen Strahlentherapie im Zusammenhang.

\section{Zytostatika und Schwangerschaft}

Macht eine Erkrankung während, insbesondere im frühen Schwangerschaftsstadium, eine chemotherapeutische Behandlung notwendig, so ist mit der Patientin im Einzelfall zu prüfen und abzuwägen, ob die Schwangerschaft abgebrochen werden sollte, oder ob die Risiken einer zunächst zuwartenden Haltung mit späterem Beginn der Chemotherapie vertretbar sind.

\section{Hinweis}

Als generelle Richtlinie kann folgendes gelten: Eine zytostatische Therapie ist im 1.Trimenon der Schwangerschaft kontraindiziert.

Sofern eine gesicherte Indikation für eine zytostatische Behandlung besteht, muss der Patientin der Schwangerschaftsabbruch nahegelegt werden.

Im 2. und 3. Trimenon ist eine Fortsetzung der Schwangerschaft unter gewissen Umständen möglich. Dennoch muss auch hier die Indikation zur zytostatischen Therapie genau geprüft werden, insbesondere auch, ob der Beginn der Behandlung nicht so weit aufgeschoben werden kann, bis das Kind lebensfähig ist und die Geburt eingeleitet werden kann (Sauer 2000).

\subsubsection{Wechselwirkungen in der Anwendung von Zytostatika}

Die Kombination von Zytostatika mit anderen Substanzen bedingt in der Regel eine vermehrte Toxizität. Substanzen mit additivem toxischem Potenzial zeigt - Tab. 10.15. So hat die Kombination von Cisplatin mit Cephalosporinen oder Aminoglycosiden eine vermehrte Nephrotoxizität und Ototoxizität zur Folge.

Ein weiterer unerwünschter Effekt in der Wechselwirkung von Zytostatika mit anderen Substanzen sind antagonistische Mechanismen, die die Wirkung des Zytostatikums abschwächen (•Tab. 10.16).

Die Kombination mehrerer Chemotherapeutika oder Zufügen anderer Substanzen soll einen synergistischen Ef-

- Tab. 10.15. Substanzen mit additivem toxischem Potenzial

\begin{tabular}{|c|c|c|}
\hline Zytostatikum & Additivum & Gesteigerte Toxizität \\
\hline Bleomycin & Cyclophosphamid & Pneumotoxizität \\
\hline \multirow{9}{*}{$\begin{array}{l}\text { Cisplatin/ } \\
\text { Carboplatin }\end{array}$} & Vinblastin & Nephrotoxizität \\
\hline & Doxorubicin & \\
\hline & Methotrexat & \\
\hline & Ifosfamid & \\
\hline & Metoclopramid & \\
\hline & Furosemid & \\
\hline & Amphotericin B & \\
\hline & Cephalosporine & Nephrotoxizität + \\
\hline & Aminoglykoside & Ototoxizität \\
\hline \multirow[t]{4}{*}{ Doxorubicin } & Mitoxantron & Kardiotoxizität \\
\hline & Epirubicin & \\
\hline & Cyclophosphamid & \\
\hline & Antrazykline & \\
\hline \multirow[t]{4}{*}{ 5-Fluorouracil } & Interferon- $a$ & Myelotoxizität \\
\hline & Amphotericin B & \\
\hline & Allopurinol & \\
\hline & Leucoverin & \\
\hline \multirow[t]{5}{*}{ Methotrexat } & Alkohol & Hepatotoxizität \\
\hline & Cisplatin & Nephrotoxizität \\
\hline & Aminoglykoside & \\
\hline & Trimethoprim & \\
\hline & Etoposid & Pneumotoxizität \\
\hline Vinblastin & Mitomycin & Pneumotoxizität \\
\hline
\end{tabular}


fekt erzielen. Synergistische Wirkung wurde bei der Anwendung der in $\bullet$ Tab. 10.17 aufgeführten Substanzen erzielt.

Zytostatika können zu einer Wirkungsverstärkung oraler Antidiabetika, Antikoagulanzien und Narkotika führen. Dies kann zu lebensbedrohlichen Hypoglykämien, Blutungen oder einer Apnoe führen (•Tab. 10.18).

\subsubsection{Applikationshinweise}

Bei systemischer Applikation dürfen die Zytostatika aufgrund möglicher physikalischer und chemischer Unverträglichkeiten in der Regel nicht als Mischinfusion zubereitet werden. Die meisten Zytostatika führen zu einer starken lokalen Reaktion auch des Gefäßsystems, so dass die venöse Injektion von Chemotherapeutika über großlumige Zugänge erfolgen soll. Dies ist in der Regel durch Punktion zentral gelegener Gefäße wie der V. subclavia oder V. cava superior möglich. Die Applikation der Substanzen erfolgt über einen zentralen Venenkatheter. Die Lage des Applikationssystems wird radiologisch bzw. mittels EKG überprüft.

Bei wiederholter systemischer Anwendung von Zytostatika kann die Implantation eines subkutan gelegenen Applikationssystems mit Zugang zu einem zentralvenösen Gefäß, in der Regel der V. subclavia, alternativ auch der V.brachiocephalica, durchgeführt werden (• Abb. 10.4). Die Punktion des leicht zu tastenden Reservoirs geschieht

\begin{tabular}{l|l}
$\begin{array}{l}\text { - Tab. 10.16. Antagonistische Mechanismen mit Abschwä- } \\
\text { chung der Wirkung des Zytostatikums }\end{array}$ \\
\hline \multirow{2}{*}{ Zytostatikum } & Additivum mit antagonistischer Wirkung \\
\hline Cisplatin & Aluminiumkomplexbildner \\
\cline { 2 - 2 } Carboplatin & Metoclopramid \\
\hline Doxorubicin & Natriumthiosulfat \\
\hline Epirubicin & Barbiturate \\
\hline 5-Fluorouracil & Tamoxifen \\
\cline { 2 - 2 } & Dipyridamol \\
\hline Ifosfamid & N-Acetylcystein \\
\hline Methotrexat & Bleomycin \\
\hline \multirow{5}{*}{ Vinblastin } & Vincaalcaloide \\
\hline & Penicillin \\
\hline & Allopurinol \\
\hline & Glukokortikoide \\
\hline Paclitaxel & Doxorubicin \\
\hline & Etoposid \\
\hline \multirow{2}{*}{ Cisplatin } \\
\hline
\end{tabular}

\begin{tabular}{|c|c|}
\hline \multicolumn{2}{|c|}{$\begin{array}{l}\text { - Tab. 10.17. Synergistischer Wirkmechanismus bei der Kom- } \\
\text { bination mehrerer Substanzen }\end{array}$} \\
\hline Zytostatikum & Additivum mit synergistischer Wirkung \\
\hline \multirow[t]{2}{*}{ Doxorubicin } & Amphotericin \\
\hline & Verapamil \\
\hline \multirow[t]{2}{*}{ Etoposid } & Vincristin \\
\hline & Vinblastin \\
\hline \multirow[t]{6}{*}{ 5-Fluorouracil } & Amphotericin B \\
\hline & Allopurinol \\
\hline & Vincristin \\
\hline & Vinblastin \\
\hline & Kalziumfolinat \\
\hline & Interferon \\
\hline \multirow[t]{5}{*}{ Ifosfamid } & Cisplatin \\
\hline & 5-Fluorouracil \\
\hline & Barbiturate \\
\hline & Allopurinol \\
\hline & Glukokortikoide \\
\hline \multirow[t]{9}{*}{ Methotrexat } & Amphotericin B \\
\hline & Tetrazykline \\
\hline & Sulfonamide \\
\hline & Metamizol \\
\hline & Trimethoprim \\
\hline & Barbiturate \\
\hline & Phenytoin \\
\hline & Salicylate \\
\hline & Probenecid \\
\hline \multirow[t]{3}{*}{ Mitoxantron } & Diazepam \\
\hline & Verapamil \\
\hline & Trizyklische Antidepressiva \\
\hline Mitomycin & Cisplatin \\
\hline \multirow[t]{5}{*}{ Vinblastin } & Interferon \\
\hline & Verapamil \\
\hline & Nifedipin \\
\hline & Tamoxifen \\
\hline & Estramustinphosphat \\
\hline Zytostatikum & Additivum mit synergistischer Wirkung \\
\hline
\end{tabular}

- Tab. 10.18. Implikationen einiger Chemotherapeutika mit Antidiabetika, Antikoagulanzien und Narkotika

\begin{tabular}{l|l|l}
\hline \multirow{2}{*}{ Zytostatikum } & Substanz & Nebenwirkung \\
\hline \multirow{2}{*}{ Ifosfamid } & Antikoagulanzien & Blutung \\
\cline { 2 - 3 } & Antidiabetika & Hypoglykämie \\
\hline & Antidiabetika & Hypoglykämie \\
\cline { 2 - 3 } & Antikoagulanzien & Blutung \\
\hline
\end{tabular}


- Tab. 10.19. Spezielle Maßnahmen im Umgang mit einigen Zytostatika - Paravasate. (Mod. nach Barth u. Kloke 2003)

\begin{tabular}{|c|c|c|}
\hline Substanz & & Maßnahme \\
\hline \multirow[t]{3}{*}{ Cisplatin } & & $\begin{array}{l}3 \text { Tage lang 4-mal15-20 min Eisumschläge und Hochlagern der Paravasatstelle (Larson 1982; van Sloten } \\
\text { Harwood et al. 1984) }\end{array}$ \\
\hline & oder: & $\begin{array}{l}\text { Paravasatstelle mit } 4 \mathrm{ml} \text { einer Mischung aus } 4 \mathrm{ml} \text { von 10\%-igem Natriumthiosulfat }\left(\mathrm{Na}_{2} \mathrm{~S}_{2} \mathrm{O}_{3}\right) \text {-Lösung und } \\
6 \mathrm{ml} \text { Wasser für Injektionszwecke infiltrieren (Ignoffo u. Friedmann 1980; Leyden u. Sullivan 1983) }\end{array}$ \\
\hline & oder: & mit $1 \mathrm{ml}$ Ascorbinsäure (50 mg/ml) infiltrieren (lgnoffo u. Friedmann 1980) \\
\hline \multirow[t]{7}{*}{$\begin{array}{l}\text { Doxorubicin } \\
\text { und Epirubicin }\end{array}$} & & $\begin{array}{l}3 \text { Tage lang 4-mal 15-20 min Eisumschläge und Hochlagern der Paravasatstelle (Larson 1982; van Sloten } \\
\text { Harwood et al. 1984) }\end{array}$ \\
\hline & oder: & $\begin{array}{l}\text { 25-50 mg Hydrokortison pro geschätztem ml Paravasat subkutan oder intradermal injizieren (Bellone } \\
\text { 1981; van Sloten Harwood et al. 1984) }\end{array}$ \\
\hline & oder: & $\begin{array}{l}\text { Paravasatstelle mit } 2 \text { Ampullen (à } 150 \text { IE) Hyaluronidase (z. B. Kinetin), gelöst in } 5 \mathrm{ml} \text { 0,9\%-iger NaCl-Lösung, } \\
\text { infiltrieren, danach Paravasatbereich mit } 3 \text { Ampullen Hyaluronidase, gelöst in ca. } 20 \mathrm{ml} \mathrm{0,9 \% -iger} \mathrm{NaCl-} \\
\text { Lösung, infiltrieren und aufschwemmen, dann weitere } 3-4 \text { Infiltrationen von ca. je } 20 \mathrm{ml} \mathrm{0,9 \% -iger} \mathrm{NaCl}- \\
\text { Lösung und zur Beschleunigung des Abflusses die betroffene Stelle hochlagern (Gallmeier 1979) }\end{array}$ \\
\hline & oder: & $\begin{array}{l}\text { Paravasatbereich mit } 5000 \text { IE Heparin (z. B. Liquemin), gelöst in 5-20 ml 0,9\%-iger NaCl-Lösung großflächig } \\
\text { unter- und umspritzen, danach dasselbe mit } 4 \text { mg Dexamethason (z. B. Decadron-Phosphat, Fortecortin) }\end{array}$ \\
\hline & oder: & 100 mg Hydrokortison (Köstering u. Nagel 1982; Wander u. Nagel 1985) \\
\hline & oder: & $\begin{array}{l}\text { Paravasatbereich mit 5-20 ml 8,4\%-iger (1 mol) Natriumhydrogenkarbonatlösung unter- und umspritzen, } \\
\text { danach dasselbe mit } 4 \mathrm{mg} \text { Dexamethason (z. B. Decadron-Phophat, Fortecortin) }\end{array}$ \\
\hline & oder: & $\begin{array}{l}100 \text { mg Hydrokortison; 2-mal täglich 1\% Hydrokortison-Creme (z. B. Cordes H); ca. } 24 \text { h mit Eisbeuteln ab- } \\
\text { decken; Umspritzungen, falls erforderlich, wöchentlich mehrmals wiederholen (Köstering u. Nagel 1982) }\end{array}$ \\
\hline Estramustin & & $\begin{array}{l}\text { 50-100 mg Hydrokortison infiltrieren; } 1 \% \text { Hydrokortison-Creme (z. B. Cordes } \mathrm{H}) \text { mehrmals auftragen; } 24 \mathrm{~h} \\
\text { lang Eispackungen auflegen }\end{array}$ \\
\hline Etoposid/VP16 & & $\begin{array}{l}\text { Paravasatstelle mit } 1 \mathrm{ml} \text { Hyaluronidase (150 IE; z. B. Kinetin) infiltrieren und mäßige Wärmeanwendung } \\
\text { (van Sloten Harwood u. Aisner 1984) }\end{array}$ \\
\hline \multirow[t]{6}{*}{ Mitomycin C } & & $\begin{array}{l}\text { Paravasatbereich mit } 5000 \text { IE Heparin (z. B. Liquemin), gelöst in 5-20 ml 0,9\%-iger NaCl-Lösung, großflächig } \\
\text { unter- und umspritzen, danach dasselbe mit } 4 \mathrm{mg} \text { Dexamethason (z. B. Decadron-Phophat, Fortecortin) }\end{array}$ \\
\hline & oder: & 100 mg Hydrokortison (Köstering u. Nagel 1982; Wander u. Nagel 1985) \\
\hline & oder: & $\begin{array}{l}\text { Paravasatbereich mit 5-20 ml 8,4\%-iger (1 mol) Natriumhydrogenkarbonatlösung unter- und umspritzen, } \\
\text { danach dasselbe mit } 4 \mathrm{mg} \text { Dexamethason (z. B. Decadron-Phophat, Fortecortin) }\end{array}$ \\
\hline & oder: & $\begin{array}{l}100 \text { mg Hydrokortison; 2-mal täglich 1\% Hydrokortison-Creme (z. B. Cordes H); ca. } 24 \text { h mit Eisbeuteln ab- } \\
\text { decken; Umspritzungen, falls erforderlich, wöchentlich mehrmals wiederholen (Köstering u. Nagel 1982) }\end{array}$ \\
\hline & oder: & $\begin{array}{l}\text { Paravasatstelle mit } 4 \mathrm{ml} \text { einer Mischung aus } 4 \mathrm{ml} \text { von 10\%-igem Natriumthiosulfat }\left(\mathrm{Na}_{2} \mathrm{~S}_{2} \mathrm{O}_{3}\right) \text {-Lösung und } \\
6 \mathrm{ml} \text { Wasser für Injektionszwecke infiltrieren (Ignoffo u. Friedmann 1980; Leyden u. Sullivan 1983) }\end{array}$ \\
\hline & oder: & mit $1 \mathrm{ml}$ Ascorbinsäure (50 mg/ml) infiltrieren (Ignoffo u. Friedmann 1980) \\
\hline \multirow[t]{6}{*}{ Vinblastin } & & Paravasatstelle schwach erwärmen \\
\hline & oder: & $\begin{array}{l}\text { Paravasatstelle mit } 1 \text { ml Hyaluronidase (150 IE; z. B. Kinetin) infiltrieren und mäßige Wärmeanwendung } \\
\text { (van Sloten Harwood u. Aisner 1984) }\end{array}$ \\
\hline & oder: & $\begin{array}{l}\text { Paravasatstelle mit } 2 \text { Ampullen (à } 150 \text { IE) Hyaluronidase (z. B. Kinetin), gelöst in } 5 \mathrm{ml} \mathrm{0,9 \% -iger} \mathrm{NaCl-Lösung,} \\
\text { infiltrieren, danach Paravasatbereich mit } 3 \text { Ampullen Hyaluronidase, gelöst in ca. } 20 \mathrm{ml} \text { 0,9\%-iger NaCl- } \\
\text { Lösung, infiltrieren und aufschwemmen, dann weitere 3-4 Infiltrationen von ca. je } 20 \mathrm{ml} \mathrm{0,9 \% -iger} \mathrm{NaCl}- \\
\text { Lösung und zur Beschleunigung des Abflusses die betroffene Stelle hochlagern (Gallmeier 1979) }\end{array}$ \\
\hline & oder: & $\begin{array}{l}\text { Paravasatbereich mit } 5000 \text { IE Heparin (z. B. Liquemin), gelöst in 5-20 ml 0,9\%-iger NaCl-Lösung großflächig } \\
\text { unter- und umspritzen, danach dasselbe mit } 4 \mathrm{mg} \text { Dexamethason (z. B. Decadron-Phophat, Fortecortin) }\end{array}$ \\
\hline & oder: & 100 mg Hydrokortison (Köstering u. Nagel 1982; Wander u. Nagel 1985) \\
\hline & oder: & $\begin{array}{l}\text { Paravasatbereich mit 5-20 ml 8,4\%-iger (1 mol) Natriumhydrogenkarbonatlösung unter- und umspritzen, } \\
\text { danach dasselbe mit } 4 \mathrm{mg} \text { Dexamethason (z. B. Decadron-Phophat, Fortecortin) }\end{array}$ \\
\hline
\end{tabular}


über ein speziell dafür gefertigtes Punktionssystem. Ein venöses Portsystem kann bis zu 2000-mal punktiert werden.

Die paravenöse Injektion einiger Zytostatika führt zu ausgeprägten Gewebereaktionen mit begleitender Rötung, Schwellung, Schmerzen und späterer Entwicklung von Nekrosen und ist daher als ernsthafte Komplikation zu betrachten. Treten Schmerzen oder eine Rötung auf und besteht der Verdacht auf ein Paravasat, so ist die weitere Injektion des Zytostatikums sofort zu beenden. Erfolgte die Applikation über einen peripheren Zugang, wird möglichst viel Flüssigkeit aspiriert und ggf. ein Antidot verabreicht.

- Tab. 10.19 gibt eine Übersicht über spezielle Maßnahmen im Umgang mit einigen Zytostatika.

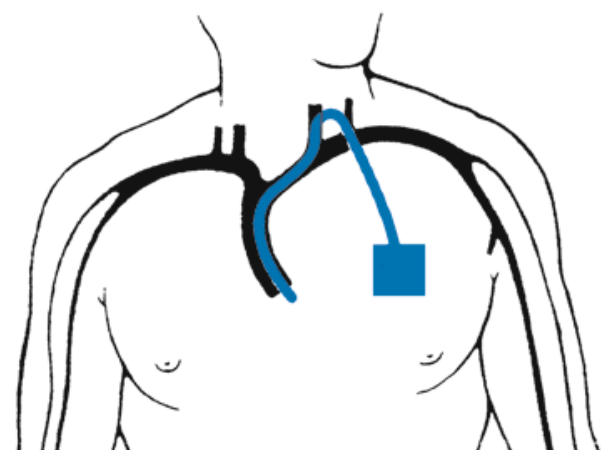

- Abb. 10.4. Venöser Port

\subsubsection{Zubereitung und Entsorgung von Zytostatika}

Die meisten Zytostatika greifen am Zellkern an. Dies führt in der Regel zu Veränderungen an der DNA und ihren Reparaturmechanismen. Somit sind die Substanzen potenziell karzinogen, teratogen und mutagen.

Diese möglichen Gefahren müssen bei der Zubereitung der Substanzen bedacht werden, so dass nur mit der Chemotherapie geschultes Personal damit betraut werden darf. Eine gefahrlosere und kostengünstigere Möglichkeit ist die Zubereitung der applikationsfertigen Substanz durch den kooperierenden Apotheker. Falls die zentrale Zubereitung durch den Apotheker nicht gewährleistet ist, muss diese unter bestimmten Schutzmaßnahmen von speziell geschultem Personal vorgenommen werden. $\mathrm{Zu}$ den Schutzvorrichtungen gehören:

- das Tragen von Handschuhen,

- Mundschutz

- Schutzbrille.

Die Zubereitung der applikationsfertigen Lösung wird unter Beachtung der genannten Schutzmaßnahmen an einer Werkbank mit vertikalem Flow der Sicherheitsstufe II vorgenommen. In - Tab. 10.20 werden Methoden der chemischen Inaktivierung für verschiedene Chemotherapeutika dargestellt.

- Tab. 10.20. Chemische Inaktivierung verschiedener Zytostatika. (Nach Schaaf u. Schott 1984)

\begin{tabular}{|c|c|c|}
\hline Substanz & Maßnahme & \\
\hline Bleomycin & $\begin{array}{l}\text { Verdünnung auf ca. 1\%-ige Lösung. Zugabe von } 1 \mathrm{~g} \text { Ätznatron } / 100 \mathrm{ml} \text {. Nach } 5 \mathrm{~h} \text { mit } \\
\text { Essig- oder Salzsäure neutralisieren. }\end{array}$ & Temperatur $900^{\circ} \mathrm{C}$ \\
\hline Cisplatin & $\begin{array}{l}\text { Behandeln mit verdünnter Salzsäure in Gegenwart von Aluminium (z. B. Bördel-Verschluss der } \\
\text { Injektionsflasche). Die Substanz wird bis zum metallischen Platin reduziert. }\end{array}$ & Temperatur $700^{\circ} \mathrm{C}$ \\
\hline Doxorubicin & $\begin{array}{l}\text { Behandeln mit Chlorbleichlauge (Liquor Natrii hypochlorosi), die mit } 10 \text { Teilen Wasser } \\
\text { verdünnt wurde. Die Oxidation des Wirkstoffmoleküls wird durch Entfärbung angezeigt. }\end{array}$ & Temperatur $700^{\circ} \mathrm{C}$ \\
\hline Estramustin & Behandeln mit 5 - bis $10 \%$-iger methanolischer Natronlauge, $24 \mathrm{~h}$ bei Raumtemperatur. & Temperatur $1000^{\circ} \mathrm{C}$ \\
\hline Etoposid & Keine Methode bekannt. & Temperatur $1000^{\circ} \mathrm{C}$ \\
\hline 5-Fluorouracil & $\begin{array}{l}\text { a) Behandeln mit konzentrierter } \mathrm{NaOH} \text { über mehrere Stunden. } \\
\text { b) Verfahren analog bei Daunorubicin. }\end{array}$ & Temperatur $700^{\circ} \mathrm{C}$ \\
\hline Ifosfamid & Geeignete Methoden werden noch entwickelt. & Keine Angaben \\
\hline Methotrexat & $\begin{array}{l}\text { Behandeln mit } 1 \mathrm{nNaOH} \text { oder } \mathrm{NH}_{4} \mathrm{OH} \text {-Lösung. Optimal wäre eine Autoklavierung dieser } \\
\text { Lösung für } 1 \mathrm{~h} \text { bei } 12,5 \text { bar. }\end{array}$ & Temperatur $1000^{\circ} \mathrm{C}$ \\
\hline Mitomycin & Behandlung mit starken Säuren, Zersetzung von Mitomycin bei pH-Wert 1. & Temperatur $1000^{\circ} \mathrm{C}$ \\
\hline Mitoxantron & Pro Gramm Mitoxantron $20 \mathrm{~g}$ einer etwa 40\%-igen Kalziumhypochloritlösung zusetzen (Abzug!). & Temperatur $1000^{\circ} \mathrm{C}$ \\
\hline $\begin{array}{l}\text { Vinblastin, Vin- } \\
\text { cristin, Vindesin }\end{array}$ & Keine Methode bekannt. Vernichtung unproblematisch, da sehr temperaturlabil. & Temperatur $500^{\circ} \mathrm{C}$ \\
\hline
\end{tabular}




\subsubsection{Chemotherapieprotokolle}

\section{Cisplatin, Methotrexat}

Indikation: metastasiertes Urothelkarzinom

(•Tab. 10.21).

\section{Methotrexat, Vinblastin, Doxorubicin (oder Epirubicin), Cisplatin}

Indikation: metastasiertes Urothelkarzinom

(•Tab. 10.22).

\section{Gemcitabin/Cisplatin}

Indikation: metastasiertes Urothelkarzinom

(•Tab. 10.23).

\section{Carboplatin, Taxol}

Indikation: metastasiertes Urothelkarzinom

(•Tab. 10.24).

\section{Mitoxantron}

Indikation: hormonrefraktäres Prostatakarzinom

(•Tab. 10.25).

\section{Docetaxel}

Indikation: hormonrefraktäres Prostatakarzinom (•Tab. 10.26).

\section{Cisplatin, Methotrexat, Bleomycin}

Indikation: metastasiertes Peniskarzinom

(- Tab. 10.27).

\section{Cisplatin, Etoposid, Bleomycin}

Indikation: Hodentumoren (alle Nichtseminome, fortgeschrittene Seminome; • Tab. 10.28).

\section{Cisplatin, Etoposid, Ifosfamid}

Indikation: fortgeschrittene Germinalzelltumorstadien, chemotherapierefraktär, Pulmonalinsuffizienz (•Tab. 10.29).

\section{Carboplatin}

Indikation: Seminom im klinischen Stadium I

(- Tab. 10.30).
- Tab. 10.21. Chemotherapieprotokoll für Cisplatin, Methotrexat

\begin{tabular}{|l|l|l|}
\hline Substanz & Dosierung & Applikation \\
\hline Cisplatin & $70 \mathrm{mg} / \mathrm{m}^{2}$ KOF & Tag 1 \\
\hline Methotrexat+ & $40 \mathrm{mg} / \mathrm{m}^{2} \mathrm{KOF}$ & Tag 8,15 \\
\hline
\end{tabular}

+ am Folgetag nach MTX-Gabe jeweils um 8 und 14 Uhr 12 mg Folinsäure.

Wiederholung nach 21 Tagen.

\begin{tabular}{|c|c|c|}
\hline \multicolumn{3}{|c|}{$\begin{array}{l}\text { Tab. 10.22. Chemotherapieprotokoll für Methotrexat, } \\
\text { Vinblastin, Doxorubicin (oder Epirubicin), Cisplatin }\end{array}$} \\
\hline Substanz & Dosierung & Applikation \\
\hline Methotrexat+ & $30 \mathrm{mg} / \mathrm{m}^{2} \mathrm{KOF}$ & Tag 1, 15, 22 \\
\hline Vinblastin & $3 \mathrm{mg} / \mathrm{m}^{2} \mathrm{KOF}$ & Tag 2, 15, 22 \\
\hline Doxorubicin* & $30 \mathrm{mg} / \mathrm{m}^{2} \mathrm{KOF}$ & $\operatorname{Tag} 2$ \\
\hline Cisplatin & $70 \mathrm{mg} / \mathrm{m}^{2} \mathrm{KOF}$ & Tag 2 \\
\hline
\end{tabular}

+ Am Folgetag nach MTX-Gabe jeweils um 8 und 14 Uhr 12 mg Folinsäure.

* Alternativ Epirubicin 45 mg $/ \mathrm{m}^{2} \mathrm{KOF}$

Wiederholung nach 28 Tagen.

\begin{tabular}{|c|c|c|}
\hline \multicolumn{3}{|c|}{$\begin{array}{l}\text { Tab. 10.23. Chemotherapieprotokoll für Gemcitabin/ } \\
\text { Cisplatin }\end{array}$} \\
\hline Substanz & Dosierung & Applikation \\
\hline Gemcitabin & $1250 \mathrm{mg} /{ }^{2} \mathrm{KOF}$ & Tag 1, 8 \\
\hline Cisplatin & $70 \mathrm{mg} / \mathrm{m}^{2} \mathrm{KOF}$ & Tag 2 \\
\hline
\end{tabular}

Wiederholung nach 21 Tagen.

- Tab. 10.24. Chemotherapieprotokoll für Carboplatin, Taxol

\begin{tabular}{|l|l|l}
\hline Substanz & Dosierung & Applikation \\
\hline Taxol & $175 \mathrm{mg} / \mathrm{m}^{2}$ KOF & Tag 1 \\
\hline Carboplatin & $400 \mathrm{mg} / \mathrm{m}^{2}$ KOF & Tag 1
\end{tabular}

Wiederholung nach 21 Tagen.

- Tab. 10.25. Chemotherapieprotokoll für Mitoxantron

\begin{tabular}{|l|l|l|}
\hline Substanz & Dosierung & Applikation \\
\hline Mitoxantron & $\begin{array}{l}14 \mathrm{mg} / \mathrm{m}^{2} \text { KOF } \\
\text { (höchste Gesamt- } \\
\text { dosis } 160 \mathrm{mg} \text { ) }\end{array}$ & Tag 1 \\
\hline
\end{tabular}

Wiederholung nach 21 Tagen. 
- Tab. 10.26. Chemotherapieprotokoll für Docetaxel

\begin{tabular}{|l|l|l|}
\hline Substanz & Dosierung & Applikation \\
\hline Docetaxel & $75 \mathrm{mg} / \mathrm{m}^{2}$ KOF & Tag 1 \\
\hline
\end{tabular}

Wiederholung nach 21 Tagen.

- Tab. 10.27. Cisplatin, Methotrexat, Bleomycin

\begin{tabular}{l|l|l}
\hline Substanz & Dosierung & Applikation \\
\hline Cisplatin & $70 \mathrm{mg} / \mathrm{m}^{2}$ KOF & Tag 1 \\
\hline Methotrexat & $40 \mathrm{mg} / \mathrm{m}^{2}$ KOF & Tag 8,16 \\
\hline Bleomycin & $30 \mathrm{mg}$ & Tag 8,16 \\
\hline
\end{tabular}

Wiederholung nach 21 Tagen.

- Tab. 10.28. Chemotherapieprotokoll für Cisplatin, Etoposid, Bleomycin

\begin{tabular}{l|l|l}
\hline Substanz & Dosierung & Applikation \\
\hline Cisplatin & $20 \mathrm{mg} / \mathrm{m}^{2}$ KOF & Tag $1-5$ \\
\hline Etoposid & $100 \mathrm{mg} / \mathrm{m}^{2}$ KOF & Tag $1-5$ \\
\hline Bleomycin & $30 \mathrm{mg}$ & Tag $1,9,16$ \\
\hline
\end{tabular}

Wiederholung nach 21 Tagen.

- Tab. 10.29. Chemotherapieprotokoll für Cisplatin, Etoposid und Ifosfamid

\begin{tabular}{|l|l|l}
\hline Substanz & Dosierung & Applikation \\
\hline Cisplatin & $20 \mathrm{mg} / \mathrm{m}^{2}$ KOF & Tag $1-5$ \\
\hline Etoposid & $75 \mathrm{mg} / \mathrm{m}^{2}$ KOF & Tag $1-5$ \\
\hline Ifosfamid & $1200 \mathrm{mg} / \mathrm{m}^{2}$ KOF & Tag $1-5$ \\
\hline
\end{tabular}

Wiederholung nach 21 Tagen.

- Tab. 10.30. Chemotherapieprotokoll für Carboplatin Monotherapie

\begin{tabular}{|l|l|l}
\hline Substanz & Dosierung & Applikation \\
\hline Carboplatin & $\begin{array}{l}\text { Gemäß AUC, Car- } \\
\text { bo }(\mathrm{mg})=\text { AUC- } \\
\text { Wert x (GFR + 25) }\end{array}$ & Tag 1 \\
\hline
\end{tabular}

Wiederholung nach 28 Tagen.

\subsubsection{Targetspezifische Therapie}

Ziel der therapeutischen Überlegungen war es immer, eine möglichst spezifisch gegen den Tumor gerichtete Therapieform zu entwickeln, die es ermöglicht, das Tumorgewebe selektiv zu zerstören. Diese Entwicklung hat dazu geführt, dass eine Reihe von Proteinen gefunden worden sind, die von Tumorgewebe im Vergleich zu Normalgewebe überexprimiert werden.

Antikörper, die spezifisch gegen diese Proteine gerichtet sind, könnten ein Ziel für hochselektive Formen der Tumorbehandlung darstellen. Generell muss aber beachtet werden, dass Antikörper insgesamt nur ein geringes Potenzial zur Tumorzellabtötung bieten. So ist bei vielen Patienten der Nachweis von Antikörpern gegen ihren Tumor erbracht worden, ein Einfluss auf den Krankheitsverlauf konnte aber nicht gezeigt werden.

Die Möglichkeit der Herstellung großer Mengen hochaffiner, gegen den Tumor gerichteter Antikörper hat zur Applikation von Antikörpern zur Malignombehandlung geführt. So wurden humanisierte Antikörper (Rituximab) gegen das CD20-Molekül, das auf B-Zellen exprimiert wird, und Antikörper gegen den HER-2/neu-Rezeptor (Trastuzumab), der auf epithelialen Tumoren überexprimiert sein kann, zu zuverlässigen Medikamenten in der onkologischen Behandlung. Jeder dieser Antikörper für sich allein kann eine Tumorregression induzieren, und beide scheinen den Effekt einer zytostatischen Chemotherapie überadditiv zu verstärken, wenn die Chemotherapie kurz nach der Antikörpergabe erfolgt.

Bei Patienten mit metastasiertem Nierenzellkarzinom konnte Atkins (2004) durch den gegen den VEGF-Rezeptor gerichteten Antikörper Bevacizumab einen positiven Effekt auf den Krankheitsverlauf nachweisen. Für das Prostatakarzinom scheinen die Tyrosinkinasen einen Angriffspunkt für eine targetspezifische Therapie zu bieten. Untersuchungen von Hofer, Di Lorenzo und Lara zeigten die Expression von PDGF-R, HER-2, c-Kit und EGF-R in $15-60 \%$ der Fälle. Durch die Inhibierung des PDGF-Rezeptors durch Glivec wurde von Rao (2005) ein positives Ansprechen des PSA-Wertes beschrieben.

Die Expression von H-Ras in 40-80\% der Fälle beim Harnblasenkarzinom ist derzeit Anlass zur Durchführung klinischer Studien unter der Fragestellung, ob auch hier durch eine antikörpergestützte Therapie ein positiver Einfluss auf den Krankheitsverlauf zu erzielen ist. - Tab. 10.31 zeigt die derzeitigen individuellen Therapieoptionen in Abhängigkeit immunhistochemischer Expressionsanalysen.

Ebenfalls wirksam könnte auch die Kopplung von Medikamenten, Toxinen, Isotopen, photodynamischen Substanzen und anderen tumorwirksamen Zusätzen sein. 


\begin{tabular}{|c|c|}
\hline \multicolumn{2}{|c|}{$\begin{array}{l}\text { Tab. 10.31. Therapieoptionen nach immunhistochemischer } \\
\text { Expressionsanalyse }\end{array}$} \\
\hline Exprimiertes Protein & Therapeutikum \\
\hline VEGF-R & Bevacizumab \\
\hline EGF-R & Iressa, Erbitux \\
\hline c-Kit & Glivec \\
\hline PDGF-R & Glivec \\
\hline HER-2 & Trastuzumab \\
\hline H-Ras & BAY 43-9006 \\
\hline
\end{tabular}

Radiokonjugate wie der ${ }^{90}$ Yttrium-gekoppelte und gegen das auf Lymphozyten exprimierte CD20-Molekül gerichtete Antikörper Ibritumomab-Tiuxetan (Zevalin) sind bereits zugelassen.

\subsection{Prophylaxe und Therapie von Komplikationen der Immuntherapie}

Chr. Doehn, D. Jocham

\subsubsection{Vorbemerkungen und Klassifikationen}

Die Nebenwirkungen einer Tumortherapie stellen neben dem Tumoransprechen, der Heilung und der Lebenserwartung einen wichtigen Parameter zur Beurteilung einer onkologischen Behandlung dar. Sie beeinflussen wesentlich die Lebensqualität eines Tumorpatienten. Die Kenntnis von Nebenwirkungen einer Therapie ist Voraussetzung für deren Behandlung und die Entscheidung inwieweit eine Fortführung der Therapie möglich ist. In diesem Kapitel werden Nebenwirkungen einer Immuntherapie des Prostatakarzinoms, Harnblasenkarzinoms und Nierenzellkarzinoms behandelt. Hierbei wird in erster Linie auf eine systemische mittels Antikörpern, Zytokinen, Tyrosinkinase-Inhibitoren, Inhibitoren des »mammalian target of rapamycin« (mTOR), Vakzine sowie intravesikale Therapie mit Bacille Calmette et Guérin (BCG) fokussiert.

Es existieren verschiedene Klassifikationen von $\mathrm{Ne}$ benwirkungen einer onkologischen Therapie (Seegenschmidt et al. 1999). Hierbei werden klinische Symptome wie auch Laborbefunde bewertet. Die alte WHO-Klassifikation unterscheidet eine Nebenwirkung in mild, moderat und schwer. Demgegenüber unterscheiden die »Common Toxicity Criteria (CTC) in ihrer zweiten und dritten Version (aus den Jahren 1999 bzw. 2003) zwischen milden, moderaten, schweren, lebensbedrohlichen und zum Tode führenden Nebenwirkungen (www.ctep.cancer.gov). Eine Übersicht in deutscher Sprache ist auch unter www.onkologie2008.de abrufbar. Im Jahr 2003 wurden die »Common Terminology Criteria for Adverse Events « (CTCAE) eingeführt, die Nebenwirkungen durch Operationen oder Strahlentherapie sowie Langzeitnebenwirkungen stärker berücksichtigen und derzeit in der Version 3.0 aus dem Jahr 2006 verfügbar sind (www.ctep.cancer.gov).

\subsubsection{Immuntherapie des Prostatakarzinoms}

Die Immuntherapie des Prostatakarzinoms erfolgt derzeit in erster Linie mittels Antikörper, Tyrosinkinase-Inhibitoren oder Vakzineansätzen (•Tab. 10.32).

\section{Antikörpertherapie des Prostatakarzinoms}

Antikörper sind nicht tumorspezifisch und können deshalb auch mit "normalen« Zellen reagieren. Es werden murine und humane Antikörper unterschieden. Nachteil der erstgenannten ist eine mögliche Induktion von Antikörpern durch den Empfänger mit der Folge der Inaktivierung und auch Gefahr einer anaphylaktischen Reaktion. Um dies zu verhindern, wurden chimäre (33\% Humananteil) und humanisierte (90\% Humananteil) Antikörper hergestellt. Ziel einer Antikörpertherapie beim Prostatakarzinom ist zumeist der Endothelin-Rezeptor und der endotheliale Wachstumsfaktor-Rezeptor (EGFR).

\section{Endothelin-Rezeptor-Antikörpertherapie}

Endotheline (ET) sind Faktoren, die u. a. den Gefäßtonus, die Schmerzleitung, die Hormonproduktion und die Zellproliferation beeinflussen. Die Endothelinfamilie besteht aus mehreren Isoformen (ET-1, ET-2, ET-3). Atrasentan (Xinlay) ist ein potenter Antagonist des Endothelin-ARezeptors. In einer dreiarmigen Studie wurden $288 \mathrm{~Pa}-$ tienten mit einem hormonrefraktären Prostatakarzinom entweder mit Placebo oder mit 2,5 mg bzw. 10 mg Atrasentan (Xinlay) p.o. täglich behandelt (Carducci et al. 2003). In den beiden Atrasentangruppen kam es gegenüber Placebo zu einem häufigeren Auftreten von Kopfschmerzen ( $20 \%$ vs. $10 \%)$, Rhinitis ( $28 \%$ vs. $13 \%)$, peripheren Ödemen (34\% vs. $14 \%$ ) und Dyspnoe (16\% vs. 3\%). Die Mehrzahl der Ereignisse wurde jedoch als mild bis moderat eingestuft und konnte "symptomatisch « behandelt werden. Ein Patient musste die Studie aufgrund von Nebenwirkungen abbrechen (Carducci et al. 2003).

In einer aktuellen randomisierten Phase-III-Studie wurden 467 von 941 Patienten mit einem nicht metastasierten hormonrefraktären Prostatakarzinom mit $10 \mathrm{mg}$ 
- Tab. 10.32. Neue Immuntherapeutika: Wirkmechanismus, Applikation und typische Nebenwirkungen

\begin{tabular}{|c|c|c|c|}
\hline Immuntherapeutikum & Wirkmechanismus & Applikation & Typische Nebenwirkungen \\
\hline Atrasentan (Xinlay) & Endothelin-Antikörper & p.o. & Kopfschmerzen, Rhinitis, periphere Ödeme, Dyspnoe \\
\hline Bevacizumab (Avastin) & VEGF-Antikörper & i.v. & Hypertonus, Proteinurie, Diarrhö \\
\hline Cetuximab (Erbitux) & EGFR-Antikörper & i.v. & Akne, Fieber, Überempfindlichkeitsreaktionen, Asthenie \\
\hline Erlotinib (Tarceva) & TKI gegen EGFR & p.o. & Müdigkeit, Diarrhö, Ödem, Hautausschlag \\
\hline Gefitinib (Iressa) & TKI gegen EGFR & p.o. & $\begin{array}{l}\text { Diarrhö, Hautausschlag, trockene Haut, Geschmacks- } \\
\text { veränderungen }\end{array}$ \\
\hline GVAX & Allogene Vakzine & i.d. & Lokaler Juckreiz, Rötung, Schwellung \\
\hline Imatinib (Glivec) & TKI: c-KIT, PDGFR, Bcr-Abl & p.o. & $\begin{array}{l}\text { Müdigkeit, Diarrhö, Gewichtszunahme, Ödem, } \\
\text { Hautausschlag, Myalgie }\end{array}$ \\
\hline Onyvax-P & Allogene Vakzine & i.d. & $\begin{array}{l}\text { Lokaler Juckreiz, Rötung, Schwellung; gastrointestinale } \\
\text { Symptome }\end{array}$ \\
\hline Panitumumab (Vectibix) & EGFR-Antikörper & i.v. & Hautausschlag, Asthenie, Diarrhö, Übelkeit, Stomatitis \\
\hline Provenge & Autologe Vakzine & i.v. & Rigor, Fieber, gastrointestinale Symptome \\
\hline Reniale & Autologe Vakzine & i.d. & Lokaler Juckreiz, Rötung, Schwellung \\
\hline Sorafenib (Nexavar) & RAF-Kinase-Inhibitor & p.o. & $\begin{array}{l}\text { Diarrhö, Hautausschlag, Hand-Fuß-Syndrom, Alopezie, } \\
\text { Müdigkeit, Hypertonus, Neuropathie }\end{array}$ \\
\hline Sunitinib (Sutent) & $\begin{array}{l}\text { TKI gegen VEGF, PDGFR, KIT, } \\
\text { FLT3, CSF-1R und RET }\end{array}$ & p.o. & $\begin{array}{l}\text { Müdigkeit, Diarrhö, Stomatitis, Übelkeit, Erbrechen, } \\
\text { Lymphopenie, Hautausschlag, Hypertonus }\end{array}$ \\
\hline Temsirolimus (Torisel) & mTOR-Inhibitor & i.v. & Akne, Hautausschlag, Stomatitis, Asthenie, Übelkeit \\
\hline Everolimus (Certican) & mTOR-Inhibitir & p.o. & $\begin{array}{l}\text { Stomatitis, Hautausschlag, Müdigkeit, Asthenie, Diarrhö, } \\
\text { Pneumonitis }\end{array}$ \\
\hline
\end{tabular}

VEGF vascular endothelial growth factor; EGFR endothelial growth factor receptor; TKI Tyrosinkinase-Inhibitor; mTOR mammalian target of rapamycin; p.o. per os; i.v. intravenös; i.d. intradermal

Atrasentan täglich und 474 Patienten mit Placebo behandelt (Nelson et al. 2008). In der Atrasentangruppe kam es bei $26,4 \%$ der Patienten zu einem nebenwirkungsbedingten Studienabbruch gegenüber $16,4 \%$ in der Placebogruppe. $\mathrm{Zu}$ den häufigsten Nebenwirkungen unter Atrasentan (im Gefolge jeweils erstgenannt), die sich statistisch signifikant von den Nebenwirkungen unter Placebo unterschieden, gehörten periphere Ödeme $(49,4 \%$ vs. $21,1 \%)$, nasale Kongestion (39,4\% vs. $11,1 \%)$, Kopfschmerzen $(17,7 \%$ vs. $11,3 \%)$, Dyspnoe (15,6\% vs. $9,6 \%)$ und Obstipation ( $14,5 \%$ vs. $21,5 \%$, also unter Placebo häufiger!) (Nelson et al. 2008).

\section{PSMA-Antikörpertherapie}

Es handelt sich beim PSMA (Prostataspezifisches Membranantigen) um ein Typ-II-Membranprotein, das überwiegend von Prostatazellen exprimiert wird. Der Antikörper J591 bindet an das extrazelluläre Epitop des Moleküls (Nanus et al. 2003). In einer Arbeit von Bander et al. wurde der Antikörper an ${ }^{177}$ Lutetium gekoppelt und bei 35 Patienten mit einem hormonrefraktären Prostatakarzinom i.v. verabreicht. Es bestand eine dosislimitierende Myelotoxizität oberhalb einer Dosis von $75 \mathrm{mCi} /$ $\mathrm{m}^{2}$ (Bander et al. 2005). Neuere Arbeiten sind zu diesem Thema nicht verfügbar.

\section{Tyrosinkinase-Inhibitoren beim Prostatakarzinom Gefitinib}

Gefitinib (Iressa) ist ein Inhibitor der intrazellulären Tyrosinkinase des EGF-Rezeptors. Hiermit verbunden sind eine Abnahme der Rezeptorphosphorylierung und eine potentielle Hemmung von Tumorzellproliferation, Angiogenese und Metastasierung. In einer randomisierten Phase-II-Studie wurde bei 40 Patienten mit einem metastasierten Prostatakarzinom Gefitinib (Iressa) in einer Dosierung von $250 \mathrm{mg}$ bzw. $500 \mathrm{mg}$ p.o. täglich verabreicht (Canil et al. 2005). Bis auf Müdigkeit waren 
alle Nebenwirkungen 1. oder 2. Grades: Diarrhö (56\%), Hautausschlag (39\%), trockene Haut (33\%), Geschmacksstörungen (22\%), Anorexie (17\%), Übelkeit (17\%) und Stomatitis (11\%). Es gab keine relevanten Unterschiede zwischen den beiden Dosierungen (Canil et al. 2005).

In einer weiteren Studie an 58 Patienten mit einem nicht metastasierten hormonrefraktären Prostatakarzinom gehörten zu den häufigsten Nebenwirkungen Diarrhö (71\%), Hautausschlag (57\%), trockene Haut (36\%), Übelkeit (31\%), Akne (24\%). Bei 11/58 Patienten wurde die Therapie nebenwirkungsbedingt abgebrochen (Small et al. 2007). In einer randomisierten Phase-II-Studie (Gefitinib plus Prednison versus Placebo plus Prednison) zeigte sich eine deutlich geringere Nebenwirkungsrate (Boccardo et al. 2008). Häufigste Nebenwirkungen waren Diarrhö (21,1\%), Abdominalschmerz (15,8\%) und Erythem (7,8\%).

\section{Imatinib}

Imatinib (Glivec) ist ein weiterer Inhibitor von Tyrosinkinasen. In einer Phase-II-Studie wurden der Effekt und das Nebenwirkungsprofil bei 21 Patienten mit einem hormonsensiblen Prostatakarzinom und PSA-Anstieg untersucht (Rao et al. 2005). Die Patienten erhielten $2 \times 400 \mathrm{mg}$ Imatinib (Glivec) p.o. täglich. Es zeigten sich eine Neutropenie Grad 4 in 2 Fällen sowie 9 weitere Ereignisse Grad $3(1 \times$ Neutropenie, $1 \times$ Tachykardie, $3 \times$ Hautausschlag, $1 \times$ Diarrhö, $1 \times$ Dyspepsie, $1 \times$ Hämaturie und $1 \times$ Sehstörungen. Es traten 42 Ereignisse Grad 2 (z. B. Müdigkeit und Diarrhö) und 102 Ereignisse Grad 1 (z. B. Müdigkeit und Ödeme) auf (Rao et al. 2005).

In einer weiteren Studie an 20 Männern mit PSAAnstieg nach Primärtherapie traten zahlreiche Nebenwirkungen Grad 1-3 auf, die bei 11/20 Patienten zum Therapieabbruch führten (Lin et al. 2006). Die häufigsten Nebenwirkungen waren periorbitales Ödem (80\%), Müdigkeit (60\%), Hautausschlag (55\%) und Diarrhö (40\%). Hämatologische Nebenwirkungen betrafen Anämie (80\%), Lymphopenie (70\%), Leukopenie (50\%) und Neutropenie (30\%) (Lin et al. 2006). Auch in anderen Studien kam es nebenwirkungsbedingt bei einer relevanten Patientenzahl (z. B. 7/27 Patienten) zum Studienabbruch (Bajaj et al. 2007).

\section{Vakzinetherapie des Prostatakarzinoms}

Das Prinzip einer Vakzinetherapie von Tumorerkrankungen beruht auf einem Zuführen von (Tumor)antigene(n) mit dem Ziel das Immunsystem zu aktivieren. Eine Vakzinetherapie erscheint beim Prostatakarzinom attraktiv, weil für diesen Tumor verschiedene tumorassoziierte Antigene bekannt sind (Ragde et al. 2004; Swindle et al. 2004). $\mathrm{Zu}$ den bekanntesten und wichtigsten gehören das prostataspezifische Antigen (PSA), die prostatische saure Phosphatase (PAP) und das PSMA.

\section{GVAX}

Die GVAX-Vakzine wird aus bestrahlten allogenen Prostatakarzinomzellen, die ex vivo mit dem GM-CSF-Gen transfiziert werden, hergestellt. In drei Phase-II-Studien an 41 Patienten mit einem hormonnaiven Prostatakarzinom und 55 Patienten mit einem hormonrefraktären Prostatakarzinom wurde GVAX intradermal verabreicht. Die häufigsten Nebenwirkungen waren Juckreiz, Rötung und Schwellung an der Injektionsstelle. Es wurde weder eine dosislimitierende Toxizität noch Autoimmunität beobachtet (Simons et al. 2006). Bis 2008 wurde GVAX im Rahmen von zwei Phase-III-Studien bei Patienten mit einem Prostatakarzinom getestet. In der sog. VITAL-1 -Studie wurde die Vakzine alle 2 Wochen intradermal für insgesamt 24 Wochen (entsprechend 13 Impfdosen) verabreicht. Im Vergleichsarm wurde mit Docetaxel und Prednison alle 3 Wochen für 24 Wochen (entsprechend 9 Zyklen) behandelt. Diese Studie wurde aufgrund einer Zwischenanalyse im Oktober 2008 terminiert, weil der primäre Endpunkt als nicht ausreichend sicher erreichbar erschien (www.cellgenesys.com).

In einer zweiten randomisierten Studie der Phase III (VITAL-II) wurde eine Kombination aus GVAX und Docetaxel mit Docetaxel und Prednison verglichen. Diese Studie hat im Juli 2005 begonnen und inkludierte Patienten mit einem hormonrefraktären Prostatakarzinom, messbaren Metastasen und tumorassoziierten Schmerzen. Diese Studie wurde wegen einer bis dato unerklärbar höheren Zahl an Todesfällen im Vakzinearm (67 vs. 47 Todesfälle) im August 2008 beendet (www.cellgenesys.com).

\section{Onyvax-P}

Onyvax-P besteht aus einer Kombination von 3 allogenen Prostatakarzinomzellinien. Die Vakzine wird zweimal alle 2 Wochen mit BCG als Adjuvans intradermal und anschließend in 4-wöchigen Abständen appliziert (Michael et al. 2005). In einer Phase-I-Studie wurden $60 \mathrm{~Pa}$ tienten mit einem hormonrefraktären Prostatakarzinom behandelt (Eaton et al. 2002). Sechs Patienten hatten grippeähnliche Symptome. Dalgleish et al. berichteten über 26 Patienten mit einem hormonrefraktären Prostatakarzinom ohne Knochenmetastasen. Nebenwirkungen waren von milder Natur und äußerten sich als Hautreaktionen (Rötung, Schwellung, Schmerz, Juckreiz) an der Injektionsstelle, gastrointestinale Beschwerden und grippeähnliche Symptome, die nach 1-2 Tagen wieder verschwanden (Eaton et al. 2002; Dalgleish et al. 2005). Weiterführende Ergebnisse aus Phase-IIB-Studien dürfen in absehbarer Zeit erwartet werden. 


\section{Provenge}

Ein anderer Vakzineansatz (Provenge) besteht aus autologen dendritischen Zellen, beladen mit dem Fusionsprotein PA2024 (PAP gebunden an humanes GM-CSF), und wird dreimal i.v. appliziert (alle 2 Wochen). Provenge wurde in einer randomisierten Phase-III-Studie bei 127 Patienten mit einem metastasierten Prostatakarzinom geprüft (Small et al. 2006). Es wurden entweder 3 Vakzinierungen oder ein Placebo alle 2 Wochen i.v. verabreicht. Die Therapie war bei einer Nachbeobachtungszeit von mindestens 3 Jahren insgesamt gut verträglich. Nebenwirkungen, die in der Vakzinegruppe signifikant häufiger $(\mathrm{p}<0,05)$ auftraten, waren Schüttelfrost $(59,8 \%$ vs. $8,9 \%)$, Fieber ( $29,3 \%$ vs. $2,2 \%)$, Zittern ( $9,8 \%$ vs. $0 \%$ ) und grippeähnliche Symptome ( $8,5 \%$ vs. $0 \%)$. Alle Nebenwirkungen traten zeitnah zur Infusionsgabe auf und zeigten sich in $70 \%$ der Fälle im Grad 1 oder 2. In der Vakzinegruppe traten folgende Grad 3 oder 4 Nebenwirkungen auf: Schüttelfrost $(4,9 \%)$, Schwächegefühl $(3,4 \%)$, Fieber $(2,4 \%)$, Rückenschmerzen (2,4\%), Arthralgien (1,2\%), Dyspnoe (7,1\%), Anämie (2,4\%) und Verstopfung $(3,4 \%)$. 95\% der Patienten erhielten alle drei geplanten Infusionsgaben und kein Patient musste die Studie aufgrund von Nebenwirkungen abbrechen (Small et al. 2006). Weiterführende Ergebnisse aus Phase-III-Studien dürfen in absehbarer Zeit erwartet werden.

\subsubsection{Immuntherapie des Harnblasenkarzinoms}

\section{Intravesikale Gabe von BCG}

BCG ist ein avirulenter Mycobacterium-bovis-Stamm. Seit den ersten intravesikalen Applikationen vor mehr als 30 Jahren wird BCG heute routinemäßig in der Rezidivprophylaxe des oberflächlichen Harnblasenkarzinoms eingesetzt. Intravesikal verabreichtes BCG adhäriert an der Blasenwand und führt zu einer lokalen Aktivierung verschiedener Zellen des Immunsystems. Die Zytokine Interleukin-2 (IL-2), IL-12 und Interferon- $\gamma$ (IFN- $\gamma$ ) spielen bei diesem komplexen Vorgang eine wesentliche Rolle.

\section{Standardschema}

In einem Induktionszyklus werden wöchentlich über insgesamt 6 Wochen je $2 \times 10^{8}-3 \times 10^{9}$ BCG-Bakterien in Lösungsmittel intravesikal appliziert. Die Instillation sollte frühestens 2 Wochen nach Resektion beginnen. Bei einem früheren Beginn steigt das Risiko für Nebenwirkungen, insbesondere für eine Sepsis. Die Katheterisierung sollte möglichst atraumatisch erfolgen. Bei traumatischer Katheterisierung muss die BCG-Instillation um mindestens eine Woche verschoben werden. Der Patient sollte nach der Instillation körperliche Ruhe einhalten, viel trinken und das Therapeutikum für 2 Stunden in der Blase behalten. Bei der Erhaltungstherapie wird nach den Kriterien der South Western Oncology Group (SWOG) jeweils ein halber Zyklus entsprechend 3 konsekutiven wöchentlichen Instillationen nach 3, 6, 12, 18, 24, 30 und 36 Monaten wiederholt (Lamm et al. 2000). Mit einer Erhaltungstherapie häufen sich lokale, nicht jedoch systemische Nebenwirkungen (Decobert et al. 2008).

\section{Dosismodifikationen und Kombinationstherapien}

Um die Effektivität von BCG zu steigern oder/und um die Nebenwirkungen zu mildern, wurden verschiedene Ansätze überprüft. Dazu gehören Studien mit reduzierter BCG-Dosis (1/3-1/4-1/6-Dosis, nach Lamm sogar bis zu $1 / 100$-Dosis) oder Kombinationen mit anderen Wirkstoffen.

Eine Dosisreduktion ist mit einer deutlichen $\mathrm{Ab}$ nahme von Nebenwirkungen bei vergleichbarer Wirksamkeit assoziiert. Dies gilt allerdings offenbar nur bis zur 1/3-Dosis. Martinez-Pineiro et al. untersuchten in einer randomisierten Phase-III-Studie die intravesikale Therapie mit einer BCG-Standarddosis versus einer 1/3Dosis bei 155 Patienten mit einem pT1G3-Tumor oder CIS der Harnblase (•Tab. 10.33). In dieser Studie lag die tatsächlich verabreichte Anzahl intravesikaler BCGInstillationen bei 10,5 (Standarddosis) bzw. 11,6 pro Patient (1/3-Dosis) (Martinez-Pineiro et al. 2005). In einer anderen spanischen Studie wurde die 1/3-Dosis mit einer 1/6-Dosis sowie Mitomycin C (MMC) $30 \mathrm{mg}$ intravesikal verglichen (Ojea et al. 2007). Hierbei wurden 430 Patienten mit einem Urothelkarzinom der Harnblase und intermediärem Risiko eingeschlossen. Hinsichtlich der Nebenwirkungen war MMC besser verträglich als BCG. Zwischen der 1/3- und der 1/6-Dosis BCG bestand bezüglich der Nebenwirkungen kein relevanter Unterschied (- Tab. 10.33), so dass vor dem Hintergrund der genannten Studien die 1/3-Dosis einen guten Kompromiss zwischen erhaltener Wirksamkeit bei reduzierten Nebenwirkungen darstellt (Ojea et al. 2007).

Ein anderer Ansatz betrifft die Kombination von BCG mit IFN- $\alpha$ (O'Donnell et al. 2004). Insgesamt 490 BCG-naive Patienten mit oberflächlichen Blasentumoren und Patienten mit Tumorrezidiven nach vorheriger BCG-Therapie wurden in einer multizentrischen PhaseII-Studie mit BCG plus IFN- $\alpha$ in 2 Armen behandelt, in denen ein Standard-BCG-Induktionszyklus mit simultanen IFN-Applikationen und dreimalige Erhaltungsgaben (nach 3, 9 und 12 Monaten) appliziert wurden. Beide Behandlungsarme unterschieden sich durch die BCG-Dosis im Induktionszyklus, wobei die BCG-Versager nur $1 / 3$ bis $1 / 10$ der normalen BCG-Dosis erhielten. Moderate 
- Tab. 10.33. Lokale und systemische Nebenwirkungen einer intravesikalen BCG-Therapie in Abhängigkeit zur Dosierung (Standard versus 1/3-Dosis versus 1/6-Dosis).

\begin{tabular}{|c|c|c|c|c|}
\hline & $\begin{array}{l}\text { BCG-Standarddosis } \\
(\mathrm{n}=82) \\
\text { (Martinez-Pineiro et } \\
\text { al. 2005) }\end{array}$ & $\begin{array}{l}\text { 1/3-BCG-Dosis } \\
\text { ( } n=73 \text { ) } \\
\text { (Martinez-Pineiro et } \\
\text { al. 2005) }\end{array}$ & $\begin{array}{l}\text { 1/3-BCG-Dosis } \\
(n=125) \\
\text { (Ojea et al. 2007) }\end{array}$ & $\begin{array}{l}\text { 1/6-BCG-Dosis } \\
(n=135) \\
\text { (Ojea et al. 2007) }\end{array}$ \\
\hline Keine lokalen Nebenwirkungen & $30,5 \%$ & $52,1 \%$ & $34,5 \%$ & $36 \%$ \\
\hline Lokale Nebenwirkungen Grad 1 oder 2 & $50 \%$ & $37 \%$ & $51,4 \%$ & $56,8 \%$ \\
\hline Lokale Nebenwirkungen Grad 3 oder 4 & $19,5 \%$ & $11 \%$ & $14,1 \%$ & $7,3 \%$ \\
\hline Keine systemischen Nebenwirkungen & $84,1 \%$ & $94,5 \%$ & $88,8 \%$ & $89,2 \%$ \\
\hline $\begin{array}{l}\text { Systemische Nebenwirkungen } \\
\text { Grad } 1 \text { oder } 2\end{array}$ & $15,9 \%$ & $4,1 \%$ & $11 \%$ & $8,6 \%$ \\
\hline $\begin{array}{l}\text { Systemische Nebenwirkungen } \\
\text { Grad } 3 \text { oder } 4\end{array}$ & 0 & $1,4 \%$ & $5 \%$ & $2,2 \%$ \\
\hline $\begin{array}{l}\text { Nebenwirkungsbedingter } \\
\text { Therapieabbruch }\end{array}$ & $12,2 \%$ & $9,6 \%$ & $6 \%$ & $1 \%$ \\
\hline
\end{tabular}

und schwere Nebenwirkungen waren fast ausschließlich lokal und in der BCG-Versager-Gruppe seltener $(2,6 \%)$ als in der BCG-naiven Gruppe (5,4\%) (O'Donnell et al. 2004). In der Publikation der Endergebnisse an 1007 Patienten, die BCG und IFN- $\alpha$ erhalten haben, wurden Nebenwirkungen leider nicht erwähnt (Joudi et al. 2006).

Lokale und systemische Nebenwirkungen einer intravesikalen BCG-Therapie in Abhängigkeit zur Dosierung (Standard versus 1/3-Dosis versus 1/6-Dosis).

\section{Kontraindikationen}

$\mathrm{Zu}$ den Kontraindikationen einer BCG-Therapie gehören Schwangerschaft und Stillzeit, vorherige Überreaktion auf BCG, parallele immunsuppressive Therapie, Makrohämaturie, Harnwegsinfektion oder unklares Fieber. Patienten mit Aortenaneurysma oder prothetischem Material wie Gefäßprothesen, künstlichen Gelenken, künstlichen Herzklappen oder Herzschrittmacher sollten kein BCG erhalten. Eine entsprechende Infektion ist in Einzelfällen beschreiben, so dass sicherheitshalber eine therapeutische Alternative zum Einsatz kommen sollte.

\section{Therapie lokaler Nebenwirkungen}

In einer Metaanalyse an 834 BCG-therapierten Patienten aus 6 auswertbaren Studien zeigten sich lokale bzw. systemische Nebenwirkungen bei $44 \%$ bzw. 19\% der Patienten (Shelley et al. 2003). Diese treten oft nach der zweiten oder dritten Instillation auf und bessern sich nach wenigen Tagen. Ein häufiges Symptom der BCG-Therapie ist ein Temperaturanstieg, der bei etwa 3\% der Patienten über $39,5^{\circ} \mathrm{C}$ beträgt. Bis zu $30 \%$ der Patienten zeigen
- Tab. 10.34. Seltene Nebenwirkungen einer intravesikalen BCG-Therapie bei 2602 Patienten (Lamm et al. 1992)

\begin{tabular}{l|l}
\hline Nebenwirkung & Anzahl (\%) \\
\hline Fieber $>39,5^{\circ} \mathrm{C}$ & $75(2,9 \%)$ \\
\hline Hämaturie & $24(1 \%)$ \\
\hline Granulomatöse Prostatitis & $23(0,9 \%)$ \\
\hline Pneumonie/Hepatitis & $18(0,7 \%)$ \\
\hline Arthralgie & $12(0,5 \%)$ \\
\hline Epididymitis & $10(0,4 \%)$ \\
\hline Sepsis & $10(0,4 \%)$ \\
\hline Hautausschlag & $8(0,3 \%)$ \\
\hline Harnleiterobstruktion & $8(0,3 \%)$ \\
\hline Schrumpfblase & $6(0,2 \%)$ \\
\hline Nierenabszess & $2(0,1 \%)$ \\
\hline Zytopenie & $2(0,1 \%)$
\end{tabular}

stärkere Nebenwirkungen, die eine medikamentöse Therapie erforderlich machen. So kommen beispielsweise Anticholinergika (bei irritativen Beschwerden), Antipyretika (bei Fieber) oder nichtsteroidale Antiphlogistika (bei Hautausschlag oder Arthralgie) zum Einsatz. Bei den Antibiotika haben sich Gyrasehemmer als sinnvoll erwiesen. Gyrasehemmer könnten auch prophylaktisch zum Einsatz kommen und somit die Nebenwirkungen abschwächen (•Tab. 10.35). 


\begin{tabular}{|c|c|c|}
\hline Lokale Nebenwirkungen & Grad & Therapieoptionen \\
\hline \multirow[t]{2}{*}{ BCG-Zystitis } & 1 & Oxybutinin, Phenazopyridin, Propanthelin, NSAID \\
\hline & 2 & $\begin{array}{l}\text { Oxybutinin, Phenazopyridin, Propanthelin, NSAID, falls Symptome }>48 \mathrm{~h} \text { Therapiepause } \\
\text { und spätere Dosisreduktion, evtl. auch Fluorchinolon }\end{array}$ \\
\hline Makrohämaturie & $1-2$ & Urinkultur anlegen, Therapiepause, Kathetereinlage und Blasenspülung \\
\hline Harnblasenkontraktur & $\geq 2$ & Therapiepause, Hydrodistension, selten Zystektomie \\
\hline Harnleiterobstruktion & $\geq 2$ & $\begin{array}{l}\text { Meist selbstlimitierend, Tumor als Ursache ausschließen, evtl. perkutane Nephrostomie } \\
\text { oder Harnleiterstent }\end{array}$ \\
\hline $\begin{array}{l}\text { Symptomatische granulomatöse } \\
\text { Prostatatitis }\end{array}$ & $>2$ & $\begin{array}{l}\text { Therapiepause, Gyrasehemmer in hoher Dosierung, Isoniazid + Rifampicin + Steroide + } \\
\text { Fluorchinolone für } 3 \text { Monate }\end{array}$ \\
\hline Epididym-Orchitis & $>2$ & $\begin{array}{l}\text { Therapiepause, Gyrasehemmer in hoher Dosierung, Isoniazid + Rifampicin für } 3 \text { Monate; } \\
\text { bei Persistenz Orchiektomie }\end{array}$ \\
\hline Systemische Nebenwirkungen & Grad & Therapieoptionen \\
\hline Unwohlsein, Fieber & 1 & Evtl. Antipyretika \\
\hline Persistentes Fieber $>38,5^{\circ} \mathrm{C} />48 \mathrm{~h}$ & $\geq 2$ & $\begin{array}{l}\text { Therapieabbruch, sofortige Diagnostik (Mikrobiologe), mindestens zwei antimikrobielle } \\
\text { Substanzen (z. B. Gyrasehemmer, Isoniazid, Rifampicin) }\end{array}$ \\
\hline Systemische BCG-Reaktion & 4 & $\begin{array}{l}\text { Gyrasehemmer in hoher Dosierung Isonaizid + Rifampicin + Ethambutol für } 6 \text { Monate; } \\
\text { frühzeitig Steroide in hoher Dosierung bis Asymptomatik; evtl. zusätzliches Antibiotikum } \\
\text { gegen Enterokokken und/oder gramnegative Bakterien }\end{array}$ \\
\hline \multirow[t]{2}{*}{ Allergische BCG-Reaktion } & $1-2$ & Antihistaminika, NSAID, evtl. Therapiepause \\
\hline & $3-4$ & Therapieabbruch, evtl. Isoniazid + Rifampicin + Steroide \\
\hline
\end{tabular}

NSAID non steroidal anti-inflammatory drugs

\section{Therapie systemischer Nebenwirkungen}

Systemische Nebenwirkungen wie Pneumonie, Hepatitis oder Sepsis sind selten (•Tab. 10.33 und 10.34). Die BCGTherapie muss dann abgebrochen werden und eine Therapie mit Isoniazid, Rifampicin, Ethambutol und Prednison vorgenommen werden. Die Therapiedauer beträgt dann 3 Monate (•Tab. 10.35).

\subsubsection{Immuntherapie des Nierenzellkarzinoms}

Das Nierenzellkarzinom ist einer Immuntherapie zugänglich. $\mathrm{Zu}$ den eingesetzten Präparaten gehören in erster Linie Zytokine, Antikörper, Tyrosinkinase-Inhibitoren, mTOR-Inhibitoren und Vakzineansätze (•Tab. 10.32). Bei der Zytokintherapie des Nierenzellkarzinoms kommen vor allem IFN- $\alpha$ sowie IL-2 zum Einsatz. Interferone werden s.c. (gelegentlich auch i.m.) verabreicht. Für das IFN- $\alpha$ liegt die zugelassene Dosierung bei 18 Millionen Einheiten dreimal wöchentlich. In der Literatur wird die »optimale« Dosierung allerdings nicht selten mit 10 Millionen Einheiten dreimal wöchentlich angegeben (Coppin et al. 2005). IL-2 wird i.v. (als Bolus oder kontinuierlich) oder s.c. verabreicht. Die Wirksamkeit von IL-2 bei verschiedenen Applikationsformen ist gut belegt. Bei gleicher Applikationsform scheint eine höhere Dosierung bessere Therapieergebnisse zu erzielen (Yang et al. 2003). Nebenwirkungen einer Zytokintherapie werden symptomatisch behandelt. Gleichwohl müssen 30\% der Patienten die Therapie aufgrund von Nebenwirkungen unter- oder sogar abbrechen.

\section{Adjuvante Zytokintherapie des nicht metastasierten Nierenzellkarzinoms}

Mehrere Phase-III-Studien konnten keinen günstigen Effekt auf das progressionsfreie Überleben bei Patienten mit 
einem nicht metastasierten Nierenzellkarzinom nach radikaler Nephrektomie nachweisen (Pizzocaro et al. 2001; Clark et al. 2003; Messing et al. 2003; Atzpodien et al. 2005). In zwei Studien wurde IFN- $\alpha$ jeweils i.m. verabreicht. Bei 26\% bzw. 30\% musste die Therapie aufgrund von Nebenwirkungen unter- oder abgebrochen werden (Pizzocaro et al. 2001; Messing et al. 2003). Clark et al. untersuchten den Effekt einer Hochdosistherapie mit IL-2 (versus unbehandelter Kontrolle) nach operativer Therapie des lokal fortgeschrittenen Nierenzellkarzinoms bei 69 Patienten (Clark et al. 2003). Eine Toxizität Grad 3 oder 4 wurde bei $88 \%$ der Patienten beobachtet: Hypotension (52\%), Übelkeit oder Erbrechen oder Diarrhö (27\%), Elektrolytverschiebungen wie Hypophosphatämie oder Hyponatriämie oder Hypokalziämie oder Hyperkaliämie (27\%), Anorexie oder Müdigkeit oder Fieber (18\%), Harnstoff- oder Kreatininanstieg (15\%), Bilirubinanstieg (15\%), Anämie oder Thrombozytopenie (12\%), Lymphopenie (12\%), kardiale Symptome wie Rhythmusstörungen (9\%) und zentralnervöse Nebenwirkungen (9\%) (Clark et al. 2003). In der Arbeit von Atzpodien et al. zur adjuvanten Therapie mittels IL-2, IFN- $\alpha$ und 5-FU werden keine Aussagen zu den Nebenwirkungen getätigt (Atzpodien et al. 2005).

\section{Zytokintherapie des metastasierten Nierenzellkarzinoms}

In den letzten Jahren ist die Zytokintherapie des Nierenzellkarzinoms in den Hintergrund getreten. Aus diesem Grund werden die verschiedenen Kombinationen (insbesondere die klinisch nicht mehr relevanten Kombinationspartner wie 13-cis Retinolsäure) nunmehr deutlich verkürzt dargestellt.

IFN- $a-2 a$ s.c. versus IL-2 i.v. versus IFN- $a-2 a$ s.c. plus IL-2 i.v. Negrier et al. randomisierten 425 Patienten mit einem metastasierten Nierenzellkarzinom in einen von drei Studienarmen: IFN- $\alpha-2 a$ s.c. versus IL-2 i.v. versus IFN-a-2a s.c. plus IL-2 i.v. (Negrier et al. 1998). Patienten, die mit IL-2 behandelt wurden, erhielten einen zentralen Venenkatheter, ein Antibiotikum, Acetaminophen (1 g alle $4 \mathrm{~h}$ ) und, falls nicht ausreichend, zur Fiebersenkung zusätzlich Indomethacin ( $25 \mathrm{mg}$ alle $6 \mathrm{~h}$ ). Cimetidin oder Misoprostol wurde zur Ulkusprophylaxe eingesetzt und Diphenhydramin gegen Juckreiz sowie Medikamente (nicht spezifiziert) gegen Diarrhö. Im Bedarfsfall wurden Antiemetika, Anxiolytika und Sedativa (jeweils nicht weiter spezifiziert) verabreicht. Eine Hypotension wurde zunächst mittels kolloidaler Lösungen und anschließend mit einem Vasopressor (meist Dopamin) behandelt. Die Nebenwirkungen wurden nach der WHO-Einteilung klassi- fiziert. Die Therapie wurde bei Auftreten einer Hypotonie trotz Flüssigkeitszufuhr und Gabe von Vasopressoren oder Auftreten einer Toxizität Grad 3 oder 4 unterbrochen. Bei schweren persistenten oder lebensbedrohlichen Nebenwirkungen wurde die Therapie abgebrochen. In anderen Fällen wurde die Therapie nach Normalisierung (definiert als Grad 1 oder besser) in geplanter Dosierung fortgeführt. Eine Dosisreduktion erfolgte bei Wiederauftreten einer Grad-3- oder mehr Toxizität. Nebenwirkungen Grad 3 oder 4 sind in - Tab. 10.36 dargestellt. IL-2 wurde in den ersten 10 Wochen bei 39\% der Patienten entweder reduziert verabreicht oder abgesetzt. IFN- $\alpha-2 a$ wurde bei 14\% in Arm A und 28\% in Arm C reduziert verabreicht oder abgesetzt (Negrier et al. 1998).

\section{IL-2-Hochdosis i.v. versus IL-2-Niedrigdosis i.v. versus} IL-2-Niedrigdosis S.c. In einer dreiarmigen Studie von Yang et al. wurde IL-2 bei 283 Patienten mit einem metastasierten Nierenzellkarzinom verabreicht (Yang et al. 2003a). Nebenwirkungen sind in • Tab. 10.37 aufgeführt. Es gab keine therapiebedingten Todesfälle.

\section{Vakzinetherapie des Nierenzellkarzinoms}

In einer Studie der Phase III wurden an 55 deutschen Prüfzentren insgesamt 558 Patienten innerhalb von 20 Monaten (1997-1998) eingeschlossen (Jocham et al. 2004). Die Patienten der Vakzinegruppe erhielten 6 intradermale Applikationen einer autologen Tumorzellvakzine (Reniale) in 4-wöchigen Abständen einen Monat postoperativ beginnend. Lediglich bei etwa 1\% der Patienten traten unerwünschte Ereignisse auf. Hierbei handelte es sich um Juckreiz oder Hautrötungen von geringem oder mittlerem Schweregrad (WHO Grad 1 und 2; Jocham et al. 2004). Die meisten Arbeiten zu Vakzinetherapien beim Nierenzellkarzinom wurden allerdings bei Patienten mit Metastasen vorgenommen (Doehn et al. 2004). Hierzu gehören DNS-basierte Vakzine, peptid- oder proteinbasierte Vakzine oder Antigen-gepulste dendritische Zellvakzinen. Ferner wurden Vakzineansätze vorgestellt, die transfiziert waren, um Zytokine (z.B. GM-CSF, IL-2, IL-12, IFN- $\gamma$, TNF- $\alpha$ ) oder andere immunstimulatorische Moleküle (z.B. B7-1) zu sezernieren. Als Adjuvanzien wurden spezifische Zytokine (z. B. GM-CSF), Fremdproteine (z. B. Tetanustoxoid, KLH), Bakterien oder Viren (BCG, Corynebacterium parvum, Newcastle-diseaseVirus) und spezifische Helferproteine eingesetzt, um die Immunogenität der Tumorzellen zu erhöhen. Bei geringer Effektivität war das Nebenwirkungsprofil in diesen Studien prinzipiell günstig. Die Nebenwirkungen waren in erster Linie auf die adjuvant verabreichten Substanzen zurückzuführen (Doehn et al. 2004). 
- Tab. 10.36. IFN-a s.c. versus IL-2 i.v. versus IFN- a s.c. plus IL-2 i.v.: Nebenwirkungen Grad 3 und 4 (Negrier et al. 1998)

\begin{tabular}{|c|c|c|c|}
\hline Nebenwirkung & IFN-a s.c. $(n=147)$ & IL-2 i.v. $(n=138)$ & IFN- $a$ s.c. plus IL-2 i.v. $(n=140)$ \\
\hline $\begin{array}{l}\text { Hypotension (resistent für } \\
\text { Vasopressoren) }\end{array}$ & $1 \%$ & $68 \%$ & $67 \%$ \\
\hline Fieber & $5 \%$ & $43 \%$ & $56 \%$ \\
\hline Konstitutionell & $5 \%$ & $36 \%$ & $38 \%$ \\
\hline Übelkeit oder Erbrechen & $5 \%$ & $34 \%$ & $31 \%$ \\
\hline Diarrhö & $1 \%$ & $28 \%$ & $25 \%$ \\
\hline Anämie & $6 \%$ & $17 \%$ & $16 \%$ \\
\hline Pulmonale Symptome & $7 \%$ & $16 \%$ & $15 \%$ \\
\hline Renale Symptome & 0 & $15 \%$ & $16 \%$ \\
\hline Neurologische Symptome & $1 \%$ & $12 \%$ & $14 \%$ \\
\hline Transaminasenanstieg & $3 \%$ & $11 \%$ & $11 \%$ \\
\hline Hautsymptome & 0 & $10 \%$ & $14 \%$ \\
\hline Kardiale Symptome & $1 \%$ & $12 \%$ & $6 \%$ \\
\hline Infektion & $1 \%$ & $8 \%$ & $9 \%$ \\
\hline Thrombozytopenie & 0 & $4 \%$ & $7 \%$ \\
\hline Kreatininanstieg & 0 & $4 \%$ & $5 \%$ \\
\hline Gewichtsverlust & $4 \%$ & $2 \%$ & $1 \%$ \\
\hline Leukopenie & $1 \%$ & $1 \%$ & $2 \%$ \\
\hline Bilirubinanstieg & 0 & $1 \%$ & $2 \%$ \\
\hline
\end{tabular}

- Tab. 10.37. IL-2 Hochdosis (HD) i.v. versus IL-2 Niedrigdosis (ND) i.v. versus IL-2 s.c.: Nebenwirkungen Grad 3 und 4 (Yang et al. 2003)

\begin{tabular}{|c|c|c|c|}
\hline Nebenwirkung Grad 3 und 4 & IL-2 HD i.v. (n=285 Zyklen) & IL-2 ND i.v. (n=272 Zyklen) & IL-2 s.c. ( $n=181$ Zyklen) \\
\hline Thrombozytopenie & $9,2 \%$ & $1,5 \%$ & 0 \\
\hline Bilirubinanstieg & $3,2 \%$ & $0,7 \%$ & 0 \\
\hline Transaminasenerhöhung & $3,2 \%$ & $0,7 \%$ & $0,6 \%$ \\
\hline Übelkeit und Erbrechen & $13,4 \%$ & $8,5 \%$ & $3.3 \%$ \\
\hline Diarrhö & $9,2 \%$ & $3,7 \%$ & $1,7 \%$ \\
\hline Periphere Ödeme & $0,4 \%$ & $2,6 \%$ & 0 \\
\hline Kreatininanstieg ( $\geq 8 \mathrm{mg} / \mathrm{dl}$ ) & $1,1 \%$ & $2,6 \%$ & $0,6 \%$ \\
\hline Oligurie ( $\leq 80 \mathrm{ml} / 8 \mathrm{~h}$ ) & $12 \%$ & $7,7 \%$ & $1,1 \%$ \\
\hline Pulmonale Symptome & $4,2 \%$ & $1,1 \%$ & 0 \\
\hline Schüttelfrost & $20,5 \%$ & $9,9 \%$ & $9,4 \%$ \\
\hline Infektion & $2,8 \%$ & $2,6 \%$ & $1,1 \%$ \\
\hline Herzrhythmusstörungen & $4,2 \%$ & $1,5 \%$ & 0 \\
\hline Hypotension & $36,4 \%$ & $2,9 \%$ & 0 \\
\hline Bewusstseinsstörungen & $2,5 \%$ & $2,6 \%$ & $1,7 \%$ \\
\hline Orientierungsstörungen & $10,2 \%$ & $3,7 \%$ & 0 \\
\hline
\end{tabular}


Die amerikanische Firma Antigenics hat im Jahr 2001 eine Phase-III-Studie zur adjuvanten Therapie des Nierenzellkarzinoms mittels einer autologen Hitzeschockproteinvakzine (HSPPC-96, Oncophage) nach Nephrektomie versus alleiniger Nephrektomie initiiert (Wood et al. 2008). Das rezidivfreie Überleben (primärer Endpunkt) lag bei einer medianen Nachbeobachtungszeit von 1,9 Jahren bei $75 \%$ in der Vakzinegruppe und $72,7 \%$ in der Vergleichsgruppe $(\mathrm{p}=0,390)$. Somit wurde der primäre Studienendpunkt nicht erreicht. Das Gesamtüberleben lag bei einer zusätzlichen Nachbeobachtungszeit von 17 Monaten bei $87,7 \%$ (Vakzinegruppe) gegenüber $86,8 \%$ in der Vergleichsgruppe $(\mathrm{p}=0,586)$. Lokale Nebenwirkungen waren häufig. Allerdings traten keine Grad-3- oder -4-Nebenwirkungen auf. Zwar wurde die Therapie bei 6\% der Patienten der Vakzinegruppe abgebrochen, allerdings nur bei $0,9 \%$ wegen therapiebedingter Nebenwirkungen (Wood et al. 2008).

\section{Multikinase-Inhibitoren}

Die gegen verschiedene Signalwege wie VEGF, EGFR und mTOR gerichteten Substanzen wie Sunitinib, Sorafenib, Temsirolimus und Bevacizumab sind sowohl im Erstlinienansatz als auch Zweitlinienansatz aktiv und zeigen höhere Ansprechraten als eine Therapie mit Interferon- $\alpha$. Aufgrund der mittlerweile erfolgten Zulassung der genannten Substanzen, bekommen Kriterien wie Erstlinien- bzw. Zweitlinientherapie, Prognosegruppen, Kombinationsmöglichkeiten der Substanzen sowie Nebenwirkungen, Lebensqualität, Applikationsart und Therapiekosten eine besondere Bedeutung. Die Gegenüberstellung der verschiedenen Studienergebnisse hinsichtlich der Nebenwirkungen soll hierbei - auch wenn streng wissenschaftlich genommen nicht ganz korrekt - die Übersichtlichkeit vereinfachen (•Tab. 10.38).

\section{Sorafenib}

Sorafenib (Nexavar) ist ein Inhibitor von Serin- und Thyroininkinasen sowie Rezeptor-Tyrosinkinasen. Das Präparat wurde 2005 von der FDA und 2006 von der EMEA für die Zweitlinientherapie (also Versagen einer Zytokintherapie) bzw. für Patienten, die eine Zytokintherapie nicht tolerieren, zugelassen. Sorafenib (Nexavar) wird in einer Dosierung von $2 \times 400 \mathrm{mg}$ täglich oral verabreicht. Die Nebenwirkungen, wie sie in einer Phase-III-Studie bei Patienten mit einem metastasierten Nierenzellkarzinom in der Zweitlinientherapie aufgetreten sind, sind in - Tab. 10.38 wiedergegeben (Escudier et al. 2007a). Neben den genannten Nebenwirkungen trat laut Packungsbeilage eine kardiale Ischämie mit 2,9\% deutlich häufiger als unter Placebo (0,4\%) auf. Im Falle einer Dosisreduktion kann auf $600 \mathrm{mg}$ (400 mg und $200 \mathrm{mg}$ ) bzw. $400 \mathrm{mg}$ $(2 \times 200 \mathrm{mg})$ täglich reduziert werden. Behandlungsmöglichkeiten typischer Nebenwirkungen sind in - Tab. 10.39 bis 10.41 aufgeführt.

\section{Sunitinib}

Sunitinib (Sutent) ist ein Multikinase-Inhibitor, der oral verabreicht wird. Das Präparat wurde 2006 von der FDA und der EMEA für die Zweitlinientherapie des Nierenzellkarzinoms zugelassen. Sunitinib (Sutent) wird in einer Dosierung von $1 \times 50 \mathrm{mg}$ oral täglich verabreicht (4 Wochen Therapie gefolgt von 2 Wochen Pause). Eine Dosisreduktion auf $1 \times 37,5 \mathrm{mg}$ täglich ist beschrieben. In einer Phase-III-Studie wurde Sunitinib bei Patienten mit einem metastasierten klarzelligen Nierenzellkarzinom gegen Interferon- $\alpha$ getestet (Motzer et al. 2007). Die medikamentöse Therapie bestand entweder in einer Verabreichung von $50 \mathrm{mg}$ Sunitinib p.o. täglich für 4 Wochen gefolgt von einer zweiwöchigen Pause oder Interferon- $\alpha$ in einer Dosierung von $3 \times 9$ Millionen Einheiten s.c. wöchentlich. $\mathrm{Zu}$ den Nebenwirkungen gehören insbesondere Diarrhö, Müdigkeit, Hautreaktionen und Myelosuppression. Die Grad-3- und -4-Nebenwirkungen der beiden Therapiearme sind in Tab. 10.38 wiedergegeben (Motzer et al. 2007). Im Falle einer Dosisreduktion kann diese in 12,5-mg-Schritten erfolgen. Behandlungsmöglichkeiten typischer Nebenwirkungen sind in - Tab. 10.39 bis 10.41 aufgeführt.

\section{mTOR-Inhibitoren}

Temsirolimus

Temsirolimus (Torisel) ist ein Inhibitor der mTOR-Kinase. In einer randomisierten Phase-III-Studie wurde das Präparat bei 626 Patienten mit schlechter Prognose nach Motzer (erwartetes medianes Überleben ist 4,9 Monate) im Erstlinienansatz untersucht (Hudes et al. 2007). In dieser dreiarmigen Studie wurde Interferon- $\alpha$ allein $(3 \times 18$ Millionen Einheiten wöchentlich s.c.) mit Temsirolimus plus Interferon- $\alpha(1 \times 15 \mathrm{mg}$ wöchentlich i.v. bzw. $3 \times 6$ Millionen Einheiten wöchentlich s.c.) bzw. Temsirolimus ( $1 \times 25 \mathrm{mg}$ wöchentlich i.v.) allein verglichen. Aufgrund der Ergebnisse zum progressionsfreien Überleben und Gesamtüberleben hat sich Temsirolimus in einer Dosierung von $1 \times 25 \mathrm{mg}$ wöchentlich i.v. durchgesetzt. Typische Nebenwirkungen sind Asthenie, Hautreaktionen, Hyperlipidämie sowie Anämie. Die Grad 3 und 4 Nebenwirkungen der beiden Monotherapiearme sind in - Tab. 10.38 wiedergegeben (Hudes et al. 2007). Behandlungsmöglichkeiten typischer Nebenwirkungen sind in - Tab. 10.39 bis 10.41 aufgeführt. 
- Tab. 10.38. Nebenwirkungen Grad 3 und 4 einer Erstlinientherapie mit Sunitinib versus Interferon- $a$, einer Erstlinientherapie mit Temsirolimus versus Interferon-a, einer Erstlinientherapie mit Bevacizumab plus Interferon-a versus Plazebo plus Interferon-a sowie einer Zweitlinientherapie mit Sorafenib versus Plazebo (jeweils Phase-III-Studien)

\begin{tabular}{|c|c|c|c|c|c|c|c|c|}
\hline \multirow[t]{2}{*}{$\begin{array}{l}\text { Nebenwirkungen } \\
\text { Grad } 3 \text { und } 4\end{array}$} & \multicolumn{2}{|c|}{$\begin{array}{l}\text { Sunitinib vs. } \\
\text { Interferon- } a \\
\text { (Motzer et al. 2007) }\end{array}$} & \multicolumn{2}{|c|}{$\begin{array}{l}\text { Temsirolimus vs. } \\
\text { Interferon-a* } \\
\text { (Hudes et al. 2007) }\end{array}$} & \multicolumn{2}{|c|}{$\begin{array}{l}\text { Bevacizumab plus Interferon- } a \\
\text { vs. Placebo + Interferon-a } \\
\text { (Escudier et al. 2007a) }\end{array}$} & \multicolumn{2}{|c|}{$\begin{array}{l}\text { Sorafenib vs. Placebo } \\
\text { (Escudier et al. 2007b) }\end{array}$} \\
\hline & $\begin{array}{l}\text { Sunitinib } \\
(n=375)\end{array}$ & $\begin{array}{l}\text { Inter- } \\
\text { feron- } a \\
(n=375)\end{array}$ & $\begin{array}{l}\text { Temsi- } \\
\text { rolimus } \\
(n=209)\end{array}$ & $\begin{array}{l}\text { Inter- } \\
\text { feron-a } \\
(n=207)\end{array}$ & $\begin{array}{l}\text { Bevacizumab } \\
+ \text { Interferon- } a \\
(n=327)\end{array}$ & $\begin{array}{l}\text { Plazebo }+ \\
\text { Interferon- } a \\
(n=322)\end{array}$ & $\begin{array}{l}\text { Sorafenib } \\
(n=451)\end{array}$ & $\begin{array}{l}\text { Placebo } \\
(n=452)\end{array}$ \\
\hline Hypertonus (\%) & 8 & 1 & k.A. & k.A. & 3 & $<1$ & 4 & $<1$ \\
\hline Asthenie (\%) & 4 & 4 & 11 & 26 & 10 & 7 & k.A. & k.A. \\
\hline Müdigkeit (\%) & 7 & 12 & k.A. & k.A. & 12 & 8 & 5 & 4 \\
\hline Anorexie (\%) & k.A. & k.A. & 3 & 4 & 3 & 3 & k.A. & k.A. \\
\hline Diarrhö (\%) & 5 & 0 & 1 & 2 & 2 & $<1$ & 2 & 1 \\
\hline Erbrechen (\%) & 4 & 1 & 2 & 2 & k.A. & k.A. & 1 & 1 \\
\hline Übelkeit (\%) & 3 & 1 & 2 & 4 & k.A. & k.A. & $<1$ & 1 \\
\hline Obstipation (\%) & k.A. & k.A. & 0 & 1 & k.A. & k.A. & 1 & 1 \\
\hline Stomatitis (\%) & 1 & 1 & 1 & 0 & k.A. & k.A. & k.A. & k.A. \\
\hline Hand-Fuß-Syndrom (\%) & 5 & 0 & k.A. & k.A. & k.A. & k.A. & 6 & 0 \\
\hline Tumorschmerz (\%) & k.A. & k.A. & 5 & 2 & k.A. & k.A. & 3 & 2 \\
\hline Abdominalschmerz (\%) & k.A. & k.A. & k.A. & k.A. & k.A. & k.A. & 2 & 2 \\
\hline Knochenschmerz (\%) & k.A. & k.A. & 3 & 4 & k.A. & k.A. & 1 & 3 \\
\hline Kopfschmerzen (\%) & 1 & 0 & 1 & 0 & 2 & 1 & $<1$ & $<1$ \\
\hline Depression (\%) & k.A. & k.A. & k.A. & k.A. & 3 & 1 & k.A. & k.A. \\
\hline Dyspnoe (\%) & k.A. & k.A. & 9 & 6 & $<1$ & 2 & 4 & 2 \\
\hline Husten (\%) & k.A. & k.A. & 1 & 0 & k.A. & k.A. & $<1$ & $<1$ \\
\hline Grippesymptome (\%) & 0 & 1 & k.A. & k.A. & 3 & 2 & k.A. & k.A. \\
\hline Fieber (\%) & 1 & 0 & 1 & 4 & 3 & $<1$ & k.A. & k.A. \\
\hline Blutung (\%) & k.A. & k.A. & k.A. & k.A. & 3 & $<1$ & k.A. & k.A. \\
\hline Proteinurie (\%) & k.A. & k.A. & k.A. & k.A. & 7 & 0 & k.A. & k.A. \\
\hline Anämie (\%) & 4 & 5 & 20 & 22 & 3 & 6 & 3 & 4 \\
\hline Leukopenie (\%) & 5 & 2 & 1 & 5 & k.A. & k.A. & 3 & 1 \\
\hline Lymphopenie (\%) & 12 & 22 & k.A. & k.A. & k.A. & k.A. & 13 & 7 \\
\hline Neutropenie (\%) & 12 & 7 & 3 & 7 & 4 & 2 & 5 & 2 \\
\hline Thrombozytopenie (\%) & 8 & 0 & 1 & 0 & 2 & $<1$ & k.A. & k.A. \\
\hline Verlängerte INR (\%) & k.A. & k.A. & k.A. & k.A. & k.A. & k.A. & 5 & 7 \\
\hline Lipaseerhöhung (\%) & 16 & 6 & k.A. & k.A. & k.A. & k.A. & 12 & 7 \\
\hline Amylaseerhöhung (\%) & 5 & 3 & k.A. & k.A. & k.A. & k.A. & 1 & 3 \\
\hline Hypophosphatämie (\%) & 5 & 6 & k.A. & k.A. & k.A. & k.A. & 13 & 3 \\
\hline Hyponatriämie (\%) & k.A. & k.A. & k.A. & k.A. & k.A. & k.A. & 6 & 5 \\
\hline Hyperglykämie (\%) & k.A. & k.A. & 11 & 2 & k.A. & k.A. & 3 & 5 \\
\hline Hyperkaliämie (\%) & k.A. & k.A. & k.A. & k.A. & k.A. & k.A. & 5 & 3 \\
\hline Hyperkalziämie (\%) & k.A. & k.A. & k.A. & k.A. & k.A. & k.A. & 1 & 3 \\
\hline Hypokalziämie (\%) & k.A. & k.A. & k.A. & k.A. & k.A. & k.A. & 3 & $<1$ \\
\hline Hyperurikämie (\%) & 12 & 8 & k.A. & k.A. & k.A. & k.A. & k.A. & k.A. \\
\hline Hyperbilirubinämie (\%) & 1 & 0 & k.A. & k.A. & k.A. & k.A. & k.A. & k.A. \\
\hline Transaminasenerhöhung (\%) & 5 & 4 & 1 & 4 & k.A. & k.A. & k.A. & k.A. \\
\hline
\end{tabular}

k.A. keine Angabe

*auf die Darstellung des dritten Studienarmes (Temsirolimus plus Interferon- $a$ ) wurden wegen fehlender klinischer Relevanz verzichtet 
- Tab. 10.39. Therapiemanagement hämatologischer Nebenwirkungen unter Sorafenib, Sunitinib, Temsirolimus und Bevacizumab. (Nach Bhojani et al. 2008)

\begin{tabular}{|c|c|c|}
\hline Parameter & Monitoring & Therapie \\
\hline \multirow[t]{2}{*}{ Anämie } & $\begin{array}{l}\text { Blutbildkontrolle in den ersten } 2 \text { Monaten alle } 2 \\
\text { Wochen, danach alle } 4 \text { Wochen }\end{array}$ & $\begin{array}{l}\text { Erythropoetin bei } \mathrm{Hb}<10 \mathrm{~g} / \mathrm{dl} \text {; Transfusion bei } \\
\mathrm{Hb}<8 \mathrm{~g} / \mathrm{dl}\end{array}$ \\
\hline & Kontrolle von TSH, T3/4 & $\begin{array}{l}\text { Bei Hypothyreose Levothyroxin (Dosierung in } \\
\text { Abhängigkeit kardialer Begleiterkrankungen) }\end{array}$ \\
\hline Neutropenie & Blutbildkontrolle $1-2 \times$ wöchentlich & $\begin{array}{l}\text { Neutrophile Granulozyten }<1,4 / \text { nl: Infektionspro- } \\
\text { phylaxe, Dosisreduktion, Therapieunterbrechung }\end{array}$ \\
\hline Lymphopenie & Blutbildkontrolle 1-2x wöchentlich & Keine \\
\hline Thrombozytopenie & Blutbildkontrolle 1-2x wöchentlich & $\begin{array}{l}\text { Vermeidung von Verletzungen, Vermeidung von } \\
\text { Thrombozytenaggregationshemmern, } \\
\text { Dosisreduktion, Therapieunterbrechung }\end{array}$ \\
\hline
\end{tabular}

- Tab. 10.40. Therapiemanagement gastrointestinaler Nebenwirkungen unter Sorafenib, Sunitinib, Temsirolimus und Bevacizumab. (Nach Bhojani et al. 2008)

\begin{tabular}{|c|c|c|}
\hline Parameter & Supportive Maßnahmen & Medikation \\
\hline Diarrhö & $\begin{array}{l}\text { Vermeidung von übermäßig gewürzter oder fetter Nahrung } \\
\text { und Koffein; Flüssigkeits- und Elektrolytsubstitution }\end{array}$ & Loperamid; Cholestyramin \\
\hline Übelkeit/Erbrechen & Kleine Mahlzeiten; viel Trinken & Antiemetika \\
\hline Dyspepsie & $\begin{array}{l}\text { Keine Mahlzeiten vor dem Schlafen; Vermeidung von über- } \\
\text { mäßig gewürzter oder fetter Nahrung, Alkohol und Koffein }\end{array}$ & $\begin{array}{l}\text { Antazida, } \mathrm{H}_{2} \text {-Blocker, Protonenpumpen- } \\
\text { inhibitoren }\end{array}$ \\
\hline Anorexie & Keine & Megestrolazetat \\
\hline
\end{tabular}

- Tab. 10.41. Therapiemanagement kutaner Nebenwirkungen unter Sorafenib, Sunitinib, Temsirolimus und Bevacizumab. (Nach Bhojani et al. 2008)

\begin{tabular}{|c|c|c|}
\hline Parameter & Supportive Maßnahmen & Medikation \\
\hline $\begin{array}{l}\text { Hautausschlag/ } \\
\text { Epitheliolyse }\end{array}$ & $\begin{array}{l}\text { Weite Kleidung; Vermeidung von Sonnenlicht und } \\
\text { alkoholhaltigen Lotionen }\end{array}$ & $\begin{array}{l}\text { - Grad 1-2: } 1 \% \text { Hydrokortisoncreme und/oder } \\
\text { topische Harnstofftherapie } \\
\text { - Grad 3: Prednison } 2 \text { Tage } 25 \mathrm{mg} / \mathrm{Tag}, \\
\text { danach } 10 \mathrm{mg} / \mathrm{Tag} \\
\text { - Grad 4: dermatologisches Fachkonsil }\end{array}$ \\
\hline Hand-Fuß-Syndrom & $\begin{array}{l}\text { Tragen dicker Handschuhe und Socken aus Wolle, } \\
\text { heißes Wasser vermeiden }\end{array}$ & $\begin{array}{l}\text { Melkfett; Kortikosteroide sind ohne nachge- } \\
\text { wiesene Wirkung; bei Grad-3-Toxizität Dosis- } \\
\text { reduktion oder -verzögerung }\end{array}$ \\
\hline Mukositis/Stomatitis & $\begin{array}{l}\text { Übliche Mundhygiene; Mundspülung; } \\
\text { Vermeidung von übermäßigem Kauen }\end{array}$ & $\begin{array}{l}\text { Ohne Pilzinfektion: Lidocainlösungen; mit } \\
\text { Pilzinfektion: Fluconazol oder Clotrimazol }\end{array}$ \\
\hline Juckreiz & $\begin{array}{l}\text { Hautpflege; Vermeidung von Kratzen; Luftbefeuchtung } \\
\text { und kühle Atmosphäre; Kein heißes Duschen; Verwendung } \\
\text { milder Seife }\end{array}$ & $\begin{array}{l}\text { Medikamente gegen Juckreiz (z. B. Benzocain, } \\
\text { Dexpanthenol); } \mathrm{H}_{1} \text {-Blocker }\end{array}$ \\
\hline
\end{tabular}

\section{Everolimus}

Everolimus (Certican) ist ein oral $\mathrm{zu}$ verabreichender mTOR-Inhibitor. In einer randomisierten Studie der Phase-III wurde Everolimus $(1 \times 10 \mathrm{mg}$ täglich p.o.) mit Placebo in der Zweitlinientherapie des Nierenzellkarzi- noms an 410 Patienten untersucht (Motzer et al. 2008). Grad-3- und -4-Nebenwirkungen von Everolimus (versus Placebo) waren Lymphopenie (15\% vs. 5\%), Hyperglykämie ( $12 \%$ vs. $1 \%$ ), Anämie ( $9 \%$ vs. $5 \%$ ) und Hypophosphatämie ( $4 \%$ vs. $0 \%)$. Stomatitis, Hautausschlag, 
Müdigkeit, Asthenie, Diarrhö und Pneumonitis traten in verschiedenen Schweregraden auf (Motzer et al. 2008). Das Präparat befindet sich derzeit im Zulassungsverfahren für die Zweitlinientherapie des metastasierten Nierenzellkarzinoms.

\section{Monoklonale Antikörper gegen VEGF Bevacizumab}

Die Mehrzahl der klarzelligen Nierenzellkarzinome sind Folge eines Verlustes des von Hippel-Lindau (VHL) Tumorsuppressorgens. Eine Konsequenz besteht in der Hochregulation des Vascular Endothelial Growth Factor (VEGF). In einer randomisierten Studie der PhaseIII wurde Bevacizumab (Avastin) in Kombination mit Interferon- $\alpha(10 \mathrm{mg} / \mathrm{kg}$ KG i.v. alle 2 Wochen bzw. $3 \times 9$ Mio. E pro Woche) gegenüber Placebo plus Interferon- $\alpha$ verglichen (Escudier et al. 2007b). Diese Kombination ist seitens der FDA und EMEA seit 2007 zur Therapie des Nierenzellkarzinoms zugelassen. An Grad-3- und -4 -Nebenwirkungen traten Proteinurie ( $7 \%$ vs. $0 \%$ ), Hypertonus ( $3 \%$ vs. $<1 \%$ ) und Blutung ( $3 \%$ vs. $<1 \%$ ) häufiger in der Bevacizumabgruppe auf (-Tab. 10.38). Weitere relevante Grad-3- und -4-Ereignisse in der Bevacizumabgruppe waren vier gastrointestinale Perforationen (1\% vs. $0 \%$ ) und 10 thrombembolische Ereignisse (3\% vs. $<1 \%)$. Es traten 8 Todesfälle (2\%) in Zusammenhang mit unerwarteten Ereignissen bei Patienten auf, die Bevacizumab erhielten und 7 (2\%) in der Placebogruppe. In beiden Gruppen waren die bekannten Interferon-assoziierten Nebenwirkungen am häufigsten vertreten (alle Grade): Fieber ( $45 \%$ vs. $43 \%$ ), Blutungen (33\% vs. $9 \%$ ), Müdigkeit (33\% vs. $27 \%$ ), Asthenie (32\% vs. $28 \%$ ), Neutropenie (7\% vs. $7 \%$ ). Nebenwirkungen Grad 3 oder 4 sind in - Tab. 10.38 dargestellt. Behandlungsmöglichkeiten typischer Nebenwirkungen sind in - Tab. 10.39 bis 10.41 aufgeführt.

\section{Monoklonale Antikörper gegen EGFR}

Rowinsky et al. führten bei 88 Patienten mit einem metastasierten Nierenzellkarzinom eine Zweitlinientherapie mit dem humanen monoklonalen Antikörper Panitumumab durch. Die Therapie erfolgte unter Verwendung verschiedener Dosierungen (1-2,5 mg/kg KG $1 \times$ wöchentlich i.v.). Von 76 getesteten Patienten war der Tumor immunhistologisch bei $91 \%$ positiv (Rowinsky et al. 2004). Die häufigste Nebenwirkung war ein Hautausschlag, der je nach Dosierung bei 68\% bis 100\% der Patienten auftrat. Diese Nebenwirkung war jedoch nicht dosislimitierend. Interessanterweise konnte eine Korrelation zwischen dem Auftreten von Hautreaktionen und dem progressionsfreien Intervall beobachtet werden (Rowinsky et al. 2004).

Motzer et al. therapierten im Rahmen einer PhaseII-Studie 55 Patienten mit einem metastasierten Nierenzellkarzinom mit dem EGFR-Antikörper Cetuximab (Erbitux) (Motzer et al. 2003). Die Patienten wurden nach einer Initialdosis (400 oder $500 \mathrm{mg} / \mathrm{m} 2$ ) mit einer wöchentlichen Gabe von $250 \mathrm{mg} / \mathrm{m}^{2}$ i.v. therapiert. Als Nebenwirkungen traten Akne (57\%), Hautausschlag (44\%), Fieber (35\%) und Asthenie (31\%) auf. In 22 Fällen trat eine Toxizität Grad 3 oder 4 auf. Die Autoren schlussfolgerten, dass die erzielten Ergebnisse hinsichtlich Effektivität keine Monotherapie mittels Cetuximab rechtfertigen würden (Motzer et al. 2003).

\section{Kombinationstherapien und Sequenztherapien}

Kombinationstherapien werden bereits bei Bevacizumab plus Interferon- $\alpha$ und Sorafenib plus Interferon- $\alpha$ (unter Studienbedingungen) realisiert. Temsirolimus bzw. Sunitinib haben sich nicht als sinnvoll hinsichtlich einer Kombination mit Interferon- $\alpha$ erwiesen. Kombinationen von Sunitinib mit Temsirolimus oder mit Bevacizumab zeigen ebenfalls erhöhte Nebenwirkungsraten. Demgegenüber scheinen Kombinationen von Temsirolimus mit Sorafenib, Bevacizumab mit Temsirolimus bzw. Bevacizumab mit Sorafenib ein günstigeres Nebenwirkungsprofil (bei möglicherweise bestehender Notwendigkeit einer Dosisreduktion) zu besitzen. Derzeit aktive Studien müssen zur endgültigen Beurteilung der Nebenwirkungen von Kombinationstherapien und Sequenztherapien abgewartet werden.

\section{- Zusammenfassende Bewertung}

Die Immuntherapie von Prostatakarzinom, Harnblasenkarzinom und Nierenzellkarzinom erfolgt in erster Linie mittels Antikörpern, Zytokinen, Tyrosinkinase-Inhibitoren, mTOR-Inhibitoren, Vakzine sowie mittels intravesikaler Therapie mit BCG. Neben Fieber, Müdigkeit und Abgeschlagenheit treten vor allem gastroenterologische, dermatologische und hämatologische Nebenwirkungen auf. Klinisch weniger fassbar ist die Bildung von Antikörpern gegen ein Immuntherapeutikum. Die derzeit zur Therapie des metastasierten Nierenzellkarzinoms zugelassenen Substanzen haben teilweise spezifische und klinisch relevante Nebenwirkungen, die oftmals symptomorientiert beherrscht werden können. Erst bei Auftreten höhergradiger Nebenwirkungen oder bei Versagen der symptomorientierten Therapie wird eine Dosisreduktion oder ein Aussetzen der Therapie vorgenommen. 


\section{Literatur}

\section{Literatur 10.1}

Astrinidis A, Henske EP (2005) Tuberous sclerosis complex: linking growth and energy signaling pathways with human disease. Oncogene 24(50): 7475-81

Hilger RA, Scheulen ME, Strumberg, D (2002) The Ras-Raf-MEK-ERK pathway in the treatment of cancer. Onkologie 25: 511-518

Meiler J, Schuler M (2006) Therapeutic targeting of apoptotic pathways in cancer. Curr Drug Targets 7: 1361-1369

Weis SM, Cheresh DA (2005) Pathophysiological consequences of VEGF-induced vascular permeability. Nature 437: 497-504

Wilhelm SM, Carter C, Tang L, Wilkie D, McNabola A, Rong, H (2004) BAY 43-9006 exhibits broad spectrum oral antitumor activity and targets the RAF/MEK/ERK pathway and receptor tyrosine kinases involved in tumor progression and angiogenesis. Cancer Res 64: 7099-7109

\section{Literatur zu Kap. 10.2}

Aapro M (2005) Optimising antiemetic therapy: what are the problems and how can they be overcome? Curr Med Res Opin 21 (6): 885-897

Atkins MB, Hidalgo M, Stadler WM, Logan TF, Dutcher JP, Hudes GR, Park Y, Liou SH, Marshall B, Boni JP, Dukart G, Sherman ML (2004) Randomized phase II study of multiple dose levels of $\mathrm{CCl}-779$, a novel mammalian target of rapamycin kinase inhibitor, in patients with advanced refractory renal cell carcinoma. J Clin Oncol 22 (5): 909-918

Barth J, Kloke M (2003) Paravasation bei Zytostatika. In: Seeber S, Schütte J (Hrsg) Therapiekonzepte Onkologie, 4. Aufl. Springer 2003, Berlin Heidelberg New York Tokio, S 1708-1715

Basser RL, Green MD (1994) Pulmonary toxicities. In: Kirkwood JM, Lotze MT, Yasko JM (eds). Current cancer therapeutics. Current Medicine, Philadelphia, pp 272-278

Bellone JD (1981) Treatment of vincristin extravasation. JAMA 245: 343

Billingham ME, Mason GW, Bristow MR et al. (1978) Anthracycline cardiomyopathy monitored by morphological changes. Cancer Treat Pep 62: 865-872

Bokemeyer C, Oechsle K, Hartmann JT, Schoffski P, Schleucher N, Metzner B, Schleicher J, Kanz L. (2002) Treatment-induced anaemia and ist potential clinical impact in patients receiving sequential high dose chemotherapy for metastatic testicular cancer. $\mathrm{Br} \mathrm{J}$ Cancer 87 (10): 1066-1071

Bokemeyer C, Schmoll HJ, Polivoda H (1994) Sekundäre Leukämien nach Etoposid-haltiger Chamotherapie. Dtsch Med Wochenschr 119: 707-713

Bowyer GW, Davies TW (1987) Methotrexate toxicity associated with an ileal conduit. Br J Urol 60: 592

Bristow MR, Thompson PD, Martin RP, Mason JW, Billingham ME, Hassison D (1978) Early anthracycline cardiotoxicity. Am J Med 65: 823-832

Bronchud MH, Scarffe JH, Thatcher N (1988) Phase I/II study of recombinant human granulocyte colonystimulating factor in patients receiving intensive chemotherapy for small cell lung cancer recombinant human granulocyte-macrophage colonystimulating factor in AIDS (letter). N Eng J Med 318: 579

Bronner A, Hood A (1983) Cutaneous complications of chemotherapeutic agents. J Am Acad Dermatol 9: 646-666

Canon JL (2005) Final Results of a Randomized, Double-Blind, ActiveControlled Trial of Darbepoetin alfa Administered Once Every 3 Weeks (Q3 W) for the Treatment of Anemia in Patients Receiving Multicycle Chemotherapy. Proc ASCO 23: 8284
Carmichael DJS (1992) Handling of drugs in kidney disease. In: Cameron S, Davison AM, Grünfeld JP, Kerr D, Ritz E (eds) Oxford textbook of clinical nephrology. Univ Press Oxford, pp 175-196

Cooper JAD Jr, White DA, Matthay RA (1986) Drug-induced pulmonary disease. Part 1: Cytotoxic drugs. Am Rev Respir Dis 133: 321-340

De Wit R, Herrstedt J, Rapoport B, Carides AD, Carides G, Elmer M, Schmidt C, Evans JK, Horgan KJ (2003) Addition of the oral NK1 antagonist aprpitant to standard antiemetics provides protection against nausea and vomiting during multiple cycles of cisplatinbased chemotherapy. J Clin Oncol 21(22): 4105-11

Di Lorenzo G, Autorino R, DArmiento FP, Mignogna C, De Laurentiis M, De Sio M, Darmiento M, Damiano R, Vecchio G, De Placido S (2004) Expression of proto-oncogene c-kit in high risk prostate cancer. Eur J Surg Oncol 30(9): 987-92

Di Lorenzo G, Autorino R, De Laurentiis M, Cindolo L, DArmiento M, Bianco AR, De Placido S (2004) HER-2/neu receptor in prostate cancer development and progression to androgen independence. Tumori 90(2): 163-70

Drasga RE, Einhorn LH, Williams SD, Patel DN, Stevens EE (1983) Fertility after chemotherapy for testicular cancer. J Clin Oncol 1: 179-183

Du XX, Williams DA (1994) Interleukin 11: a multifunctional growth factor derived from the hematopoitic microenvironment. Blood 83: 2023-2030

Fink U, Peters HD, Schmoll HJ (1987) Antiemetische Therapie. In: Schmoll H-J, Peter H-D, Fink U (Hrsg) Kompendium internistische Onkologie. Springer, Berlin Heidelberg New York Tokyo, S 317-345

Fossa SD, Ous S, Abyholm T, Norman N, Loeb M (1985) Post-treatment fertility in patients with testicular cancer. II. Influence of cis-platinbased combination chemotherapy and of retroperitoneal surgery on hormone and sperm cell production. Br J Urol 57: 210-214

Fossa SD, Heilo A, Botinger O (1990) Unexpected high serum levels in cystectomiced bladder cancer patients with an ileals conduit treated intermediate doses of the drug. J Urol 143: 498

Gabrilove JL, Jakukowski A, Scher H (1988) Effect of granulocyte colony-stimulating factor on neutropenia and associated morbidity due to chemotherapy for transitional cell-carcinoma of the urothelium. N Engl J Med 318: 1414

Gallmeier WM (1979) Zytostatikum para: was tun? Münch Med Wochenschr 121: 11

Golde DW (1990) Hämatopoetine gleichen Abwehrschwäche aus. Oncol Rev 5/2: 6

Hesketh PJ, Grunberg SM, Gralla RJ, Warr DG, Roila F, de Wit R, Chawla $\mathrm{SP}$, Carides $\mathrm{AD}$, lanus J, Elmer ME, Evans JK, Beck K, Reines S, Horgan KJ; Aprepitant Protocol 052 Study Group (2003) The oral neurokin-1 antagonist aprepitant for the prevention of chemotherapy-induced nausea and vomiting: a multinational, randomized, double-blind, placebo-controlled trial in patients receiving high-dose cisplatin- the Aprepitant Protocol 052 Study Group. J Clin Oncol 21(22): 4112-4119

Hesketh PJ, Van Belle S, Aapro M, Tattersall FD, Naylor RJ, Hargreaves R, Carides AD, Evans JK, Horgan KJ (2003) Differential involvement of neurotransmitters through the time course of cisplatin-induced emesis as revealed by therapy with specific receptor antagonists. Eur J Cancer 39(8): 1074-80

Hofer MD, Fecko A, Shen R, Setlur SR, Pienta KG, Tomlins SA, Chinnaiyan AM, Rubin MA (2004) Expression of the platelet-derived growth factor receptor in prostate cancer and treatment implications with tyrosine kinase inhibitors. Neoplasia 6(5): 503-12

Ignoffo RJ, Friedman A (1980) Therapy of local toxicities caused by extravasation of cancer chemotherapeutic drugs. Cancer Treat Rev 7: 17 
Kaplan RS, Wiernik PH (1982) Neurotoxicity of antineoplastic drugs. Semin Oncol 9: 103-130

Köstering H, Nagel G (1982) Prophylaxe und Therapie von Zystostatika-Hautnekrosen. Onkologie: 3: 317

Krege S (2003) Chemotherapy of advanced urological tumors. Onkologie Suppl 4: 13-7

Kreisman H, Wolkove N (1992) Pulmonary toxicity of antineiplastic therapy. In: Perry MC (ed) The chemotherapy source book. Williams \& Wilkins, Baltimore, pp 598-619

Kuderer et al. (2005) Meta-analysis of prophylactic granulocyte-colony-stimulating-factor (G-CSF) in cancer patients receiving chemotherapy. Proc ASCO 2005; 23: \#8117 Abstract

La Bianca R, Beratta G, Cleric M et al. (1982) Cardiac toxicity of 5-fluorouracil: a study of 1083 patients. Tumori 68: 505-510

Lara PN Jr, Twardowski P, Quinn DI (2004) Angiogenesis-targeted therapies in prostate cancer. Clin Prostate Cancer 3 (3): 165-173

Larson DL (1982) Treatment of tissue extravasation by antitumor agents. Cancer 49: 1796

Leyden M, Sullivan J (1983) Full-Sickness skin-necrosis due to inadvertent interstitiell infusion of cis-platin. Cancer Treal Rep 67: 199

Miller RS, Freiha FS, Torti FM (1991) Surgical restaging of PTS with advanced TCC of the urothelium treated with CHV. Proc ASCO 10: 530

National Cancer Institute (NCl) (1993) Investigator's handbook. A manual for participants in clinical trials of investigational agents. Cancer therapy evaluation program. Diversion of cancer treatment. National Cancer Institute, Bethesda/MD

Nichols CR, Breeden ES, Loehrer PJ, Williams SD, Einhorn LH (1993) Secondary leukemia associated with a conventional dose of etoposide. J Natl Cancer Inst 85: 36-40

Perez CA, Brady LW (1993) Principles and practice of radiation oncology, $2^{\text {nd }}$ edn. Lippincott, Philadelphia, pp 51-55

Petersen PM, Hansen SW, Giwercman A, Rorth M, Stakkebaek NE (1994) Dose-dependent impairment of testicular function in patients treated with cisplatin-based chemotherapy for germ cell cancer. Ann Oncol 5: 355-358

Pizzo PA (1984) Granulocytopenia and cancer therapy. cancer 54: 2649

Platzer E (1990) Human haemotopoetic growth factors. Eur J Haematol 42: 1

Pogothesis CJ, Dexeus FH, Sella A, Amato RJ, Kilbourn RG, Finn L, Gutterman JU (1990) Excalated therapy for refractory urothelial tumors: methotrexate-vinblastine-doxorubicin-cisplatin plus unglycosyleted recombinant human granulocyte macrophage colony-stimulating factor. J Natl Cancer Inst 828: 667

Pont J, Albrecht W (1997) Fertility after chemotherapy for testicular germ cell cancer. Fertil Steril 68: 1-5

Rao K, Goodin S, Levitt MJ, Dave N, Shih WJ, Lin Y, Capanna T, DoyleLindrud S, Juvidian P, DiPaola RS (2005) A phase II trial of imatinib mesylate in patients with prostate specific antigen progression after local therapy for prostata cancer. Prostate 62 (2): 115-22

Rizzo JD, Lichtin AE, Woolf SH (2002) Use of Epoetin in patients with cancer: evidence-based clinical practice guidelines of American Society of Clinical Oncology and the American Society of Hematology. J Clin Oncol 20: 1-25

Roberts JT, Fossa SD, Parmar MKB (1991) Results of medical research council phase II study of low dose cisplatin and methotrexate in the primary treatment of locally advanced transitional cell carcinoma of the bladder. Br J Urol 68: 162

Rosenow III EC, Meyers JL, Swensen SJ, Pisani RJ (1992) Drug-induced pulmonary disease- an update. Chest 102: 239-250

Sauer H (2000) In: Wilmanns W, Huhn D, Wilms K (Hrsg) Internistische Onkologie. Thieme, Stuttgart New York
Schaaf D, Schott E (1984) Entsorgung und Vernichtung von Zytostatikaabfällen. Krankenhauspharmazie 5. Jahrgang, Heft 10

Schmoll HJ, Höffken K, Possinger K (1996) Kompendium Internistische Onkologie, Teil 1. 2. Aufl. Springer, Berlin Heidelberg New York Tokio

Sternberg CN, Yagoda A, Scher HI et al. (1986) Surgical staging and long term survival in patients with advanced transitional cell carcinoma (TCC) of the urothelium treated with M-VAC. Proc ASCO 5: 390

Thurber WA (1989) Offspring of childhood cancer survivors. J Assoc Pediatr Oncol Nurses 6: 17-19

Van Sloten Harwood K, Aisner J (1984) Treatment of chemotherapy extravasation: Current status. Cancer Treat Rep 68: 939

Wander HE, Nagel GA (1985) Mammakarzinome, 3. Aufl. Zuckschwerdt, München Bern Wien

Wood AJJ (1998) Drug therapy. N Engl J Med 339: 746-754

World Health Organisation (1979) WHO handbook for reporting results of cancer treatment. World Health Organization Offset Publication No. 48, Geneva, Retrieved July 2004

\section{Literatur zu Kap. 10.3}

Atzpodien J, Schmitt E, Gertenbach U, Fornara P, Heynemann H, Maskow A, Ecke M, Woltjen HH, Jentsch H, Wieland W, Wandert T, Reitz M; German Cooperative Renal Carcinoma Chemo-Immunotherapy Trials Group (DGCIN) (2005) Adjuvant treatment with interleukin-2- and interferon-alpha2a-based chemoimmunotherapy in renal cell carcinoma post tumour nephrectomy: results of a prospectively randomised trial of the German Cooperative Renal Carcinoma Chemoimmunotherapy Group (DGCIN). Br J Cancer 92: 843-846

Bajaj GK, Zhang Z, Garrett-Mayer E, Drew R, Sinibaldi V, Pili R, Denmeade SR, Carducci MA, Eisenberger MA, DeWeese TL (2007) Phase II study of imatinib mesylate in patients with prostate cancer with evidence of biochemical relapse after definitive radical retropubic prostatectomy of radiotherapy. Urology 69: 526-531

Bander NH, Milowsky MI, Nanus DM, Kostakoglu L, Vallabhajosula S, Goldsmith SJ (2005) Phase I trial of 177lutetium-labeled J591, a monoclonal antibody to prostate-specific membrane antigen, in patients with androgen-independent prostate cancer. J Clin Oncol 23: 4591-4601

Bhojani N, Jeldres C, Patard JJ, Perrotte P, Suardi N, Hutterer G, Patenaude F, Oudard S, Karakiewicz PI (2008) Toxicities associated with the administration of sorafenib, sunitinib, and temsirolimus and their management in patients with metastatic renal cell carcinoma. Eur Urol 53: 917-930

Boccardo F, Rubagotti A, Conti G, Battaglia M, Cruciali G, Manganelli A, Ricci S, Lapini A (2007) Prednisone plus gefitinib versus prednisoen plus placebo in the treatment of hormone refractory prostate cancer: a randomized phase-II trial. Oncology 74: 223-228

Canil CM, Moore MJ, Winquist E, Baetz T, Pollak M, Chi KN, Berry S, Ernst DS, Douglas L, Brundage M, Fisher B, McKenna A, Seymour L (2005) Randomized phase II study of two doses of gefitinib in hormone-refractory prostate cancer: a trial of the National Cancer Institute of Canada-Clinical Trials Group. J Clin Oncol 23: 455-460

Carducci MA, Padley RJ, Breul J, Vogelzang NJ, Zonnenberg BA, Daliani DD, Schulman CC, Nabulsi AA, Humerickhouse RA, Weinberg MA, Schmitt JL, Nelson JB (2003) Effect of endothelin-A receptor blockade with atrasentan on tumor progression in men with hormone-refractory prostate cancer: a randomized, phase II, placebo-controlled trial. J Clin Oncol 21: 679-689 
Clark J, Atkins MB, Urba WJ, Creech S, Figlin RA, Dutcher JP, Flaherty L, Sosman JA, Logan TF, White R, Weiss GR, Redman BG, Tretter CP, McDermott D, Smith JW, Gordon MS, Margolin KA (2003) Adjuvant high-dose bolus interleukin-2 for patients with high-risk renal cell carcinoma: a cytokine working group randomized trial. J Clin Oncol 21: 3133-3140

Coppin C, Porzsolt F, Awa A, Kumpf J, Coldman A, Wilt T (2005) Immunotherapy for advanced renal cell cancer. Cochrane Database Syst Rev 25: CD001425

Dalgleish AG, Quatan N, Michael A., Wushishi F, Pandha H (2007) Increased time to progression and sustained PSA velocity responses in a phase II trial in advanced metastatic prostate cancer following treatment with ONY-P1, an allogeneic whole cell vaccine. J Clin Oncol 23(16S): Abs 4726, 2005.

Decobert M, LaRue H, Harel F, Meyer F, Fradet Y, Lacome L (2008) Maintenance bacillus Calmette-Guerin in high-risk nonmuscle invasive baldder cancer: how much is enough? Cancer 113: 710-715

Doehn C, Jocham D (2004) Vaccination immunotherapy-an update. Scand J Surg 93: 163-169

Eaton JD, Perry MJ, Nicolson S, Guckian M, Russel N, Whelan M, Kirby RS (2002) Allogeneic whole-cell vaccine: a phase I/II study in men with hormone-refractory prostate cancer. BJU Int 89: 19-26

Escudier B, Pluzanska A, Koralewski P, Ravaud A, Bracarda S, Szczylik C, Chevreau C, Filipek M, Melichar B, Bajetta E, Gorbunova V, Bay JO, Bodrogi I, Jagiello-Gruszfeld A, Moore N; AVOREN Trial investigators (2007a) Bevacizumab plus interferon alfa-2a for treatment of metastatic renal cell carcinoma: a randomised, double-blind phase III trial. Lancet 370: 2103-2111

Escudier B, Eisen T, Stadler WM, Szczylik C, Oudard S, Siebels M, Negrier S, Chevreau C, Solska E, Desai AA, Rolland F, Demkow T, Hutson TE, Gore M, Freeman S, Schwartz B, Shan M, Simantov R, Bukowski RM; TARGET Study Group (2007b) Sorafenib in advanced clear-cell renal-cell carcinoma. N Engl J Med 356: 125-134

Hudes G, Carducci M, Tomczak P, Dutcher J, Figlin R, Kapoor A, Staroslawska E, Sosman J, McDermott D, Bodrogi I, Kovacevic Z, Lesovoy V, Schmidt-Wolf IG, Barbarash O, Gokmen E, O'Toole T, Lustgarten S, Moore L, Motzer RJ; Global ARCC Trial (2007) Temsirolimus, interferon alfa, or both for advanced renal-cell carcinoma. $\mathrm{N}$ Engl J Med 356: 2271-2281

Jocham D, Richter A, Hoffmann L, Iwig K, Fahlenkamp D, Zakrzewski G, Schmitt E, Dannenberg T, Lehmacher W, von Wietersheim J, Doehn C (2004) Adjuvant autologous renal tumour cell vaccine and risk of tumour progression in patients with renal-cell carcinoma after radical nephrectomy: phase III, randomised controlled trial. Lancet 363: 594-599

Joudi FN, Smith BJ, O'Donnell MA; National BCG-Interferon Phase 2 Investigator Group (2006) Final results from a national multicenter phase II trial of combination bacillus Calmette-Guerin plus interferon alpha-2B for reducing recurrence of superficial bladder cancer. Urol Oncol 24: 344-348

Lamm DL, van der Meijden PM, Morales A, Brosman SA, Catalona WJ, Herr HW, Soloway MS, Steg A, Debruyne FM (1992) Incidence and treatment of complications of bacillus Calmette-Guerin intravesical therapy in superficial bladder cancer. J Urol 147: 596-600

Lamm DL, Blumenstein BA, Crissman JD, Montie JE, Gottesman JE, Lowe BA, Sarosdy MF, Bohl RD, Grossman HB, Beck TM, Leimert JT, Crawford ED (2000) Maintenance bacillus Calmette-Guerin immunotherapy for recurrent TA, T1 and carcinoma in situ transitional cell carcinoma of the bladder: a randomized Southwest Oncology Group Study. J Urol 163: 1124-1129

Lin AM, Rini Bl, Weinberg V, Fong $\mathrm{K}$, Ryan $\mathrm{CJ}$, Rosenberg JE, Fong L, Small EJ (2006) A phase II trial of imatinib mesylate in patients with biochemical relapse of prostate cancer after definitive local therapy. BJU Int 98: 763-769

Martinez-Pineiro JA, Martinez-Pineiro L, Solsona E, Rodriguez RH, Gomez JM, Martin MG, Molina JR, Collado AG, Flores N, Isorna S, Pertusa C, Rabadan M, Astobieta A, Camacho JE, Arribas S, Madero R; Club Urologico Espanol de Tratamiento Oncologico (CUETO) (2005) Has a 3-fold decreased dose of bacillus Calmette-Guerin the same efficacy against recurrences and progression of T1G3 and Tis bladder tumors than the standard dose? Results of a prospective randomized trial. J Urol 174: 1242-1247

Messing EM, Manola J, Wilding G, Propert K, Fleischmann J, Crawford ED, Pontes JE, Hahn R, Trump D; Eastern Cooperative Oncology Group/Intergroup trial (2003) Phase III study of interferon alfa-NL as adjuvant treatment for resectable renal cell carcinoma: an Eastern Cooperative Oncology Group/Intergroup trial. J Clin Oncol 21: 1214-1222

Michael A, Ball G, Quatan N, Wushishi F, Russell N, Whelan J, Chakraborty P, Leader D, Whelan M, Pandha H (2005) Delayed disease progression after allogeneic cell vaccination in hormone-resistant prostate cancer and correlation with immunologic variables. Clin Cancer Res 11: 4469-4478

Motzer RJ, Amato R, Todd M, Hwu WJ, Cohen R, Baselga J, Muss H, Cooper M, Yu R, Ginsberg MS, Needle M (2003) Phase II trial of antiepidermal growth factor receptor antibody $C 225$ in patients with advanced renal cell carcinoma. Invest New Drugs 21: 99-101

Motzer RJ, Hutson TE, Tomczak P, Michaelson MD, Bukowski RM, Rixe O, Oudard S, Negrier S, Szczylik C, Kim ST, Chen I, Bycott PW, Baum CM, Figlin RA (2007) Sunitinib versus interferon alfa in metastatic renal-cell carcinoma. N Engl J Med 356: 115-124

Nanus DM, Milowsky MI, Kostakoglu L, Smith-Jones PM, Vallabahajosula S, Goldsmith SJ, Bander NH (2003) Clinical use of monoclonal antibody HuJ591 therapy: targeting prostate specific membrane antigen. J Urol 170: S84-S88

Negrier S, Caty A, Lesimple T, Douillard J-Y, Escudier B, Rossi J-F, Viens P, Gomez F (2000) Treatment of patients with metastatic renal carcinoma with a combination of subcutaneous interleukin-2 and interferon alfa with or without fluorouracil. J Clin Oncol 18: 4009-4015

Nelson JB, Love W, Chin JL, Saad F, Schulman CC, Sleep DJ, Qian J, Steinberg J, Carducci M; Atrasentan Phase 3 Study Group (2008) Phase 3, randomized, controlled trial of atrasentan in patients with nonmetastatic, hormone-refractory prostate cancer. Cancer 113: 2478-2487

O'Donnell MA, Lilli K, Leopold C; National Bacillus Calmette-Guerin/Interferon Phase 2 Investigator Group (2004) Interim results from a national multicenter phase II trial of combination bacillus Calmette-Guerin plus interferon alfa-2b for superficial bladder cancer. $J$ Urol 172: 888-893

Ojea A, Nogueira JL, Solsona E, Flores N, Gómez JM, Molina JR, Chantada V, Camacho JE, Piñeiro LM, Rodríguez RH, Isorna S, Blas M, Martínez-Piñeiro JA, Madero R; CUETO Group (Club Urológico Español De Tratamiento Oncológico) (2007) A multicentre, randomised prospective trial comparing three intravesical adjuvant therapies for intermediate-risk superficial bladder cancer: low-dose bacillus Calmette-Guerin (27 mg) versus very low-dose bacillus CalmetteGuerin (13.5 mg) versus mitomycin C. Eur Urol 52: 1398-1406

Pizzocaro G, Piva L, Colavita M, Ferri S, Artusi R, Boracchi P, Parmiani G, Marubini E (2001) Interferon adjuvant to radical nephrectomy in Robson stages II and III renal cell carcinoma: a multicentric randomized study. J Clin Oncol 19: 425-431

Ragde H, Cavanagh WA, Tjoa BA (2004) Dendritic cell based vaccines: progress in immunotherapy studies for prostate cancer. J Urol 172: $2532-2538$ 
Rao K, Goodin S, Levitt MJ, Dave N, Shih WJ, Lin Y, Capanna T, DoyleLindrud S, Juvidian P, DiPaola RS (2005) A phase II trial of imatinib mesylate in patients with prostate specific antigen progression after local therapy for prostate cancer. Prostate 62: 115-122

Rowinsky EK, Schwartz GH, Gollob JA, Thompson JA, Vogelzang NJ, Figlin R, Bukowski R, Haas N, Lockbaum P, Li YP, Arends R, Foon KA, Schwab G, Dutcher J (2004) Safety, pharmacokinetics, and activity of ABX-EGF, a fully human anti-epidermal growth factor receptor monoclonal antibody in patients with metastatic renal cell cancer. J Clin Oncol 22: 3003-3015

Seegenschmidt MH, Müller RP, Höffken K, Junginger T, Sauer H (1999) Dokumentation von Nebenwirkungen in der Onkologie. Dtsch Ärztebl 96: A-489-A495

Shelley MD, Court JB, Kynaston H, Wilt TJ, Coles B, Mason M (2003) Intravesical bacillus Calmette-Guerin versus mitomycin $\mathrm{C}$ for Ta and T1 bladder cancer. Cochrane Database Syst Rev 3:CD003231

Simons JW, Sacks N (2006) Granulocyte-macrophage colony-stimulating factor-transduced allogeneic cancer cellular immunotherapy: the GVAX vaccine for prostate cancer. Urol Oncol 24: 419-424

Small EJ, Schellhammer PF, Higano CS, Redfern CH, Nemunaitis JJ, Valone FH, Verjee SS, Jones LA, Hershberg RM (2006) Placebocontrolled phase III trial of immunologic therapy with sipuleucel-T (APC8015) in patients with metastatic, asymptomatic hormone refractory prostate cancer. J Clin Oncol 24: 3089-3094

Small EJ, Fontana J, Tannir N, DiPaola RS, Wilding G, Rubin M, lacona RB, Kabbinavar FF (2007) A phase-II trial of gefitinib in patients with non-metastatic hormone-refractory cancer. BJU Int 100: 765-769

Swindle PW, Tepes S, Clements J (2004) DC therapy for prostate cancer. Cytotherapy 6: 164-171

Witjes JA, Polou J, Soloway M, Lamm D, Brausi M, Spermon JR, Persad R, Buckley R, Akaza H, Colombel M, Bohle A (2008) Clinical practice recommendations for the prevention and management of intravesical therapy-associated adverse events. Eur Urol Suppl 7: 667-674

Wood C, Srivastava P, Bukowski R, Lacombe L, Gorelov Al, Gorelov S, Mulders $\mathrm{P}$, Zielinski $\mathrm{H}$, Hoos $\mathrm{A}$, Teofilovici $\mathrm{F}$, Isakov $\mathrm{L}$, Flanigan $\mathrm{R}$, Figlin R, Gupta R, Escudier B; C-100-12 RCC Study Group (2008) An adjuvant autologous therapeutic vaccine (HSPPC-96; vitespen) versus observation alone for patients at high risk of recurrence after nephrectomy for renal cell carcinoma: a multicentre, openlabel, randomised phase III trial. Lancet 372: 145-154

Yang JC, Sherry RM, Steinberg SM, Topalian SL, Schwartzentruber DJ, Hwu P, Seipp CA, Rogers-Freezer L, Morton KE, White DE, Liewehr DJ, Merino MJ, Rosenberg SA (2003) Randomized study of highdose and low-dose interleukin-2 in patients with metastatic renal cancer. J Clin Oncol 21: 3127-3132

www.cellgenesys.com (aufgerufen am 25.11.2008)

www.ctep.cancer.gov (aufgerufen am 25.11.2008)

www.onkologie2008.de (aufgerufen am 25.11.2008) 